\title{
Munc18 function in large dense-core vesicle exocytosis
}

\author{
Dissertation \\ zur Erlangung des Doktorgrades \\ der Mathematisch-Naturwissenschaftlichen Fakultäten \\ der Georg-August-Universität zu Göttingen
}

vorgelegt von

Attila Gulyás-Kovács

aus Budapest, Ungarn

Göttingen 2004 
D 7

Referent: Prof. Dr. Erwin Neher

Korreferent: Prof. Dr. Ralf Heinrich

Tag der mündlichen Prüfung: 26.01.2005 


\section{Contents}

RESEARCH OF NEUROTRANSMITTER RELEASE (INTRODUCTION) ................................. 7

$\mathrm{Ca}^{2+}$-dependent exocytosis releases the transmitter from the synaptic vesicles ....................................................................... 8 Landmarks 8

Direct electrophysiological measurements of $\mathrm{Ca}^{2+}$-dependent exocytosis ..........................................................................11

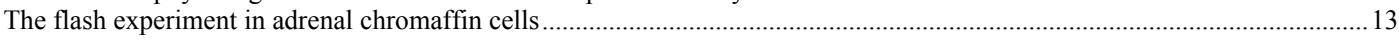

The '4 vesicle pool model'

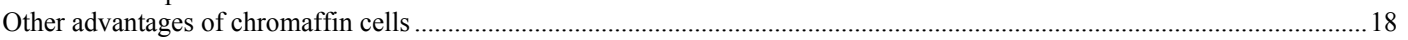

THE MOLECULAR MACHINERY OF EXOCYTOSIS (INTRODUCTION)................................. 19

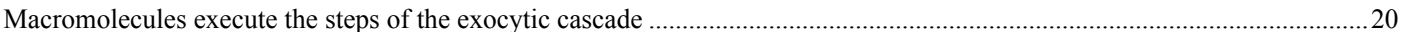

Evolution of functional studies on exocytic proteins in chromaffin cells...............................................................................2.

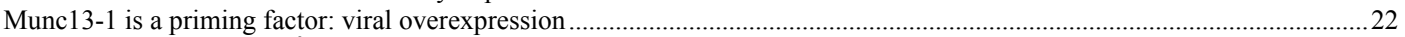

Synaptotagmin- 1 is the $\mathrm{Ca}^{2+}$ trigger for the fusion of rapidly releasable vesicles: knockout/knockin mice.................................22

SNAP-25 isoforms and homologs differentially regulate the releasable pools: the rescue approach .................................................24

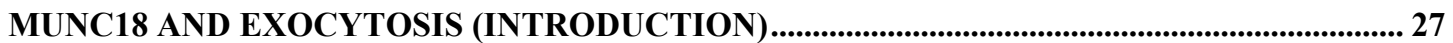

Sec1/Munc18 protein family is essential in vesicle trafficking and exocytosis .........................................................................28

Sec1/Munc18 and not SNARE isoforms define the specificity of distinct trafficking pathways...............................................28

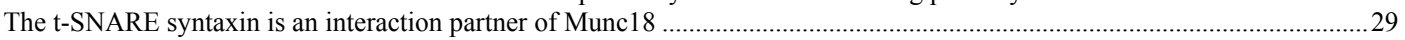

Current molecular model for exocytosis based on protein structure......................................................................................30

SM proteins positively or negatively regulate secretion in different model organisms ............................................................3

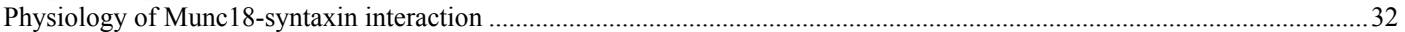

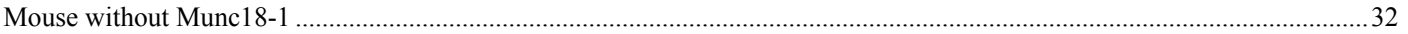

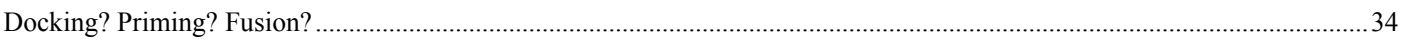

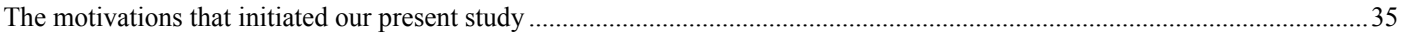

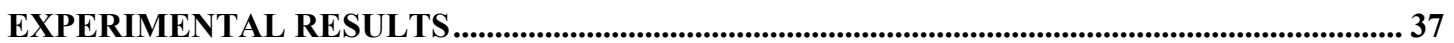

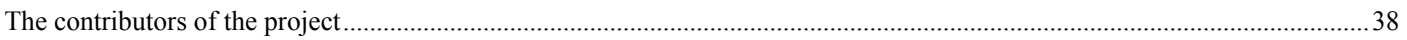

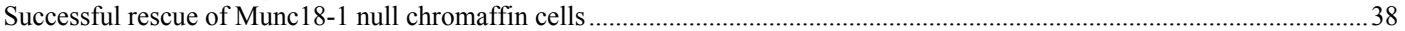

Confirmation of the positive role of Munc18-1 and the question of dose dependency ...........................................................42

Is the F-actin cytoskeleton a physiologically important downstream target of Munc18-1? ........................................................45

The syntaxin-Munc18-1 interaction regulates docking and secretion.................................................................................49

Regulation of Munc18-1 dependent and independent secretion: protein kinase C? .................................................................53

Another Munc18 isoform differently promotes docking and secretion .....................................................................................56

DISCUSSION

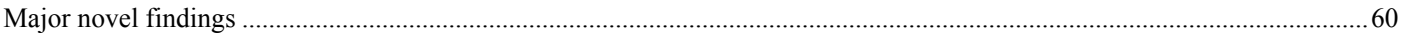

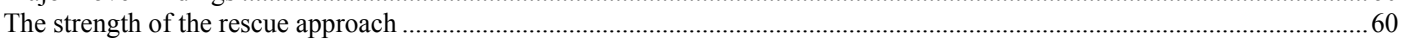

Munc18-1 is a positive regulator of large dense-core vesicle exocytosis ................................................................................61

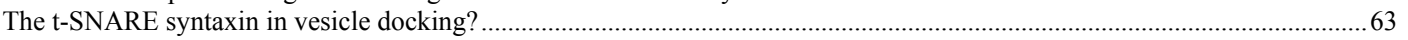

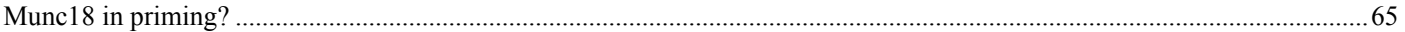

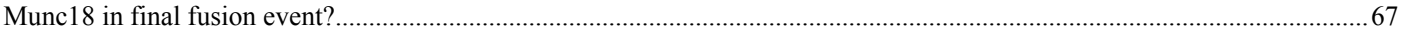

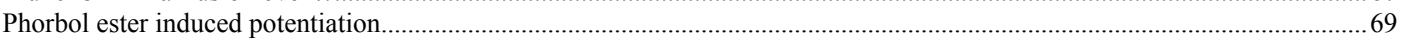

SUMMARY OF THE THESIS .................................................................................................................... 71

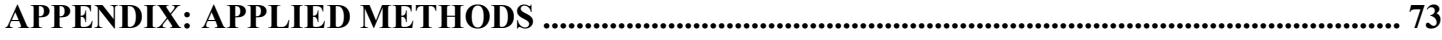

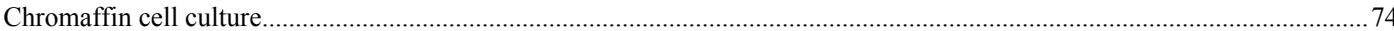

Electrophysiological recordings.............................................................................................................................

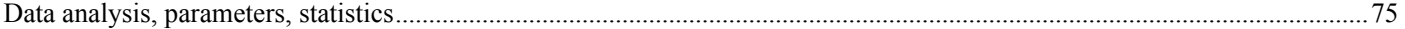

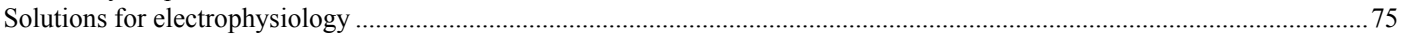

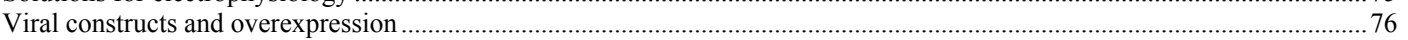

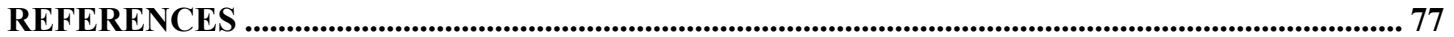





\section{ACKNOWLEDGEMENTS}

A few years ago the Munc18-1 null (knockout) mouse was generated (Verhage et al., 2000). This mutant mouse was later investigated in a collaboration between $\mathrm{Dr}$ Verhage's and Dr. Neher's laboratory (Voets et al., 2001b). After I joined Dr. Neher's department the collaboration continued and I became involved with a project using adrenal chromaffin cells of Munc18-1 null mice. My thesis is based on this work.

In the Experimental results chapter I list all the contributors to this project. Here, I would like to acknowledge the people that supported me throughout my $\mathrm{PhD}$ period generally, also in other projects that are not referred here.

I thank Dr. Erwin Neher for giving me the opportunity to work in his department in exceptionally stimulating conditions and advanced circumstances. I am grateful to Dr. Jakob Sørensen for his professional supervision and especially for his indispensable help in the technical troubleshootings of the patch clamp setup. My work was greatly promoted by Dr. Gábor Nagy who helped me in a large number of issues ranging from electrophysiological recordings to cloning.

My work was supported by numerous members of the Membrane Biophysics Department. Dr. Ralf Nehring provided me expert help with standard molecular biology techniques in various projects concerning LIM kinase 1, synaptotagmin 1, SNAP-25 and -23 and synaptobrevin2. Dirk Reuter was instrumental in making the virus constructs for overexpression experiments. Ina Herfort helped me with the bovine chromaffin cell culture and genotyping of the Munc18-1 mouse line.

Finally I would like to thank the chromaffin cell group, Jakob Sørensen, Gábor Nagy, Ira Milosevic, Jean-Sebastien Schonn and Ignacio Delgado, for their helpful comments and the friendly working atmosphere. 



\section{Research of neurotransmitter release (introduction)}




\section{$\mathrm{Ca}^{2+}$-dependent exocytosis releases the transmitter from the synaptic vesicles}

One of key questions in neurobiology is how neurons communicate with each other to form a functionally plastic system (network), which is capable to process, store and recall information. For the plastic changes, the system needs functional elements that are easy to regulate. Synapses - communication sites between excitable cells - are thought to be such adjustable elements. While the molecular organization and regulation of the postsynaptic side was fairly well understood ten years ago, the presynaptic molecular machinery then appeared incomprehensively complex and undiscovered (Jessell and Kandel, 1993). By now, 2004, most of the molecular elements of the presynaptic machinery seem to be known and the complex physiological function has been delineated by the entering of genetics into physiology (Sudhof, 2004).

Figure 1 shows the currently accepted functional scheme of the synaptic vesicle cycle (Sudhof, 2004) at the cellular level without the molecular machinery. It is strongly believed that the release of the neurotransmitter, which establishes the signal transduction between two nerve cells, is based on the $\mathrm{Ca}^{2+}$-dependent exocytosis of synaptic vesicles (explained in Figure1). This exocytosis consists of three major steps: vesicle docking, priming and fusion. The goal of many laboratories is to resolve the molecular events that underlie each step and reveal where and how these molecular events can be regulated.

Before reviewing the molecular principles I will mention some of the experimental and theoretical landmarks that led to our knowledge depicted in Figure 1.

\section{Landmarks}

It had been known for a good half a century that $\mathrm{Ca}^{2+}$ is needed for the transduction of electrical signal between nerve and muscle, when Katz and colleagues started to study synaptic transmission in the bullfrog neuromuscular junction in the early 1950s. Without stimulating the nerve fiber they observed spontaneous endplate potentials (Fatt and Katz, 1952) in the muscle cell. Later these discrete events were called miniature endplate potentials (mEPP). When they lowered the extracellular $\left[\mathrm{Ca}^{2+}\right]$ the evoked endplate potential (EPP) fluctuated from trial to trial between preferred amplitudes, which coincided the multiples of the mEPP amplitude (Del Castillo and Katz, 1954). The mEPP was too large to be accounted for by the release of a single acetyl-choline because exogenous application (by iontophoresis) of low concentrations of acetyl-choline induced much smaller responses in the endplate. They concluded that acetyl-choline is released in packages, quantae. Katz and colleagues introduced a model, which is known as the quantal theory or quantal hypothesis.

The quantal theory states that the transmitter is released in quantae with a given probability. Several quantae are available and each of them elicits the same electrical signal at the postsynaptic cell, which is characterized by the quantal amplitude (quantal 


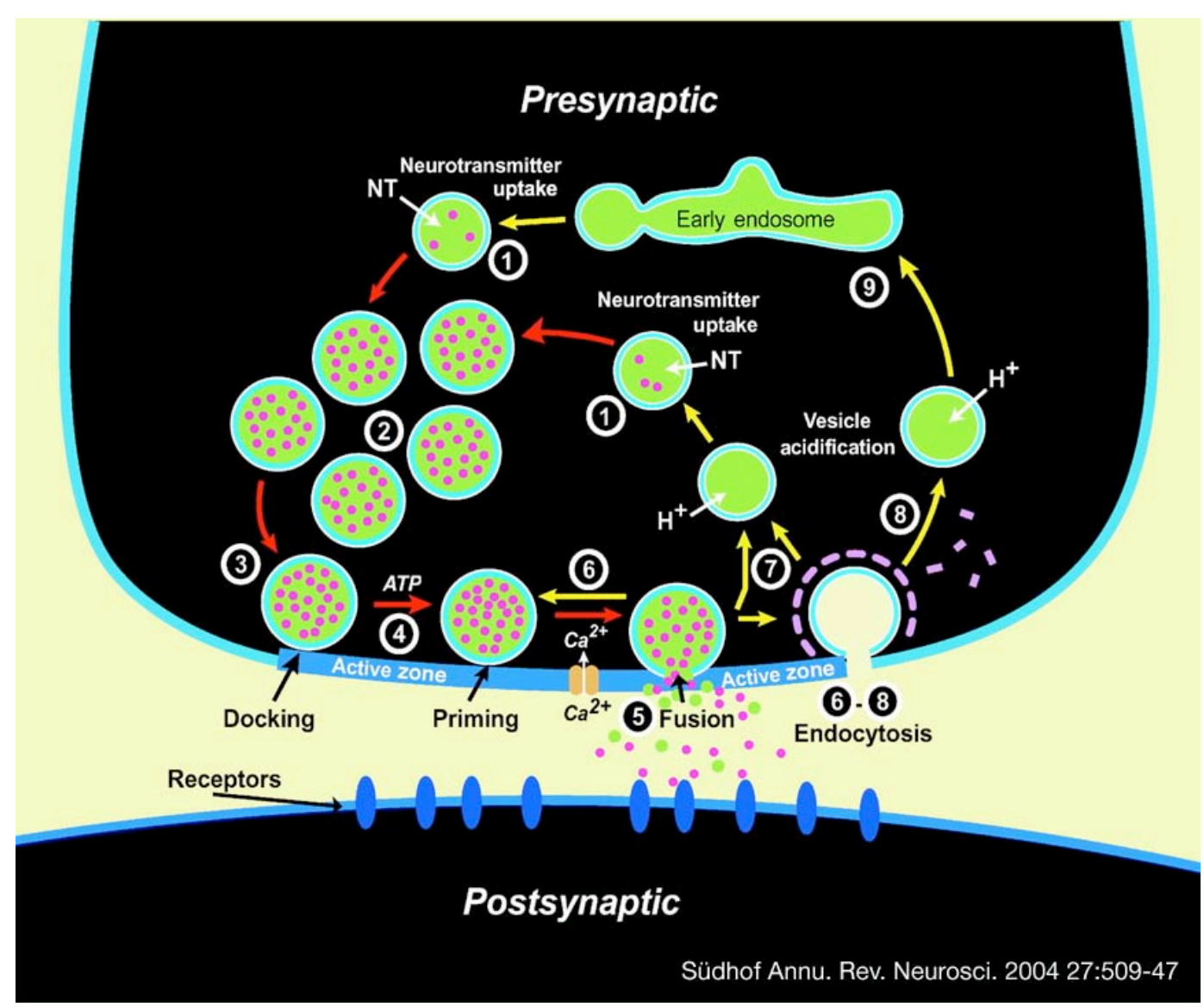

\section{Figure 1}

The synaptic vesicle cycle. The synaptic vesicles are loaded with neurotransmitter (1) and form a reserve (or depot) pool. From the reserve pool vesicles dock to the plasmamembrane (3), where they can be activated through maturation processes called priming (4). Only the primed vesicles can fuse with the plasma membrane and release their content, the neurotransmitter molecules (5). The release has a high probability when the intracellular $\mathrm{Ca}^{2+}$ signal arrives through voltage dependent $\mathrm{Ca}^{2+}$ channels. After partial or full neurotransmitter release the vesicles are retreaved with at least three different modes of endocytosis (6-9).

size). The average number of released quantae depends on the number of available quantae and the probability by which an available quantum is released.

They proposed that the probability is increased as an action potential invades the nerve terminal. This proposal led then to another hypothesis that is often referred as the $\mathrm{Ca}^{2+}$ hypothesis (Stevens, 2003), see later in this section.

The observation that prolonged trains of stimuli led to depression of EPPs was interpreted by Elmqvist and Quastel in such a way that the number of available (releasable) quanta but not the quantal size decreases during the depression. They assumed an immediately releasable store of quantae which is depleted during the initial, declining part of the response but in the later phase it is replenished from a larger store of quantae (Elmqvist and Quastel, 1965). 
In the 1960s Katz and his long-term collaborator Miledi chose the giant neurons of the squid as a convenient preparation where the pre- and postsynaptic cell could be impaled with microelectrodes and simultaneous pre- and postsynaptic recordings could be carried out. They supported the quantal theory with the finding that tetrodotoxin, which blocks the presynaptic sodium currents and therefore the action potential, also decreased the postsynaptic current (by decreasing the probability of quantal release) (Katz and Miledi, 1967a). They showed that calcium but not sodium or potassium ions are directly needed for neurotransmission (Katz and Miledi, 1967b). Thus, $\mathrm{Ca}^{2+}$ is the ionic factor which is indispensable for high release probability. Around these times two postdoctoral fellows associated with Katz, Dodge and Rahamimoff, worked on the $\left[\mathrm{Ca}^{2+}\right]$ dependence of transmitter release at the neuromuscular junction. They showed that the EPP amplitude (the number of released quantae) depends steeply on the extracellular $\left[\mathrm{Ca}^{2+}\right]$ justifying Del Castillo's and Katz's original $\mathrm{Ca}^{2+}$ hypothesis. The steepness of the dependence suggested that four calcium ions bind cooperatively to a hypothetical $\mathrm{Ca}^{2+}$ sensor (Dodge and Rahamimoff, 1967).

The introduction of electron microscopy brought another breakthrough in the field. Heuser and colleagues provided ultrastructural evidence that the membrane of synaptic vesicles (seen on the electronmicrograph) recycle and this recycling coincides with neurotransmitter release (Heuser and Reese, 1973). In the same year Ceccarelli and colleagues found another, faster type of recycling, also with electronmicroscopy (Ceccarelli et al., 1973). A few years later the so-called freeze-fracture technique provided further evidences for the idea that one quantum corresponds to one synaptic vesicle and the vesicles fuse into the presynaptic plasma membrane with exocytosis (Heuser et al., 1979).

More than a decade later live imaging of stained synaptic vesicles at the neuromuscular junction directly showed that the vesicles recycle during repetitive stimulation and found a good correlation between the destaining rate and the cumulative release rate measured simultaneously by electrophysiology (Betz and Bewick, 1993). Both rates depended on the stimulation frequency suggesting interplay between vesicle release and recruitment.

Experiments using adrenal chromaffin cells showed that strong cytosolic $\left[\mathrm{Ca}^{2+}\right]$ elevation leads to secretory depression but weak cytosolic $\left[\mathrm{Ca}^{2+}\right]$ elevation results in augmentation, suggesting that a pool of readily releasable vesicles is depleted by the strong stimulation but it is later restored from a larger pool by a $\left[\mathrm{Ca}^{2+}\right]$ dependent priming step (von Ruden and Neher, 1993).

In the next year, 1994, the synaptotagmin 1 knockout mouse was characterized and published initiating a new, molecule oriented era in the presynaptic research (Geppert et al., 1994). 


\section{Direct electrophysiological measurements of $\mathrm{Ca}^{2+}$-dependent exocytosis}

In the previous chapter I referred to the most widespread techniques to study the dynamic cycling of synaptic vesicles and release of transmitters, such as electrophysiology, electronmicroscopy or live optical imaging. While electronmicroscopy still has the best available spatial resolution it captivates only a rigid snapshot of the presynapse. Live imaging of labeled vesicles has poorer spatial resolution than electronmicroscopy but it allows a direct tracking of the cycling and movement of vesicles in a live cell. However, imaging techniques are still too slow to resolve the fastest, downstream steps of exocytic cascade. Electrophysiology offers a submillisecond temporal resolution (but no spatial resolution) therefore it is the most suitable to study the kinetics of the last steps of $\mathrm{Ca}^{2+}$-dependent exocytosis underlying transmitter release.

Figure 2A1 shows an experimental setup where neurotransmitter release is measured through the postsynaptic signal. In this setup a biological detector namely the postsynaptic membrane is wedged between the studied phenomenon (transmitter release) and the instrumental detector (the electrode). The problem is that the postsynapse is not a high fidelity detector because the matrix of the synaptic cleft, the desensitization of transmitter receptors and passive and active dynamic electrical properties of the membrane between the transmitter receptors and the electrode all may deteriorate the recorded postsynaptic signal and they can introduce activity dependent plastic changes in the measured parameters. Recording directly from the presynaptic membrane is technically impossible or at least unreproducible and inconvenient because the small size of the presynapse (apart from some special preparations such as the giant axon of the squid, retinal bipolar cells or the calyx of Held).

Alternative systems are neuroendocrine cell preparations, where the hormon (insulin, histamin, serotonin, adrenalin and other catecholamines) is secreted similarly to neurotransmitters: via $\mathrm{Ca}^{2+}$ dependent exocytosis. Furthermore the molecular machinery of hormon release is largely homologous with (but not absolutely identical to) the release of neurotransmitters (Rettig and Neher, 2002). Figure 2B1 depicts such a neuroendocrine cell with two electrodes. Both electrodes record signals arriving directly from the secretory cell, the correspondent of the presynapse. The electrode on the left is a carbon microfiber, which detects the released quantae of the hormon molecules. The detection is based on a redoxi reaction - therefore the hormon must be oxidizable - and the method, first described in the early 1990s in adrenal chromaffin cells (Leszczyszyn et al., 1991), is now wide-known as carbon fiber amperometry (Neher, 1998; Bruns, 2004).

The second electrode, on the right, is a patch electrode, which is used here in the whole-cell configuration (Hamill et al., 1981) to measure the capacitance of the plasma membrane (Neher, 1998). First it was observed in sea urchin eggs that fusion of the socalled cortical vesicles into the plasma membrane - a key reaction of the egg upon insemination - coincides with a change in the capacitance of the plasma membrane (Jaffe et al., 1978). The explanation is that both the plasma membrane and the vesicle 


\section{A1}
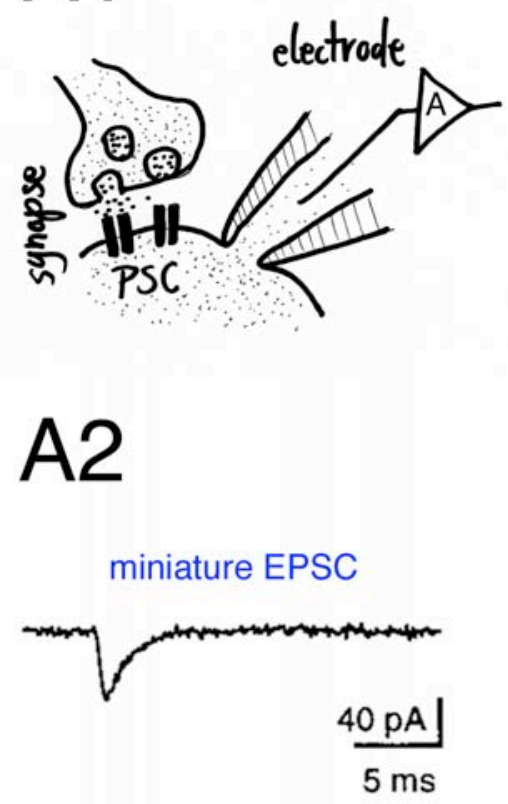

B1
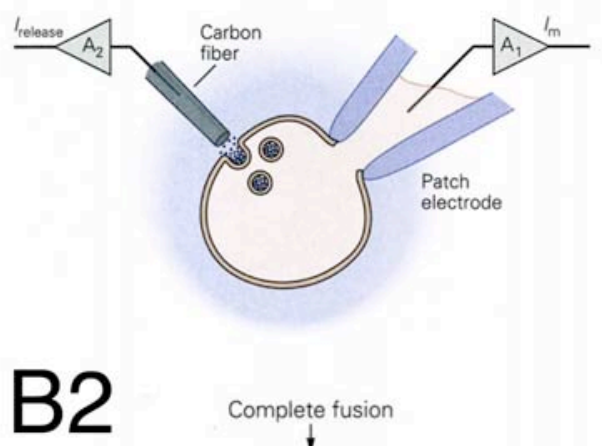

Flickering fusion

Complete fusion

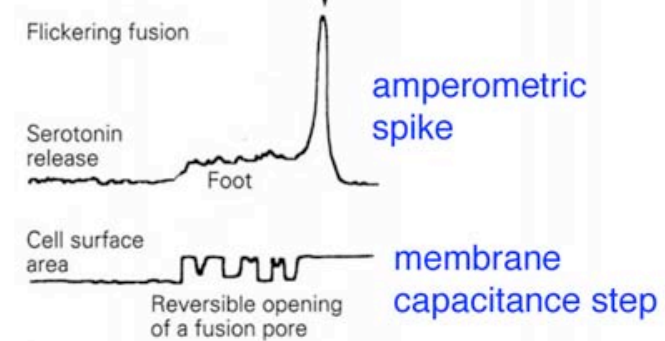

Figure 2

Electrophysiological strategies to assay neurosecretion. A1) Measuring postsynaptic currents (PSC) at the synapse is an indirect strategy. A2) A miniature excitatory postsynaptic current (EPSP) represents the fusion of a single synaptic vesicle. Figure taken from (Schneggenburger et al., 1999). B1) A direct strategy in neurosecretory cells for the measurement of exocytosis and secretion is membrane capacitance measurement (with patch-clamp), which may be combined with carbon fiber amperometry. Taken from (Kandel and Siegelbaum, 2000). B2) Simultaneous recording of an amperometric spike and a step-like increase in the membrane capacitance proved that serotonin is released concomitantly upon the opening of the fusion pore between the secretory vesicle and the plasma membrane in mast cells. Modified after (Alvarez de Toledo et al., 1993).

membrane represent electrical capacitors whose capacitance depends only on their surface area (if we assume that the thickness of the biological lipid bilayer is constant). Thus, changes in the cell surface area upon vesicle fusion during exo- and endocytosis can be measured using this principle.

What are the signals that these different electrophyisological techniques measure during the fusion of synaptic- and other type of secretory vesicles? Figure 2A2 shows a miniature excitatory postsynaptic current (EPSC) recorded from the postsynaptic cell at a calyx type synapse (Schneggenburger et al., 1999), which is homologous to the miniature endplate potentials that Katz and his colleagues recorded fifty years ago (Fatt and Katz, 1952), therefore represents the fusion one synaptic vesicle (the release of one transmitter quanta). 
Figure 2B2 depicts a so-called amperometric spike (on the top) recorded from a degranulating (secreting) mast cell (Fernandez et al., 1984). The amperometric spike represents release from a single secretory vesicle (Wightman et al., 1991) and it has an initial foot component which is believed to reflect a narrow fusion pore between the vesicle and the plasma membrane before complete exocytosis. In Figure 2B2 on the bottom, the membrane capacitance of the degranulating mast cell is displayed, recorded simultaneously with the amperometric spikes (Fernandez et al., 1984). A fast, step-like increase can be observed just preceding the amperometric foot in time. During the foot the membrane capacitance 'flickers' as the fusion pore forms, disappears and reforms. Finally the secretory vesicle undergoes full fusion and the membrane capacitance stays at the increased value. Thus, the amperometric spike and the simultaneous leap in membrane capacitance are signals homologous to the miniature postsynaptic currents and they all represent the same scheme: the fusion of a secretory/synaptic vesicle and the concomitant hormon/transmitter release.

\section{The flash experiment in adrenal chromaffin cells}

In my work described later in this thesis I used a direct strategy similar to Figure 2B1 to assay $\mathrm{Ca}^{2+}$-dependent exocytosis, namely the flash experiment. Figure 3 shows and explains the flash experiment in adrenal chromaffin cells and shows one of my records as a 'representative' example. Here I will list the advantages of this system and try to grasp the importance of each point.

Adrenal chromaffin cells (Figure 3A) provide a useful system to study the molecular mechanisms of transmitter release (Rettig and Neher, 2002) because they fulfill the following criteria:

1. they originate from the neural crest and have a set of exocytic proteins similar to the presynaptic terminals of neurons

2. sudden and large increase in the intracellular $\left[\mathrm{Ca}^{2+}\right]$ triggers rapid release of catecholamines from large dense-core vesicles like the rapid release of the transmitter at the synapse

3. the released catecholamines can be measured with carbon fiber amperometry (Figure 2B1, 3B)

4. the fusion of large dense-core vesicles can be followed by membrane capacitance measurements (Figure 2B1, 3B)

5. ratiometric intracellular $\left[\mathrm{Ca}^{2+}\right]$ measurement with fluorescent dyes is possible (Figure 3B)

6. intracellular $\left[\mathrm{Ca}^{2+}\right]$ can be kept spatially homogenous with $\mathrm{Ca}^{2+}$ buffers

7. the possibility of direct control and sudden, strong elevation of intracellular $\left[\mathrm{Ca}^{2+}\right]$ using photolyzable $\mathrm{Ca}^{2+}$-cages 


\section{A}

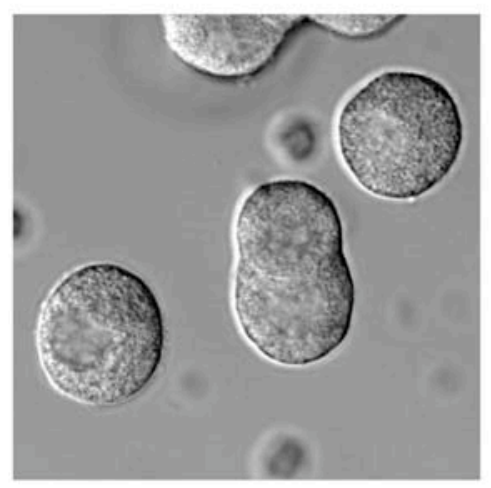

B
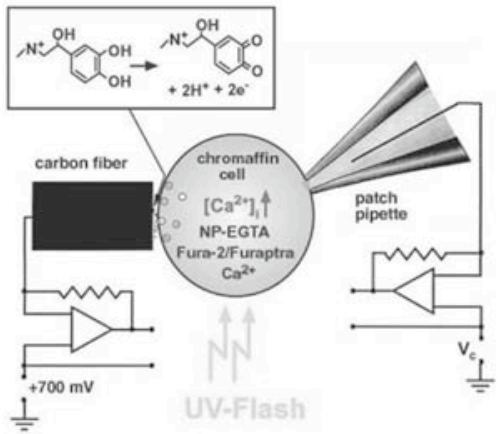

C
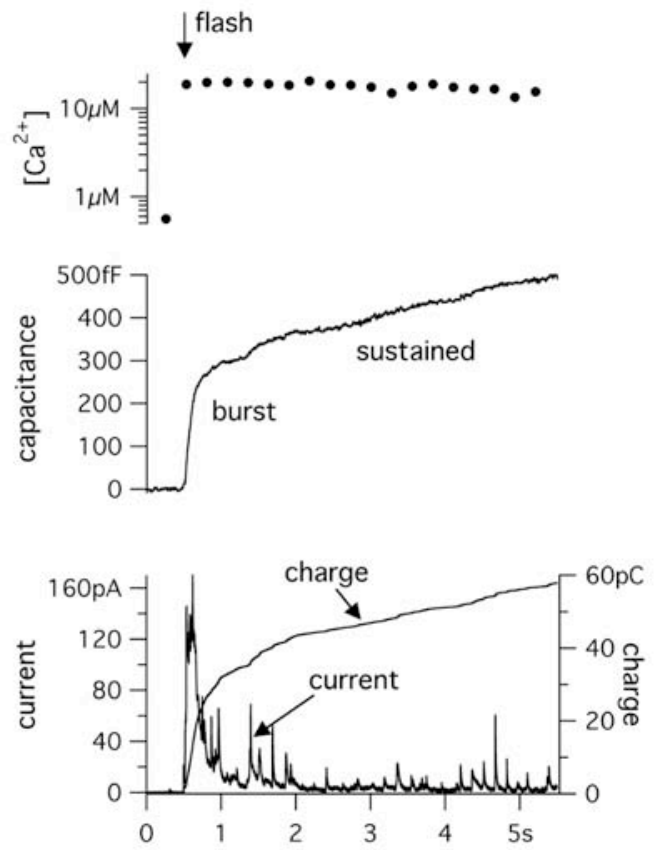

\section{Figure 3}

The flash experiment in adrenal chromaffin cells. A) cultured chromaffin cells from the adrenal medulla. B) Membrane capacitance recording combined with amperometry, flash photolysis of caged $\mathrm{Ca}^{2+}$ and ratiometric intracellular $\left[\mathrm{Ca}^{2+}\right.$ ] measurement. Whole cell patch clamp in voltage clamp mode provides the basis of membrane capacitance measuremet. It also offers the possibility of loading the cell with the photolysable $\mathrm{Ca}^{2+}$ cage NP-EGTA, and the mixture of a higher and a lower affinity $\mathrm{Ca}^{2+}$ indicator dye (e.g. Fura-2 and Furaptra) to measure intracellular $\left[\mathrm{Ca}^{2+}\right]$ in a broad dynamic range. A flash of UV light liberates $\mathrm{Ca}^{2+}$ from the cage and triggers secretion of chatecolamines. A carbon fiber electrode kept at a positive potential in respect to the bath oxididises the chatecolamine molecules and takes up the released electrons. The subsequent amperometric current is measured. C) Simultaneously measured intracellular $\left[\mathrm{Ca}^{2+}\right]$, membrane capacitance increase and amperometric current in response to flash stimulation. The intracellular $\left[\mathrm{Ca}^{2+}\right]$ is elevated from a lower basal level $(\sim 0.6 \mu \mathrm{M})$ to a higher postflash level $(\sim 20 \mu \mathrm{M})$. The high $\left[\mathrm{Ca}^{2+}\right]$ fuses vesicles with the plasma membrane, which involves an increase in cell capacitance. An early, steep component, the burst is followed by a later, shallow sustainded component. The amperometric current shows massively superimposing spikes in the burst phase and less intensive spike activity in the sustained phase. The integral of the current is the charge, which mirrors the capacitance increase.

Points 3 and 4 mean that two direct and independent recording technique can assay the exocytic process. When they are simultaneously utilized, the recorded signals should well correlate (Chow et al., 1996) if both of them report only the fusion of large dense-core vesicles and not other fusion types (Xu et al., 1998) or endocytosis (Smith and Neher, 1997). With the optimal control of intracellular $\left[\mathrm{Ca}^{2+}\right]$ the latter two can be eliminated (Xu et al., 1998), see also point 7. 
The importance of point 5 is that intracellular $\left[\mathrm{Ca}^{2+}\right]$, which is a key regulator for multiple components of exocytosis during transmitter release (Zucker, 1999), directly and quantitatively can be measured in chromaffin cells. For most neuronal preparations it is still the Dodge-Rahamimoff equation that is used (Dodge and Rahamimoff, 1967), which operates with the extracellular $\left[\mathrm{Ca}^{2+}\right]$, an important but not the only determinant of the intracellular $\left[\mathrm{Ca}^{2+}\right]$.

Point 6 assures that no $\mathrm{Ca}^{2+}$ microdomains exist in the cell, which would complicate the estimation of the $\left[\mathrm{Ca}^{2+}\right]$ dependence of different steps of the exocytic cascade (Neher, 1998).

The significance of point 7 is that $\left[\mathrm{Ca}^{2+}\right]$ can be set to preferred values to investigate the $\left[\mathrm{Ca}^{2+}\right]$ dependence of distinct steps. In addition the strong $\mathrm{Ca}^{2+}$ stimulation depletes the releasable pools so that the pool sizes (before stimulation, in rest) can be estimated. Furthermore, the flash photolysis of the $\mathrm{Ca}^{2+}$ cage leaps the intracellular $\left[\mathrm{Ca}^{2+}\right]$ so rapidly to the stimulating value that fusion rates and delays from different pools can be faithfully measured.

\section{The '4 vesicle pool model'}

What is the interpretation of the flash responses? What kind of information do they contain? Figure 4A shows the burst and sustained component of the capacitance increase after flash stimulation. The burst is exponential in nature implying that the fusion of large dense-core vesicles starts after the flash (with a short delay) with an initial rate (the initial steepness of the capacitance curve) but as time passes the rate decreases to a smaller constant level, which is seen during the sustained phase.

This kind of behavior is very reminiscent of synaptic depression during prolonged trains of presynaptic fiber stimulation especially if the cumulative postsynaptic charge is displayed instead of the current (against time or the number of stimulus in the train). In that system the interpretation is that a pool of readily releasable quantae is depleted in the beginning. As soon as the depletion begins a restoration process starts up to supply new readily releasable quantae from a large reserve store that is not directly releasable (Elmqvist and Quastel, 1965). The replenishment is a slower process than release itself, therefore it limits the rate of release after the initial depletion of the releasable pool, keeping release at a low rate. This low release rate is constant as long as the reserve store itself is preserved by e.g. vesicle recycling. If the reserve store is not replenished fast enough it will be depleted too, and the rate of release declines to zero.

Figure 4B shows a recent model with four distinct vesicle pools in chromaffin cells. According to the model, the pool of releasable vesicles is depleted/emptied in the burst phase of the flash response. The time constant of the exponential fitted to the burst defines the rate constant of fusion meaning the initial release rate (Table 1). The amplitude of the exponential fitted to the burst reflect the number of releasable (fusion competent) vesicles. Because typically two exponentials with different time constants 


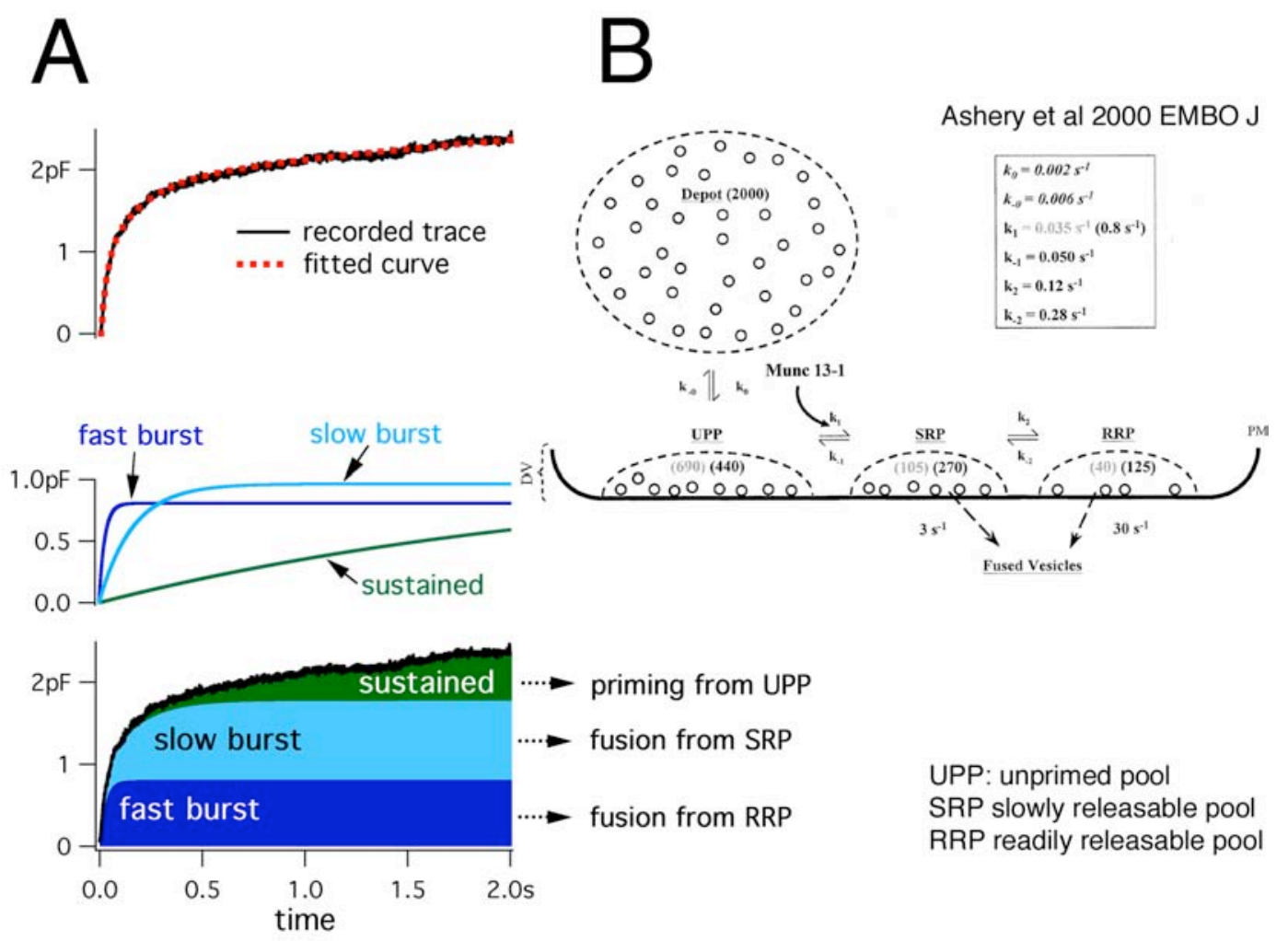

\section{Figure 4}

Three kinetic components of the flash response and the ' 4 vesicle pool model'. A) A triple exponential curve is fitted to the capacitance trace (top graph). The fastest and the somewhat slower exponential defines the fast and slow burst components, respectively. The remaining, slowest exponential is the sustained component (middle graph). The fast and the slow burst is interpreted as fusion of all vesicles from a so-called readily and a slowly releasable pool. According to the following model, the sustained component corresponds to fusion of those vesicles that primed after the flash stimulation (bottom graph). B) A model was created with four vesicle pools, where the pools are in dynamic equilibrium before the flash stimulation. The amplitude of the fast and slow burst component defines the size of the readily and slowly releasable pools, respectively (RRP, SRP). Exponential time constants determine fusion rates (dashed arrows). The sustained component reflects the priming rate $\left(k_{1}\right)$ and/or the size of the unprimed pool (UPP). Figure was taken from EMBO J., Vol 19, 3586-3596.

describe the burst more faithfully than a single exponential, the burst was subdivided into fast and slow burst (Voets et al., 1999). Thus, there is a readily releasable vesicle pool (RRP) with fast vesicle fusion rate and a slowly releasable pool with a slower fusion rate. It was shown that both fusion constants (that of the RRP and of the SRP) increase with increasing intracellular $\left[\mathrm{Ca}^{2+}\right]$ jump in response to the flash stimulation while the amplitudes remained constant (Voets, 2000). Thus, the postflash $\left[\mathrm{Ca}^{2+}\right]$ controls the fusion rates and not the size of the releasable vesicle pools.

The amplitudes of the two exponentials fitted to the burst define the sizes of the releasable pools (the number of vesicles in the RRP and SRP), as summarised in Table 1. It was observed that the amplitudes but not the time constants of the two burst components depend on the intracellular $\left[\mathrm{Ca}^{2+}\right]$ before the flash (Voets, 2000). Therefore it 


\begin{tabular}{|c|c|c|c|}
\hline component & parameter & unit & simplified meaning \\
\hline \multirow{2}{*}{ fast burst $^{\star}$} & amplitude & $\mathrm{F}$ & size of the readily releasable pool (RRP) \\
\cline { 2 - 4 } & time constant $\left(\tau_{\text {fast }}\right)$ & $\mathrm{S}$ & fusion rate from the RRP \\
\hline \multirow{2}{*}{ slow burst } & amplitude & $\mathrm{F}$ & size of the slowly releasable pool (SRP) \\
\cline { 2 - 4 } & time constant $\left(\tau_{\text {slow }}\right)$ & $\mathrm{S}$ & fusion rate from the SRP \\
\hline sustained & amplitude & $\mathrm{F}^{\star \star}$ & priming rate and size of the unprimed pool \\
\hline burst & $\begin{array}{c}\text { amplitude ratio of } \\
1^{\text {st }} / 2^{\text {nd }} \text { flash response }\end{array}$ & - & refilling of releasable pools after depletion \\
\hline
\end{tabular}

Table 1

Summary of the components and measured parameters of the flash responses with their simplified interpretation based on the '4 vesicle pool model' in Figure 4B.

* The (overall) 'burst' ampitude later in the 'Experimental results' section is defined as the membrane capacitance change in the first $0.5 \mathrm{~s}$ after the flash.

** The 'amplitude' of the sustained component is defined as the membrane capacitance change between $0.5 \mathrm{~s}$ and $5.0 \mathrm{~s}$ after the flash therefore it is a rate in fact with a unit of F/4.5s

was concluded that the sizes of the releasable pools but not the fusion rates depend on the preflash $\left[\mathrm{Ca}^{2+}\right]$. This phenomenon was interpreted as $\left[\mathrm{Ca}^{2+}\right]$ dependent priming of vesicles (Voets, 2000).

The model contains a docked but unprimed pool of vesicles (UPP). These vesicles are mobilized when the RRP and SRP are depleted/emptied in the burst phase and go through priming to reach the SRP. Since the intracellular $\left[\mathrm{Ca}^{2+}\right]$ is kept high long after the burst (Figure 3C top graph), these newly primed vesicles immediately fuse from the SRP resulting in the sustained component. Because the vesicles the SRP fuse faster than they arrive from the UPP by priming, it is the rate of priming $\left(\mathrm{k}_{1}\right)$ that defines the rate of the sustained increase of the membrane capacitance. In other words the sustained component reflects priming from an unprimed pool (Table 1).

The unprimed pool is not replenished (refilled) during the timespan of the flash experiment (maximum 10 minutes) therefore the sustained release of catecholamines slowly ceases if the intracellular $\left[\mathrm{Ca}^{2+}\right]$ is kept high for minutes. If however the intracellular $\left[\mathrm{Ca}^{2+}\right]$ is let fall back to a low basal value for a minute, the releasable pools are fully refilled from the unprimed pool and a second flash evokes a response similar to the first one. If the priming process after the first flash stimulation is somehow impaired, the releasable pools will not refill properly and the second flash response will be smaller in amplitude than the first one (Nagy et al., 2002). Thus the second flash response carries information about the refilling of the releasable pools (Table 1).

In Figure 4B a fourth vesicle pool is depicted, the depot pool, which consists of vesicles that are not docked to the plasma membrane. The size of this pool has to be determined by an alternative method, namely electronmicroscopy, because the docking process is too slow for the flash experiment to 'see' it within a couple of minutes. The 
flash experiment though, can give only indirect predictions about the size of the depot pool.

A convincing number of studies has supported the ' 4 pool model' by now (Sorensen, 2004). The challenge now is to utilize it in the molecular mapping of transmitter release.

\section{Other advantages of chromaffin cells}

Here I would like to mention some additional features of adrenal chromaffin cells that supported our work:

8. the number and spatial distribution of the large (electron)dense-core vesicles can be studied with electronmicroscopy

9. the live imaging of the movement of vesicles is possible total internal reflection microscopy (TIRF)

10. the cultured adrenal chromaffin cells can be infected with viral vectors to overexpress different proteins

11. functional cell culture can be made from mouse embryos therefore perinatally lethal genomic mutations are possible to study

The importance of points 8 and 9 is that electronmicroscopy and TIRF microscopy are complementary methods to electrophysiology. They assay upstream steps of exocytosis (vesicle docking, moving) while the flash experiment keeps track of more downstream steps (priming and fusion).

Points 10 and 11 lead us to the coupling of genetics with cell physiology to study the molecular machinery of transmitter release. Next I will review some of the known principles of that machinery and give powerful examples how experiments on adrenal chromaffin cells contributed to these principles. 
The molecular machinery of exocytosis (introduction) 


\section{Macromolecules execute the steps of the exocytic cascade}

The molecular essence of synaptic vesicle exocytosis remained unknown until the early nineties. In 1993 a breakthrough study was published by Rothman and colleagues (Sollner et al., 1993). They isolated three principal proteins from a presynaptic ' $20 \mathrm{~S}$ fusion complex', associated to $\alpha$-SNAP and they gave these proteins the general name: SNAREs (SNAP receptors). One of the SNAREs they isolated, synaptobrevin/VAMP (Trimble et al., 1988; Baumert et al., 1989) is an integral vesicle membrane protein whereas the other two SNAREs are located in or at the presynaptic plasma membrane. These latter SNAREs were identified as syntaxin and SNAP-25 (Oyler et al., 1989; Bennett et al., 1992). Upon their findings, Rothman and colleagues introduced the SNARE hypothesis (Sollner et al., 1993), depicted in Figure 5A.

They assumed a universal mechanism for all types of eukaryotic membrane fusion including the exocytosis of neurosecretory vesicles. They speculated that the SNAREs on the vesicle (v-SNAREs) and those on the target membrane (t-SNAREs) associate with each other bringing the two membranes together. They hypothesized that the main role of the SNARE machinery is that they dock the vesicle onto the target membrane. They further assumed that the different SNARE protein homologs could provide the specificity of fusion of membranes originating from different intracellular compartments.

The idea that SNAREs are essential in synaptic vesicle exocytosis was supported by studies with neurotoxins, which cleave the SNARE proteins and arrest neurotransmitter release at the same time (Blasi et al., 1994). However after neurotoxin treatment, morphological docking of synaptic vesicles is normal (Schiavo et al., 2000) suggesting a role for the SNARE proteins downstream to docking.

The next landmark was laid in 1998 when the crystal structure of the neuronal SNARE complex was published (Sutton et al., 1998). The structure of the so-called core complex - that is not the entire SNARE complex - was found as a four $\alpha$-helix bundle (Figure 5B1). This structure is very stable, having a melting temperature of $90^{\circ} \mathrm{C}$ (Fasshauer et al., 1997) therefore energetically highly preferable. Based on these findings, the most plausible model for the function of the SNARE complex is that the released energy during assembly of the complex is utilized in pulling vesicle and target membrane together (Sutton et al., 1998). Furthermore, the elongated form of the SNARE core complex supports the 'zipper hypothesis'(Sutton et al., 1998). According to the 'zipper hypothesis', the core complex is assembling from the distal end to the end proximal to both membranes and the contact between the vesicle and the target membrane gradually tightens. This gradual assembly and the concomitant energy release could form the molecular backbone of vesicle priming and later fusion (Fasshauer, 2003).

In the same year, 1998, the SNARE complex was demonstrated as a 'minimal machinery for membrane fusion' using liposomes incorporating v- and t-SNAREs (Weber et al., 1998). In living organisms (mice) genetical ablation of different SNAREs caused severe defect in neurosecretion and early lethality (Schoch et al., 2001; 

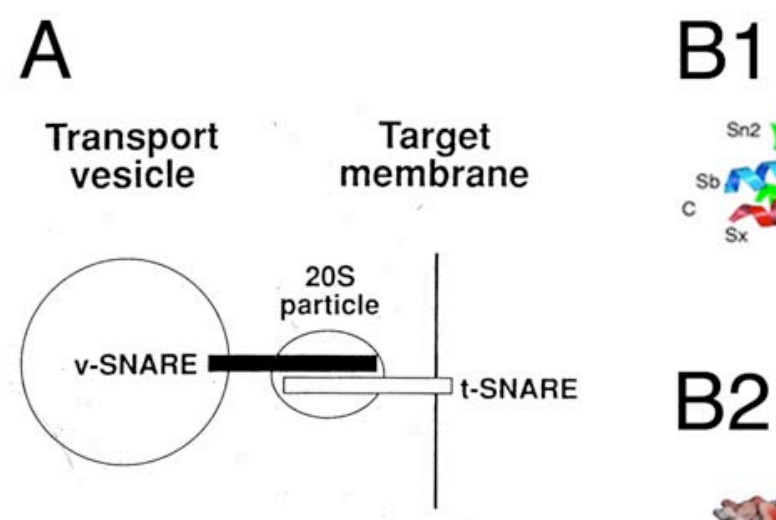

Söllner et al 1993 Nature
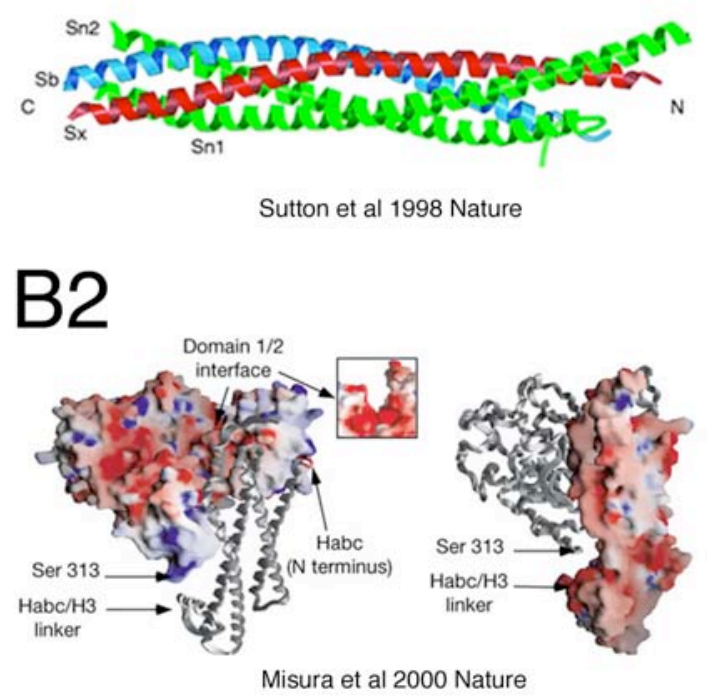

\section{Figure 5}

Molecular essence of vesicle fusion. A) The SNARE hypothesis from (Sollner et al., 1993). B1) Three dimensional structure of the neuronal core complex consisting of four SNARE motifs of three SNARE proteins: SNAP-25 (Sn1, Sn2), syntaxin (Sx) and synaptobrevin/VAMP (Sb) from (Sutton et al., 1998). The complex is a termodinamically very stable 'four helix boundle'. B2) Left and right (rotated in space): three dimensional structure of the protein complex between Munc18-1 and syntaxin 1 (Misura et al., 2000). Electrostatic surface is shown for Munc18-1 with red and blue while the gray polypeptide backbone represents syntaxin 1. Linker region in syntaxin 1 is pointed between the Habc domain and the H3 domain (with the SNARE motif). Ser313 is a protein kinase C phosphorylation site (Fujita et al., 1996).

Washbourne et al., 2002). Finally v- and t- SNAREs 'flipped' outside the plasma membrane could fuse living cells (Hu et al., 2003). These findings strongly support the first notion of the SNARE hypothesis. The SNARE complex is very likely to represent the molecular essence of eukaryotic membrane trafficking generally, including exocytosis during transmitter release. Yet it must be noted that this view is not without a challenge (Peters et al., 2001).

\section{Evolution of functional studies on exocytic proteins in chromaffin cells}

Here I would like to reduce the previously listed 11 advantages of the chromaffin cell system to two points:

1. a quantitative investigation of secretory vesicle pool dynamics in the function of intracellular $\left[\mathrm{Ca}^{2+}\right]$

2. mutations can be studied in a genetically 'clean' system in order to correlate protein structure with cellular function 
I dealt with the first point in detail when I described the flash experiment and the '4 vesicle pool' model (Figure 3-4). Now I wish to guide the reader through the short history of the development of the 'knockout and rescue' approach. The knockout and rescue approach or simply the rescue approach is what enables the chromaffin cell system to have the second advantage. I will illustrate the main developmental steps with publications from Dr. Neher's department. All of these studies have one in common: a genetical manipulation of a protein had a profound and specific effect on the flash responses. These effects could be very well explained by the idea that the studied protein controls a certain step in large dense-core vesicle exocytosis according to the 4 vesicle pool model'.

\section{Munc13-1 is a priming factor: viral overexpression}

The aim of the overexpression technique is to express the wildtype or mutant form of a protein 'over' the endogenous protein pool. The recombinant RNA of that protein is introduced (transfected) into the cell where it is translated into polypeptide. The Semliki Forest virus system (SFV) was successfully utilized in cultured bovine chromaffin cells to transfect and express enhanced green fluorescent protein (eGFP) (Ashery et al., 1999). eGFP is generally used to report overexpression of the protein of interest because it has a strong fluorescent but usually weak biological activity. Indeed, SFV mediated overexpression of eGFP had little effect on the flash responses in bovine chromaffin cells (Ashery et al., 1999). This finding paved the way to the coexpression of eGFP and the protein of interest. One possibility is when the small eGFP is bound covalently to the other protein forming a single polypeptide chain, a fusion protein. This setup has the advantage that the level of overexpression can be quantitatively correlated with the fluorescent activity of the cell. In another mode the RNA has an internal ribosomal entry site (IRES). The IRES splits the translation of the mRNA to two peptides: to the eGFP and to the protein of interest. The IRES method is advantageous when the investigator does not want to risk the possibility that eGFP somehow interferes with the natural conformation and activity of the protein of interest.

Munc13-1 was the first exocytic protein that was overexpressed in bovine chromaffin cells (Ashery et al., 2000). It was found that the fast burst the slow burst and the sustained component was largely increased upon overexpression but the time course of the burst phase was not affected (Ashery et al., 2000). Computer simulation using the ' 4 vesicle pool model' showed that an increase of only one kinetic constant can explain the above described phenotype (Ashery et al., 2000). This constant was the "priming constant' $\mathrm{k}_{1}$ seen in Figure 4B. Therefore it was concluded that Munc13-1 is a priming factor for large dense core vesicles in chromaffin cells (Ashery et al., 2000). 


\section{Synaptotagmin-1 is the $\mathrm{Ca}^{2+}$ trigger for the fusion of rapidly releasable vesicles: knockout/knockin mice}

It is a relatively rare finding that increased level of a protein results in a gain of function. It happens only when the limited amount of that protein is the rate limiting factor (the bottleneck) of a biochemical process. A more common case is when overexpression of a protein has no or little effect even though the protein has an important or even essential role (Rettig and Neher, 2002). In these cases the gene knockout approach can be fruitful. In a knockout mouse usually a 'neomycin cassette' is inserted into an exon of the targeted gene with homologous recombination. This results in a null mutation of that gene and the endogenous expression of the given protein is completely arrested.

Shortly after its isolation Synaptotagmin 1 was proposed to be a $\mathrm{Ca}^{2+}$ sensor $\left(\mathrm{Ca}^{2+}\right.$ trigger) for the latest stage of exocytosis (Brose et al., 1992) but this view became generally accepted only ten years later (Koh and Bellen, 2003). The use of the synaptotagmin 1 knockout mouse line was instrumental during that decade. When synaptotagmin 1 was knocked out of the mouse genom it was found that the mice carrying the null mutation (null mutants) died shortly after birth due to a dramatic decrease in neurotransmitter release (Geppert et al., 1994).

In a following study the adrenal glands of the synaptotagmin 1 null mutant mice were recovered to prepare tissue slices to study the kinetics of $\mathrm{Ca}^{2+}$-triggered flash responses (Voets et al., 2001a). If (one of) the $\mathrm{Ca}^{2+}$-trigger is missing vesicle fusion of (one of) the releasable pool should be converted to a release incompetent pool. This speculation was perfectly coincided with the experimental finding: the fast burst component - representing the readily releasable pool (RRP) - was absent in the synaptotagmin 1 null chromaffin cells (Voets et al., 2001a) as seen in Figure 6A. It was however early to conclude that synaptotagmin 1 is the $\mathrm{Ca}^{2+}$ sensor for the RRP because several other schemes could explain the observed effect just as well (Voets et al., 2001a).

Qualitative modification of the protein is a more sophisticated way to study its function compared to the complete removal by a null mutation in the genom. This scenario would allow the investigators to compare protein function in biochemical and cellular level. The R233Q mutation causes a twofold decrease in the $\left[\mathrm{Ca}^{2+}\right]$ dependent phospholipid binding of the so-called C2A-C2B tandem domain of synaptotagmin 1 in vitro (Fernandez-Chacon et al., 2001). This mutation was introduced to the synaptotagmin 1 gene of the mouse genom with the 'knockin' technique and the R233Q mutant mice showed a milder overall phenotype than the synaptotagmin 1 null mutant mice (Fernandez-Chacon et al., 2001). They survived after birth but their neurons had a different mode of short-term plasticity than their wildtype mates (Fernandez-Chacon et al., 2001).

When flash responses were analyzed from the R233Q mutant chromaffin cells it was found that the fast burst phase was present with normal or even slightly increased amplitude but it was rising slower than in wildtype cells (Sorensen et al., 2003a), as 
A

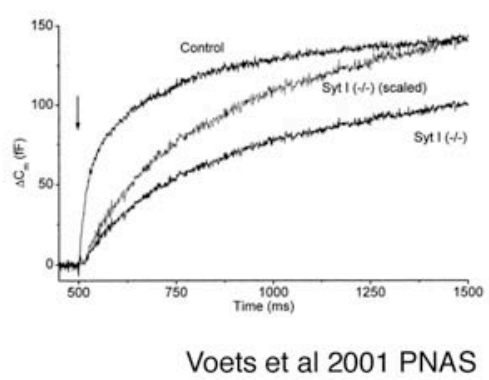

$\mathrm{B}$
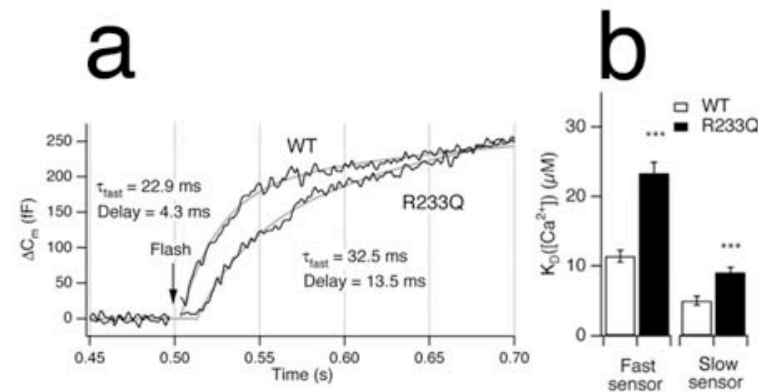

Sørensen et al 2003 J Gen Physiol

\section{Figure 6}

Synaptotagmin 1 is one of the $\mathrm{Ca}^{2+}$-sensors for vesicle fusion in chromaffin cells. A) A selective loss of the fast burst component suggested that vesicles from the rapidly releasable pool are unable to fuse upon direct $\mathrm{Ca}^{2+}$-stimulation. This finding supported the hypothesis that Synaptotagmin 1 is one of the $\mathrm{Ca}^{2+}$-sensors for vesicle fusion. Adapted from Proc. Natl. Acad. Sci. USA, Vol 98, 11680-11685. B) Fusion from the rapidly releasable pool is slowed down in the R233Q mutant knockin mouse chromaffin cells. First, careful analysis of the $\left[\mathrm{Ca}^{2+}\right]$-dependence of secretion revealed a 2-fold increase in the $\mathrm{Ca}^{2+}$-affinity of the $\mathrm{Ca}^{2+}$-sensors in mutant cells. Second, previous biochemical experiments showed that the R233Q mutation causes a 2-fold increase in the $\mathrm{K}_{\mathrm{D}}$ of $\mathrm{Ca}^{2+}$-dependent phospholipid binding. Combining these two well correlating findings provided an evidence that Synaptotagmin 1 functions in the $\mathrm{Ca}^{2+}$-triggering step. Adapted from J. Gen. Phisol., Vol 122, 265-276.

illustrated in Figure 6Ba. Kinetical analysis and biophysical modeling revealed that this slowdown is due to a twofold decrease in $\left[\mathrm{Ca}^{2+}\right]$ sensitivity of the $\mathrm{Ca}^{2+}$ trigger for vesicle fusion (Sorensen et al., 2003a). This twofold decrease in cellular function perfectly correlated with the twofold decrease in biochemical function strongly suggesting that synaptotagmin 1 is identical to the hypothetical $\mathrm{Ca}^{2+}$ sensor.

\section{SNAP-25 isoforms and homologs differentially regulate the releasable pools: the rescue approach}

Generation of a transgenic knockin mouse line is labour consuming and slow. Besides that, compensatory mechanisms e.g. upregulation of other genes can mask the effects of the mutation. An alternative way of studying mutations in chromaffin cells is the acute overexpression of the mutant protein over the endogenous wildtype protein pool. This strategy was fruitful in some cases (Nagy et al., 2002; Nagy et al., 2004) but it has a major disadvantage: the endogenous wildtype proteins can outcompete the mutant if the latter has a decreased affinity to the physiologically important binding partner.

Therefore it is not an effective method to study the strength of protein-protein interactions. One would need to remove the endogenous wildtype protein pool first. This can be achieved by generating a knockout mouse line. In the null mutant (knockout) cells now many mutants of the given protein can be acutely (over)expressed on a 'clean genetical background'. This is called the 'rescue' approach because a loss of function in 

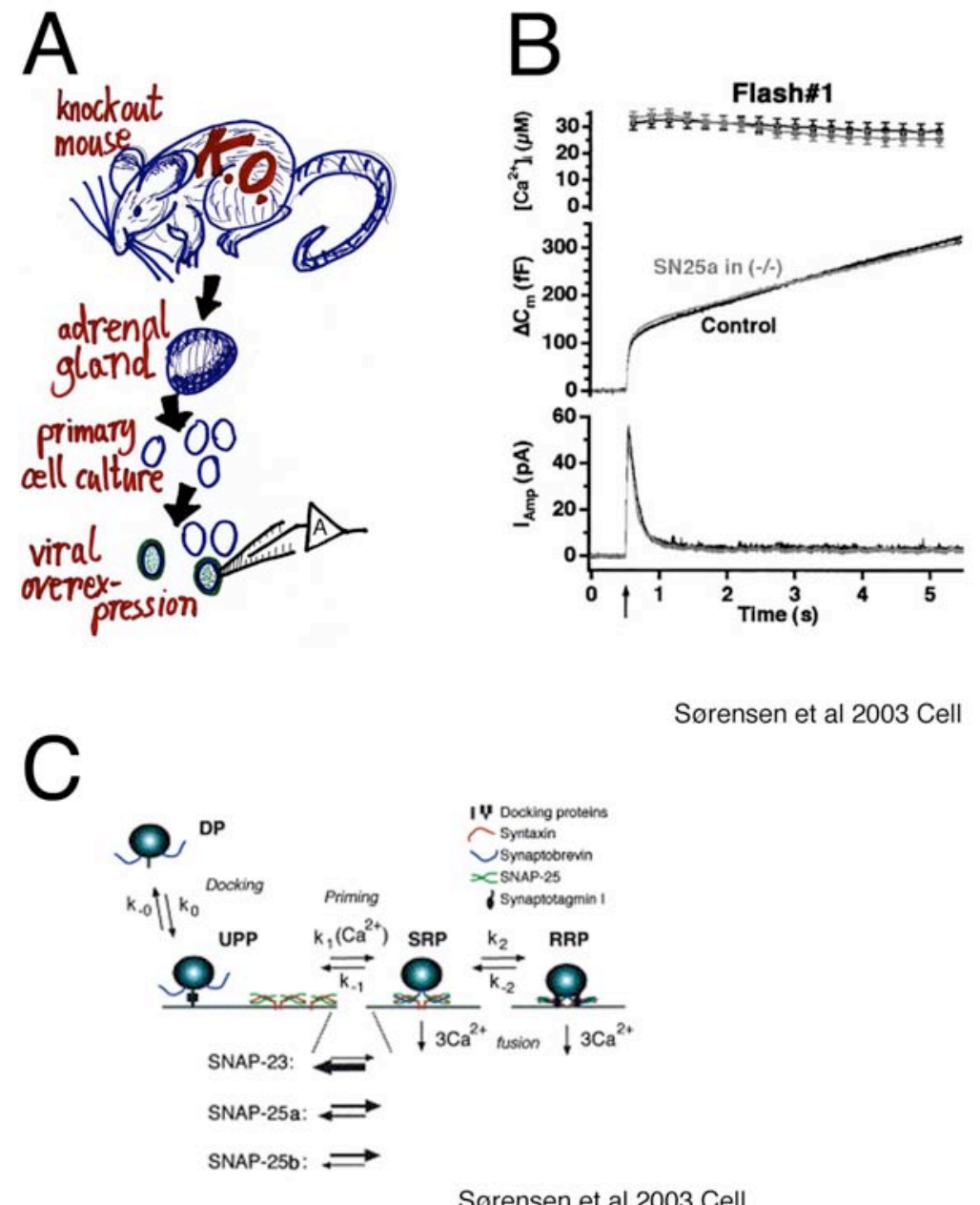

Sørensen et al 2003 Cell

\section{Figure 7}

The rescue experiment lead to the conclusion that SNAP-25 splice variants and SNAP-23 differentially control the releasable vesicle pools. A) For the rescue experiment a knockout mouse is needed, where the gene of interest is not expressed. Elaboration of the mouse adrenal culture made it possible to introduce proteins into mouse chromaffin cells with the help of viral vectors. Reintroduction of an essential exocytic protein could therefore 'rescue' a defective secretory phenotype. Moreover, the 'clear genetic background' of the knockout cells offers a unique possibility to study mutant proteins in the absence of the wildtype gene product. B) Reintroduction of SNAP-25a into SNAP-25 null mutant cells restored secretion from reduced to normal level. C) Rescue experiments using SNAP-25 knockout cells that overexpressed SNAP-23, SNAP-25a or SNAP-25b suggested that these proteins control vesicle priming and depriming differentially. B-C) adapted from Cell, Vol. 114, 75-86.

null mutant cells is supposed to be rescued after reintroduction of that gene by overexpression (Figure 7A).

The development of the rescue approach using chromaffin cells was largely due to Gábor Nagy in Dr. Neher's department who managed to sustain mouse chromaffin cells in culture instead of acute tissue slice where viral overexpression is problematic. The approach was first published only a year ago by Nagy and colleagues when reintroducion of SNAP-25 'rescued' the drastically decreased flash responses of SNAP25 null mutant cells (Sorensen et al., 2003b). Figure 7B shows that there is no detectable 
difference in the flash responses between cells from wildtype mice (control) and those SNAP-25 null mutant cells that overexpress recombinant SNAP-25 (SN25a in -/-). Thus, the rescue was successful. Then the investigators went further on and expressed different isoforms and homologs of SNAP-25 in the null mutant cells and they showed that these cognate proteins have different efficiency in controlling the releasable pool sizes by affecting the $\mathrm{k}_{1}$ and $\mathrm{k}_{-1}$ constants in the ' 4 vesicle pool model' (Figure 4B and Figure 7C).

The rescue approach in chromaffin cells has been successfully used with at least two other kind of knockout: the synaptotagmin 1 and the Munc18-1 knockout (both yet unpublished). The latter study forms the basis of this thesis, so I will now review the literature on Munc18-1 and related proteins. 
Munc 18 and exocytosis (introduction) 


\section{Sec1/Munc18 protein family is essential in vesicle trafficking and exocytosis}

In a previous chapter I introduced the SNARE complex as the molecular essence of eukaryotic membrane trafficking and exocytosis. The exocytic machinery however constitutes many more proteins not just SNAREs (Jahn and Sudhof, 1999) Are SNAREs the only essential molecules? It seems not so.

In 1993, the same year as the SNARE hypothesis was introduced, a new syntaxin binding protein was isolated from the 'mammalian vesicle fusion complex' (Hata et al., 1993). The cDNA of the protein turned out to be homologous to the unc-18 gene of $C$. elegans (Brenner, 1974) therefore it was named Munc18 (mammalian unc18). The unc (uncoordinated) mutations in the worm were described almost two decades before causing a severe phenotype associated with uncoordinated movement (Brenner, 1974). Six years later, in 1980 a screen in yeast found the unc-18 homolog Sec1 and this later gave rise to an alternative nomenclature for Munc18: n-Sec1 or rbSec1 (Garcia et al., 1994; Pevsner et al., 1994a) meaning 'neural' and 'rat brain' Sec1, respectively. In 1994 the Drosophila homolog was found and named ROP (Schulze et al., 1994). A whole new protein family started to delineate: the Sec1/Munc18 (SM) proteins.

All three studies isolating Munc18 n-Sec1 and rbSec1 reported strong interactions with syntaxin in vitro suggesting an important role in synaptic vesicle exocytosis (Hata et al., 1993; Garcia et al., 1994; Pevsner et al., 1994a). Null mutations of SM genes in yeast, worm, fly and mouse blocked membrane fusion (Ossig et al., 1991; Hosono et al., 1992; Harrison et al., 1994; Verhage et al., 2000) promoting the SM proteins as essential factors for membrane trafficking in vivo.

\section{Sec1/Munc18 and not SNARE isoforms define the specificity of distinct trafficking pathways}

The SNAREs were shown to be sufficient factors for membrane fusion in artificial systems (Weber et al., 1998; Hu et al., 2003). Why does then Nature need another type of essential factor (the SM proteins) for physiological membrane trafficking? One of the speculations of the SNARE hypothesis was that different SNARE protein isoforms could provide the specificity of membranes originating from different intracellular compartments (Sollner et al., 1993). However, it was shown that the crystal structure of the endosomal SNARE complex is strikingly similar to that of the neuronal complex (Antonin et al., 2002). Moreover, cognate SNAREs can substitute each other and form utterly functional complexes in vivo (Sorensen et al., 2003b). Thus, SNAREs alone cannot be responsible for membrane specificity.

Shortly after its isolation, $\mathrm{n}-\mathrm{Sec} 1$ (Munc18-1) was implicated with the specificity of the 'synaptic vesicle docking complex' in vitro (Pevsner et al., 1994b). Afterwards two more Munc18 isoforms were isolated: Munc18-2 (Munc18b) (Hata and Sudhof, 1995; Katagiri et al., 1995; Tellam et al., 1995) and Munc18-3 (Munc18c) (Tellam et al., 1995). 
Munc18-2 was demonstrated to be a functional partner of syntaxin 3 in controlling apical membrane trafficking in epithelial cells (Riento et al., 2000) while the ubiquitously expressed Munc18c regulates translocation of the GLUT4 glucose transporter interacting with syntaxin 4 in the skeletal muscle (Tamori et al., 1998; Khan et al., 2001). In the following years a series of venturesome experiments were carried out where different SM isoforms and homologs from other organisms were used in combination with different SNARE isoforms and homologs (Toonen and Verhage, 2003). The results suggest that distinct vesicle trafficking pathways are conserved and their specificity is defined by different isoforms of SM proteins (Toonen and Verhage, 2003).

\section{The t-SNARE syntaxin is an interaction partner of Munc18}

It seems though that SM proteins are much more than mere labels on target membranes. They are active players in the interactions of exocytic proteins: Munc18 was isolated by virtue of its ability to bind to the N-terminal region of syntaxin 1 (Hata et al., 1993; Garcia et al., 1994; Pevsner et al., 1994a). Moreover, SM proteins from invertebrates also bound to syntaxin 1 (Rizo and Sudhof, 2002). Importantly, it was found that Munc18 competes with SNAP-25 and synaptobrevin/VAMP in binding to syntaxin (Pevsner et al., 1994a). Interestingly Munc13 and synaptotagmin also bind to the Nterminal region of syntaxin 1 .

In 1998 the three-dimensional structure of an evolutionary conserved $\mathrm{N}$-terminal domain of syntaxin 1A (Nsyx domain) was published consisting of the HA, HB and HC domain (Fernandez et al., 1998). The Nsyx domain was already known as Habc complex (Wang et al., 1992). It was suggested that the evolutionary conserved Nsyx/Habc domain could serve as a surface for diverse protein-protein interactions because formerly binding of Munc13 and synaptotagmin 1 to the Nsyx/Habc domain was reported (Betz et al., 1997; Shao et al., 1997). Shortly after the structure of the Habc domain was described it was found that of syntaxin exists in a 'closed' conformation in isolation but to assemble into the SNARE complex syntaxin needs to adopt an 'open' conformation (Dulubova et al., 1999). A mutation that disrupted the closed conformation of syntaxin, also disrupted its binding to Munc18-1 (Dulubova et al., 1999). It was suggested that the function of Munc18 is to retain syntaxin from entering the SNARE complex therefore Munc18 could be a negative regulator of neurosecretion (Dulubova et al., 1999). Shortly after this several other modes of SM protein-syntaxin interaction were published: in one mode the SM protein binds the 'open' syntaxin in the SNARE complex while in another mode the SM protein interacts with a short, conserved $\mathrm{N}$-terminal domain of syntaxin distinct from the Habc domain (Toonen and Verhage, 2003).

From these findings it became apparent that there is a strong evolutionary divergence of the interaction between SM proteins and syntaxin and the function of Munc 18 could be much more complex than mere inhibition of syntaxin by retaining it in the closed conformation. 
a
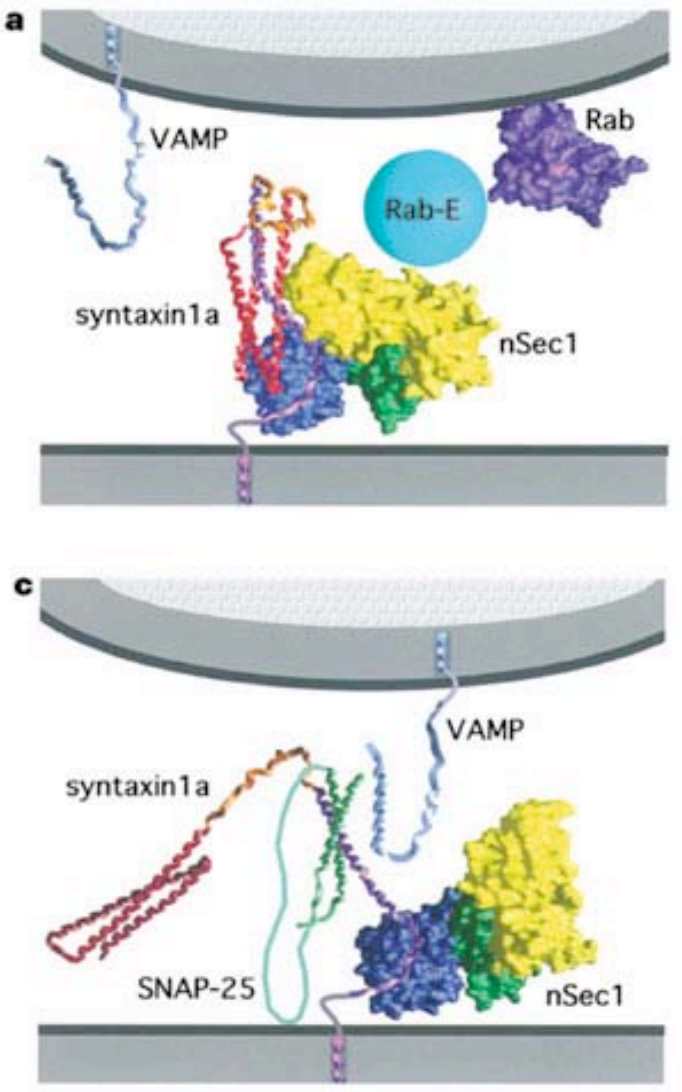

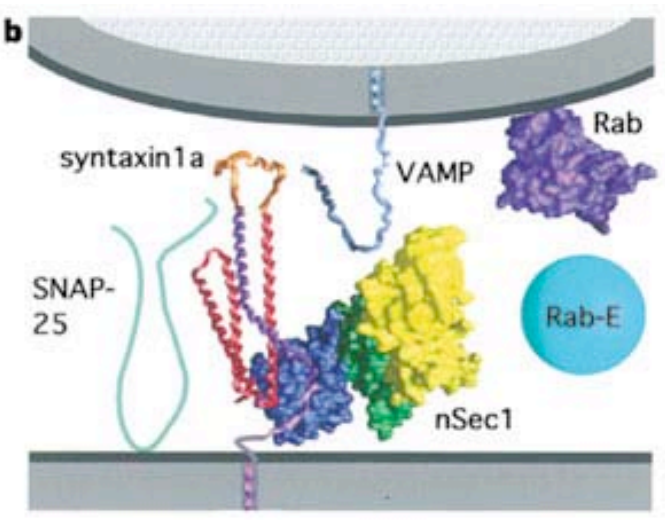

d

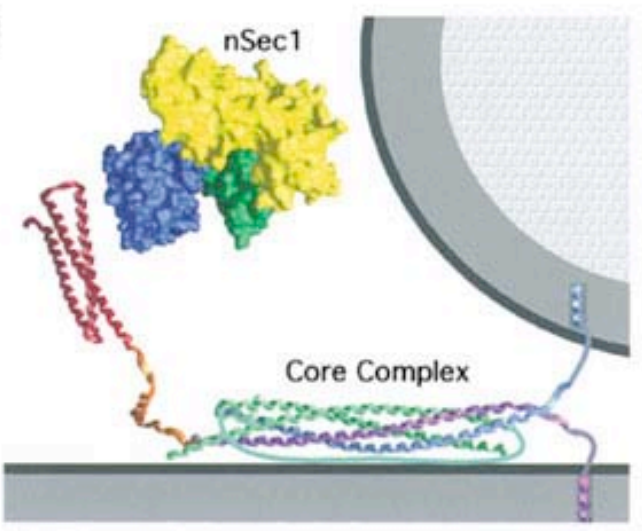

Misura et al 2000 Nature

\section{Figure 8}

Molecular model for the role of nSec/Munc18-1 in membrane fusion (Misura et al., 2000). a) nSec/Munc18-1 forms a stable complex with the 'closed' syntaxin 1a. b) The interaction between nSec/Munc18-1 and syntaxin 1a is weakened possibly by a Rab effector (RabE). c) nSec/Munc18-1 dissociates from syntaxin 1a thus syntaxin 1a switches into the 'open' conformation and the assembly of the 'loose' SNARE complex begins. d) After 'zippering up' the tight SNARE complex (core complex) forms and forces the vesicle against the plasmamembrane.

It must be noted that several other binding partners for Munc18 were found such as Doc2 or Mint but interaction with Munc13, which is a 'vesicle priming factor' in different systems (Augustin et al., 1999; Ashery et al., 2000), was not yet reported (Toonen and Verhage, 2003). Apart from Munc13, the role of the above listed presynaptic proteins in exocytosis is still elusive or was not found to be essential for neurosecretion (Duncan et al., 1999; Ho et al., 2003).

\section{Current molecular model for exocytosis based on protein structure}

In 2000 the three-dimensional structure of the Munc18-syntaxin 1a complex was published and it was found that Munc18 'wraps around' syntaxin in the complex (Misura et al., 2000) as seen in Figure 5B2. In the same study a refined model was proposed, 
where conformational changes in both proteins contribute to exocytosis (Figure 8). In this model at the first stage of exocytosis (Figure 8a) the SNARE proteins do not interact with each other. The t-SNARE syntaxin 1a however, being in the closed conformation, forms a very stable complex with Munc18 (referred as $\mathrm{nSec} 1$ in the figure). This tight complex is somehow loosened by other molecules e.g. Rab or Rab effectors (Rab-E on the figure) putatively (Figure $8 \mathrm{~b}$ ). This loosening of the complex could result in a conformational switch in syntaxin 1a so that the N-terminal Habc domain opens up from the so-called SNARE motif of syntaxin (Figure 8c). This opening up could lead to first a loose SNARE complex between t-SNAREs syntaxin 1a and SNAP-25 and v-SNARE VAMP/synaptobrevin. With gradual 'zippering up' of the SNARE $\alpha$-helices finally a tight SNARE complex (core complex) would form that could pull the vesicle and plasma membrane near together preparing the vesicle to the final fusion event (Figure 8d).

\section{SM proteins positively or negatively regulate secretion in different model organisms}

Structural and biochemical studies provide suggestive hints about the function of SM proteins in vesicle trafficking and exocytosis but they have major limitations in foretelling the mode and place of action in the synaptic/secretory vesicle cascade in living cells. Genetically modified organisms can give physiologically more relevant informations about protein function in vivo. In yeast, fly, worm and mouse the null mutations of Munc18 homolog genes had a profound negative effect on secretory processes (Brenner, 1974; Novick and Schekman, 1979; Harrison et al., 1994; Verhage et al., 2000). The general consistency between model systems, however, ends here.

Overexpression of Munc18 homolog ROP in Drosophila reduced neurotransmitter release supporting the 'negative regulator' role for Munc18 (Schulze et al., 1994) although the ROP null mutation caused severe disorders in general secretory processes (Harrison et al., 1994). In the giant axon of squid Munc18 inhibited $\mathrm{Ca}^{2+}$ evoked vesicle exocytosis (Dresbach et al., 1998). In mammalian epithelial cells Munc182 overexpression inhibited apical transport (Riento et al., 2000). In intact bovine chromaffin cells, however, Munc18-1 overexpression increased flash induced secretory responses (Voets et al., 2001b).

In contrast again, using permeabilized bovine chromaffin cells, overexpression of Munc18-1 had no effect on the frequency or the kinetics of large dense-core vesicle fusion events measured by single spike amperometry (Fisher et al., 2001). The discrepancies between different model organisms and experimental approaches induced a vivid debate about the role of Munc18, roughly speaking: is Munc18 a positive or negative regulator of exocytosis during transmitter release? 


\section{Physiology of Munc18-syntaxin interaction}

One key to understand the function of Munc18 could be the physiological role of its interaction with syntaxin. In the fruitfly it was found that separate overexpression Munc18 homolog (ROP) and syntaxin inhibits neurotransmitter release but when the two proteins are overexpressed in the same fly, no inhibition was observed (Wu et al., 1998). When mutant mammalian neurosecretory cells were transfected with syntaxin 1a, the protein was not delivered to the cell surface. When, however, syntaxin was coexpressed with Munc18, the latter could prohibit the defect in syntaxin delivery (Rowe et al., 1999). It seems that the delivery of syntaxin and the proper function of these two proteins at the presynapse or vesicle release site require the simultaneous presence in the optimal relative amount of Munc18 and syntaxin.

Syntaxin is an extensively studied regulator of voltage gated $\mathrm{Ca}^{2+}$ channels (Catterall, 1999; Zamponi, 2003). Syntaxin 1a promoted voltage-dependent inactivation of N-type $\mathrm{Ca}^{2+}$ channels but coexpression of Munc18 eliminated this promoting effect of syntaxin (Gladycheva et al., 2004). Furthermore, expressing Munc13-1 in addition completely disrupted the eliminating effect of Munc18 (Gladycheva et al., 2004). Another ion channel, the cyclic AMP-gated chloride channel (CFTR) is also inhibited by syntaxin 1a, and Munc18 coexpression was also found to suppress this inhibition (Naren et al., 1997). When Munc18 was mutated at two amino acid residues (D34N/M38V) it failed to bind to syntaxin detectably in vitro and concomitantly it also failed to suppress the syntaxin induced CFTR inhibition (Naren et al., 1997). Strikingly, expression of the constitutively open form of syntaxin (Dulubova et al., 1999) could rescue the severe unc13 null mutant phenotype in worms (Richmond et al., 2001). These studies demonstrate directly or indirectly that Munc18 (and Munc-13/unc-13 also) interact with syntaxin in vivo and the disruption of this interaction can result in a strong physiological effect.

\section{Mouse without Munc18-1}

Mice are the main and so far only mammalian genetical model organisms. A few years a null mutation was introduced into the Munc18-1 gene in the mouse genom giving rise to the Munc18 knockout mouse line (Verhage et al., 2000). The Munc18-1 null (Munc18-1 -/-) mice do not express the Munc18-1 protein therefore they offered an exquisit possibility to study (the lack of) Munc18-1 function in vivo. The null mutant mice are born dead because and they are smaller than their wildtype (Munc18+/+) or heterozygous (Munc18-1 +/-) littermates. The null mutant embryos are completely paralyzed they do not react even to noxious stimuli. Synapses in the brain and in the neuromuscular junction are completely silent and it is due to a defect selectively in the presynaptic but not the postsynaptic function (Verhage et al., 2000). Indeed it is the only null mutation up to now that completely wipes out neurotransmitter release: genetical ablation of neither SNAP-25 nor synaptobrevin/VAMP (a t- and a v-SNARE) caused a $100 \%$ reduction in neurotransmitter release (Schoch et al., 2001; Washbourne et al., 2002). 


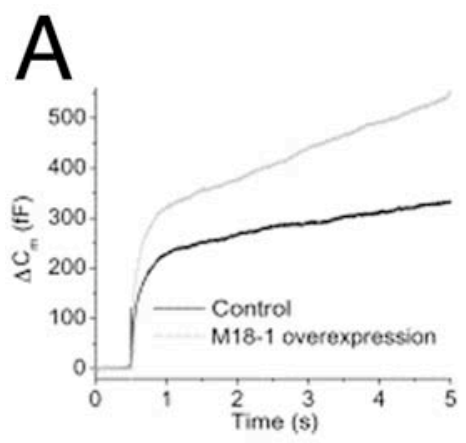

C
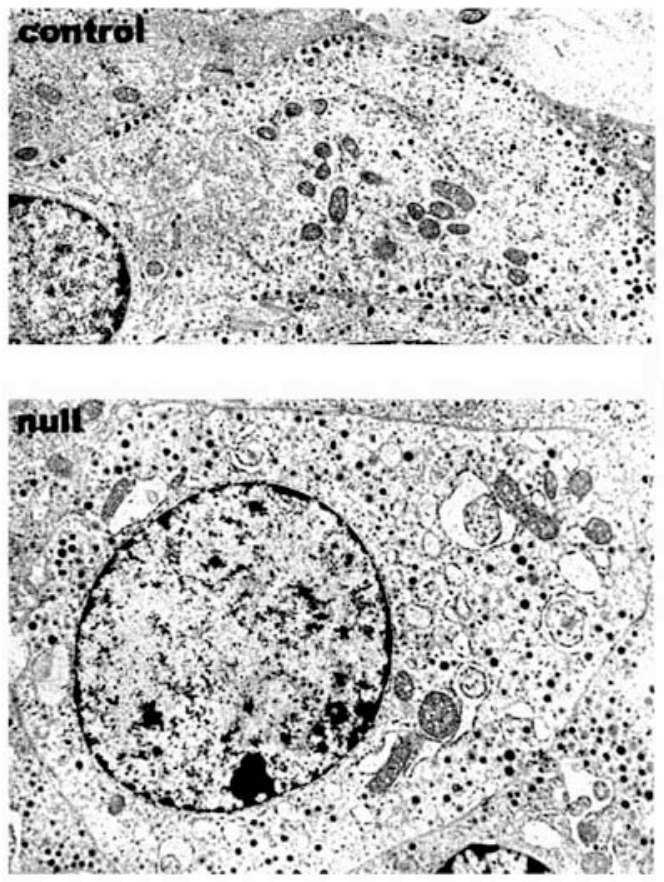

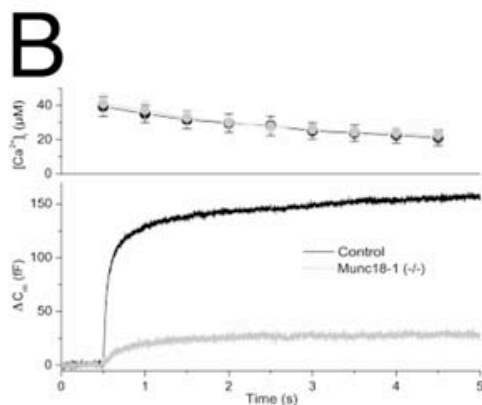

D

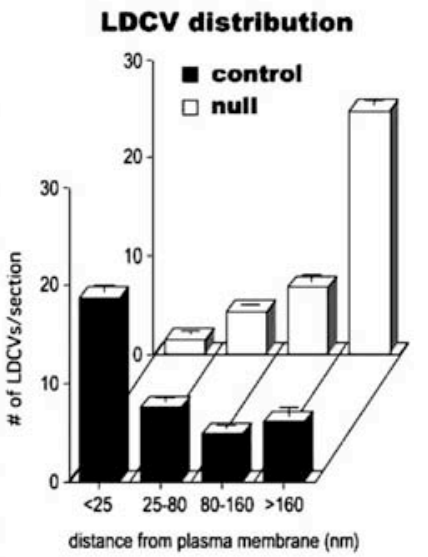

total number of LDCVs

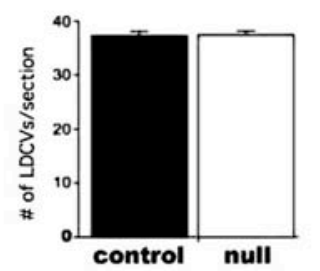

Voets et al 2001 Neuron

\section{Figure 9}

Positive role of Munc18-1 in large dense-core vesicle secretion and docking in chromaffin cells. Adapted from Neuron, Vol. 31, 581-591. A) Overexpression of Munc18-1 increases flash responses in bovine chromaffin cells. B) Secretion is severely reduced in Munc18-1 deficient mouse chromaffin cells. C-D) Electronmicroscopy and subsequent morphometry in Munc18-1 null mutant mouse chromaffin cells reports defect in the docking but not in the synthesis of large dense-core vesicles.

Despite the severe phenotype of the Munc18-1 null mutation, the brain assembly is normal until the $12^{\text {th }}$ embryonic day (E12) and only later in the ontogenesis does massive cell death appear (Verhage et al., 2000). Ultrastructural analysis using electronmicroscopy revealed that docking of synaptic vesicles is essentially normal implying that Munc18-1 is absolutely necessary for synaptic vesicle priming or fusion but not for morphological docking. 
In adrenal chromaffin cells, however, somewhat different secretory phenotype was observed than in the presynapse (Voets et al., 2001b). First, even though the loss of large dense-core vesicle (LDCV) fusion was severe still it was not complete as seen in Figure9B (Voets et al., 2001b). Second, the spatial distribution of LDCVs revealed by electronmicroscopy was strikingly different in null mutant cells compared to wildtype control cells (Figure 9C). A Figure 9D shows that much less 'morphologically' docked vesicles were present in null mutant cells even though the total number of vesicles in the whole area of the cytoplasm was unchanged (Voets et al., 2001b). From this phenotype it was concluded that Munc18-1 is a promoter, a positive regulator of large dense-core vesicle docking in adrenal chromaffin cells.

\section{Docking? Priming? Fusion?}

The published study characterizing large dense-core vesicle docking and catecholamine release in Munc18-null mutant chromaffin cells supporting the view that Munc18-1 acts at the docking step. However a molecule, especially if it is essential, can participate in multiple step of the secretory cascade. For example in chromaffin cells, the t-SNARE SNAP-25 was shown to control priming and depriming (Sorensen et al., 2003b) but it was found to be directly linked to the $\mathrm{Ca}^{2+}$-triggering process as well (Sorensen et al., 2002).

Voets and colleagues did not exclude the possibility that Munc18-1 is also a priming factor, acting downstream of docking (Voets et al., 2001b) as it can be speculated from the ultrastructurally the normal presynapses in null mutant neurons (Verhage et al., 2000). In Munc18-1 deficient chromaffin cells final fusion events were measured carbon fiber amperometry and no alteration of amperometric spike parameters were detected (Voets et al., 2001b). This finding did not support the idea that Munc18-1 is directly involved in the execution or regulation of the final fusion event between the vesicle and the plasma membrane.

Other investigators, exactly in the same year (2001), used also carbon fiber amperometry in permeabilized bovine (wildtype) chromaffin cells (Fisher et al., 2001). They came up with a different idea: overexpression of a mutant form of Munc18-1 (but not the wildtype protein) speeded up amperometric spike kinetics (Fisher et al., 2001). They concluded that Munc18-1 regulates the fusion pore dynamics and the so-called 'kiss-and-run' mode of exocytosis (Fisher et al., 2001). The same group later showed that Munc18-1 regulates fusion pore dynamics interacting with syntaxin (Graham et al., 2004) and phosphorylation of Munc18-1 by protein kinase $\mathrm{C}$ also regulates the kinetics of the final fusion step (Barclay et al., 2003; Graham et al., 2004).

Thus, Munc18-1 appears to be a versatile regulator of catecholamine secretion in chromaffin cells possibly affecting multiple steps of exocytosis. 


\section{The motivations that initiated our present study}

Munc18-1 deficient neurons are difficult to study because they show intrinsic degeneration in culture even with various trophic support in the culture medium (Heeroma et al., 2004). Chromaffin cells proved to be a useful system to investigate the function of Munc18-1 in neurosecretion because there was a clear, very consistent phenotype both in morphological docking and in secretion. In other words, two independent assays (electronmicroscopy and electrophysiology) reached similar conclusions (Voets et al., 2001b).

The development of the chromaffin cell rescue system (Figure 7A) makes it possible to ascertain that the loss of function is mainly due to the lack of the studied protein and not to secondary effects, e.g. degeneration of other structures. The latter possibility - secondary effects - is especially likely in the Munc18-1 null mice because their adrenal glands contain $70 \%$ less syntaxin 1 than wildtype cells do (Voets et al., 2001b). The rescue experiment - if successful - could lead further. Different mutations could be tested in Munc18-1 in a genetically 'clean' system, where the endogenous wildtype Munc18-1 would not 'contaminate' the mutant protein.

The main questions that remained unanswered after the characterization of Munc18-1 null chromaffin cells (Voets et al., 2001b):

1. is the severe functional defect in Munc18-1 null cells due to the specific absence of Munc18-1 or to secondary effects?

2. what are the downstream molecular targets through which Munc18-1 promotes LDCV docking?

3. what are the physiologically relevant upstream regulators of Munc18-1?

4. what molecular factors can functionally substitute Munc18-1?

In the rest of the thesis I will focus on our ongoing project that was designed to answer these questions using mouse adrenal chromaffin cells from the Munc18-1 line. First I will review our experimental approaches together with the results drawing a main conclusion from each result. 



\section{Experimental results}




\section{The contributors of the project}

We studied the role of Munc18-1 in the secretory vesicle cascade in adrenal chromaffin cells. Multiple experimental approaches were used. Electronmicroscopic analysis of large dense-core vesicle docking was carried out by Heidi deWit in Matthijs Verhage's laboratory in Amsterdam. In the same laboratory Ruud F. Toonen used biochemical and molecular biological methods to generate and test Munc18-1 mutations in vitro. In Erwin Neher's department in Göttingen two other approaches were utilized. I assayed large dense core vesicle exocytosis and catecholamine release with the flash experiment (Figure 3) in Jakob Sørensen's chromaffin cell electrophysiology group. The other approach in Dr. Neher's department was the so-called total internal reflection fluorescence microscopy (TIRF), which gives intimate informations about the movement of large dense-core vesicles in living cells. TIRF microscopy was done and analyzed by Olexiy Kochubey in Jürgen Klingauf’s imaging group.

Further on I will show and discuss my results from flash experiments in a detailed fashion. I will also show or refer to some of Dr. deWit's and Dr. Toonens results but only to those that are indispensable to understand my experiments.

\section{Successful rescue of Munc18-1 null chromaffin cells}

Previous experiments using Munc18-1 null mice imply a positive role of Munc18-1 in neurosecretion in different preparations (Verhage et al., 2000; Voets et al., 2001b). Large dense-core vesicle (LDCV) docking and catecholamine secretion was severely defective in Munc18-1 deficient mouse chromaffin cells, suggesting that Munc18-1 promotes LDCV docking (Verhage et al., 2000; Voets et al., 2001b). If the defect in docking and secretory function is specifically due to the absence of Munc18-1 in null mutant cells, reintroduction of Munc18-1 should restore the normal phenotype. We used the rescue approach (see Figure7A) to test this hypothesis.

Flash experiments, as explained in Figure 3, were carried out using Munc18-1 null chromaffin cells (Figure 10). Intracellular $\left[\mathrm{Ca}^{2+}\right]$ was set to similar levels in all experimental groups (see top graph in Figure 10A). As previously described (Voets et al., 2001b), both the burst and the sustained component of the responses were strongly reduced in null mutant cells (null) compared to cells from heterozygote littermates (control; Figure 10A). The amplitude of the burst component was $15 \pm 4 \mathrm{fF}$ in null mutant cells $(n=21)$ and $143 \pm 13 \mathrm{fF}$ in control cells $(n=36 ; P<0.001)$. The sustained component was $11 \pm 4 \mathrm{fF}$ (null; $\mathrm{n}=21$ ) and $176 \pm 13 \mathrm{fF}$ (control; $\mathrm{n}=36 ; \mathrm{P}<0.001$; Figure 10C). However, when Munc18-1 was overexpressed in null mutant cells (null + Munc18-1; Figure 10A), flash responses were essentially normal. The amplitude of the burst and sustained component was statistically indistinguishable from control (burst: 140 $12 \mathrm{fF}$; sustained: $147 \pm 14 \mathrm{fF}$ in overexpressing cells, $\mathrm{n}=36$; Figure $10 \mathrm{C}$ ). This finding suggests that reintroduction of Munc18-1 in null mutant chromaffin cells is sufficient to restore secretion. 

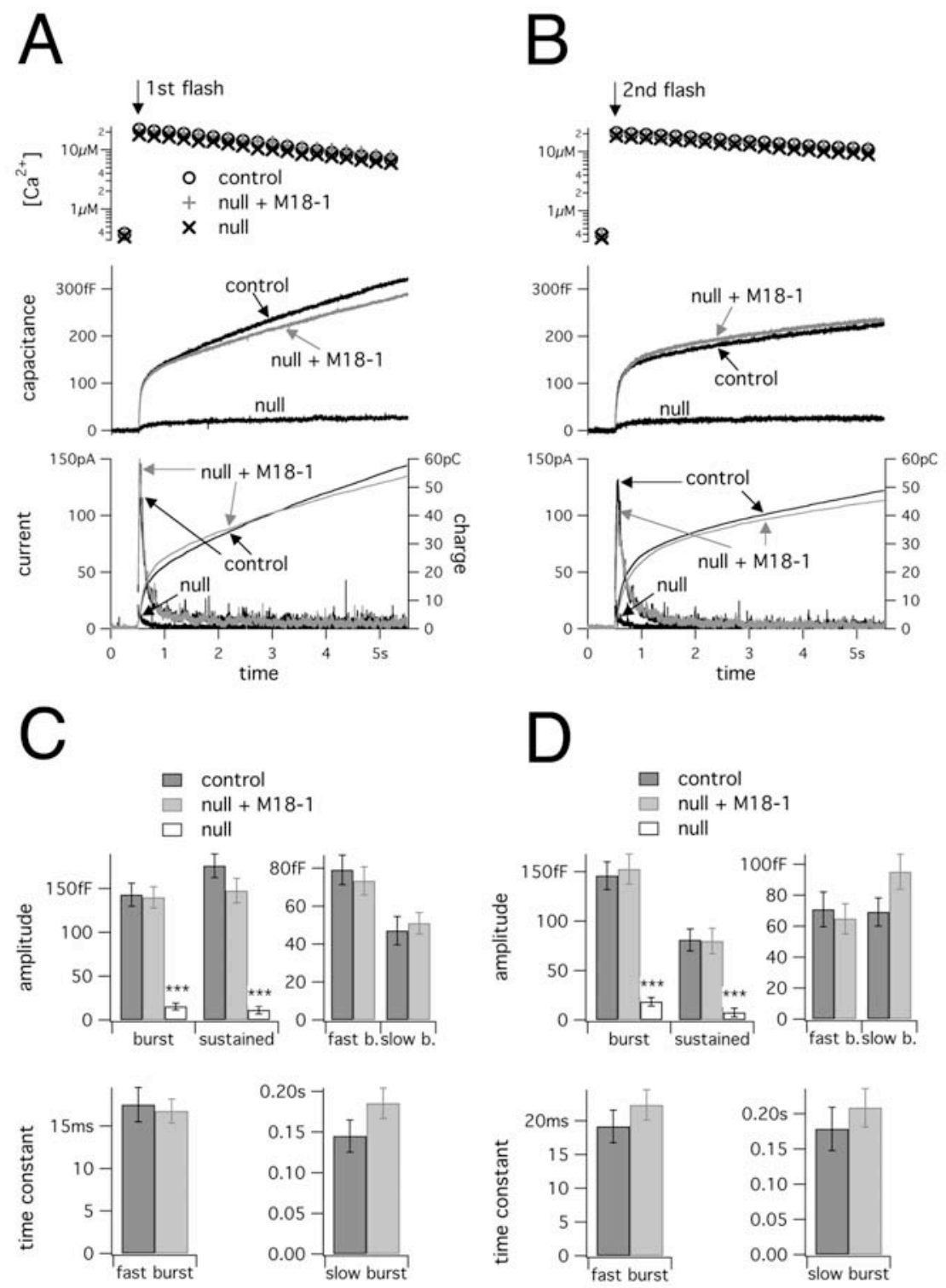

\section{Figure 10}

Reintroduction of Munc18-1 into Munc18-1 null mutant chromaffin cells restores secretion. A) Averaged responses to the first flash stimulation from Munc18-1 heterozygote cells (control; $n>35$ ), Munc18-1 null mutant cells (null $n>20$ ) and Munc18-1 null mutant cells overexpressing Munc18-1 (null + M18-1; $n>35$ ). Graphs show intracellular $\left[\mathrm{Ca}^{2+}\right]$ measurements (top), membrane capacitance recordings (middle) and amperometric responses (bottom). B) Averaged responses to the second flash stimulation. C-D) Amplitudes and time constants of different kinetic components of first and second flash capacitance responses, respectively. Bar diagrams show mean \pm S.E.M. ${ }^{\star \star \star}$ P $<0.001 ;$ Mann-Whitney test.

Then we submitted the flash responses from Munc18-1 overexpressing cells to a closer inspection. We analyzed the distinct kinetic components of the responses, the fast and the slow burst, which represent the complete depletion of the readily and slowly releasable pool (RRP, SRP), respectively (Voets, 2000) see also Figure 4. It should be noted that reliable kinetic investigation in Munc18-1 null cells was not possible up till 

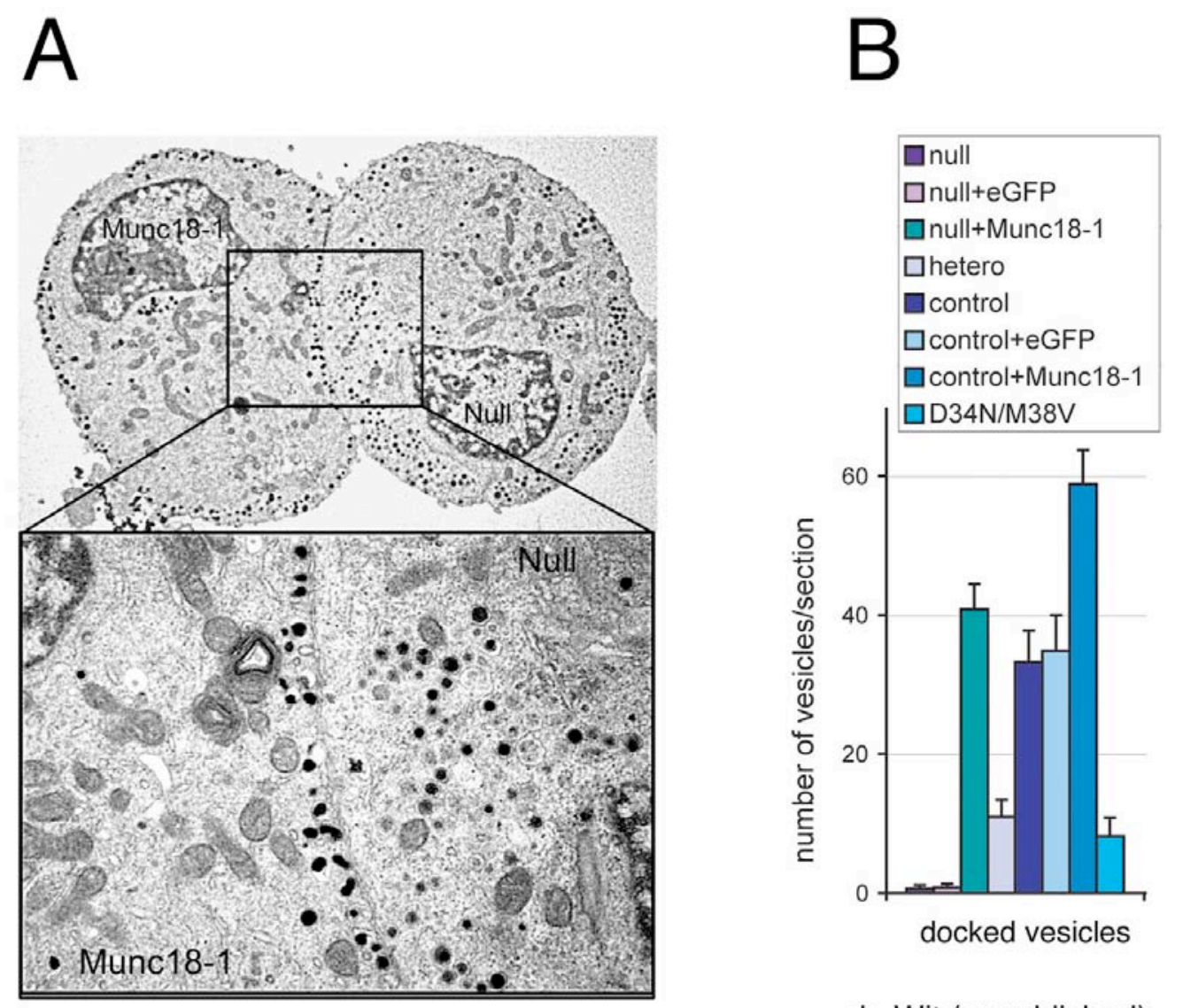

$$
\text { de Wit (unpublished) }
$$

\title{
Figure 11
}

\begin{abstract}
Large dense-core vesicles dock normally when Munc18-1 is overexpressed Munc18-1 null mutant chromaffin cells. A) Electronmicrograph shows a uninfected (Null) and a Munc18-1 overexpressing (Munc18-1) chromaffin cell from the same Munc18-1 null mutant mouse embryo after fixation and ultrathin sectioning. Zooming in reveals normally aligned large dense-core vesicles at the plasma membrane in the overexpressing cell but not in its uninfected neighbour. B) Number of docked large dense-core vesicles in different Munc18-1 embryonic mouse chromaffin cells. Vesicles within $25 \mathrm{~nm}$ distance from the plasmamembrane were defined as docked. Null: Munc18-1 null mutant cells, null+eGFP: eGFP overexpressing null mutant cells; null+Munc18-1: Munc18-1 overexpressing null mutant cells; hetero: Munc18-1 heterozygous cells; control: Munc18-1 wildtype cells; control+eGFP: wildtype cells overexpressing eGFP; control+Munc18-1: wildtype cells overexpressing Munc18-1; D34N/M38V: Munc18-1 null mutant cells that overexpressing Munc18-1 that carries the D34N/M38V mutation. Data kindly provided by Heidi de Wit.
\end{abstract}

now, because in the absence of Munc18-1 the dramatically decreased responses have too low signal to noise ratio. Using Munc18-1 overexpressing cells now we found that the fast and slow burst amplitudes (RRP and SRP sizes) were indistinguishable from control (Figure 10C; fast burst: $79 \pm 8 \mathrm{fF}$ in control and $73 \pm 4 \mathrm{fF}$ in null + Munc18-1; slow burst: $47 \pm 7 \mathrm{fF}$ in control and $51 \pm 6 \mathrm{fF}$ in null + Munc18-1), suggesting that releasable pool sizes were rescued by Munc18-1 reintroduction.

The time constants of the fast and slow burst $\left(\tau_{\text {fast }}, \tau_{\text {slow }}\right)$ report fusion rates from the rapidly and slowly releasable pools (Voets, 2000) as depicted in Figure 4. The fast 
and slow time constant was normal in Munc18-1 overexpressing cells (Figure 10C; $\tau_{\text {fast }}$ : $17.5 \pm 2.0 \mathrm{~ms}$ in control and16.8 $\pm 1.4 \mathrm{~ms}$ in null + Munc18-1; $\tau_{\text {slow }}: 145 \pm 20 \mathrm{~ms}$ in control and $186 \pm 19 \mathrm{~ms}$ in null + Munc18-1; not significantly different at $\mathrm{P}<0.05$ ). Thus, fusion of vesicles occurred with a normal rate in Munc18-1 overexpressing null mutant cells.

Responses to subsequent flash stimulations can report changes in the recruitment of the releasable vesicles (Nagy et al., 2002), therefore second flash responses were recorded $\sim 100 \mathrm{~s}$ after the first flashes (Figure 10B). The kinetic components showed similar tendency as seen in the first flash responses (compare Figure 10C and D), suggesting that refilling of the releasable pools between two stimulations is essentially normal in Munc18-1 null cells overexpressing Munc18-1.

The spontaneous secretion in resting conditions (low intracellular $\left[\mathrm{Ca}^{2+}\right]$ ) increases the cell surface by fusing vesicles into the plasma membrane assuming that the fused vesicle membranes are not immediately retrieved into the cytoplasm. Therefore reduced basal membrane capacitance (initial cell size) could report decreases in spontaneous secretion. Consistently with this, the initial size of Munc18-1 null cells was significantly less than control (null: $3.62 \pm 0.11 \mathrm{pF}, \mathrm{n}=21$; control: $4.45 \pm 0.17 \mathrm{pF}, \mathrm{n}=36$; $\mathrm{P}=0.0012$ ). Munc18-1 overexpressing null mutant cells however, were even slightly larger than control cells (null + Munc18-1: 4.68 $\pm 0.16 \mathrm{pF}, \mathrm{n}=36 ; \mathrm{P}=0.28$ vs. control), suggesting normal or mildly increased spontaneous secretion.

Taken above described results together, we confirmed the dramatic loss of catecholamine secretion in Munc18-1 deficient chromaffin cells. Second, we showed that reintroduction of Munc18-1 to these cells restores secretion to control level without apparent defects in vesicle pool sizes, fusion rates and refilling kinetics.

It was shown that Munc18-1 null mouse chromaffin cells have $\sim 10$ times less large dense-core vesicles in the close proximity of the plasma membrane than wildtype cells, due to a differential distribution of similar number of LDCVs in the two cell types (Voets et al., 2001b). Parallel to our present electrophysiological experiments, Heidi de Wit studied LDCV distribution using electronmicroscopy. She found that reintroduction of Munc18-1 to null mutant cells restored the number of morphologically docked LDCVs (Figure $11 \mathrm{~A}-\mathrm{B}$ ).

Thus, electrophysiological and ultrastructural data are in agreement with each other, suggesting that the loss of LDCV docking and secretion in Munc18-1 null mouse chromaffin cells is specifically due to the absence of Munc18-1, therefore Munc18-1 has a positive role in exocytosis during catecholamine secretion. 


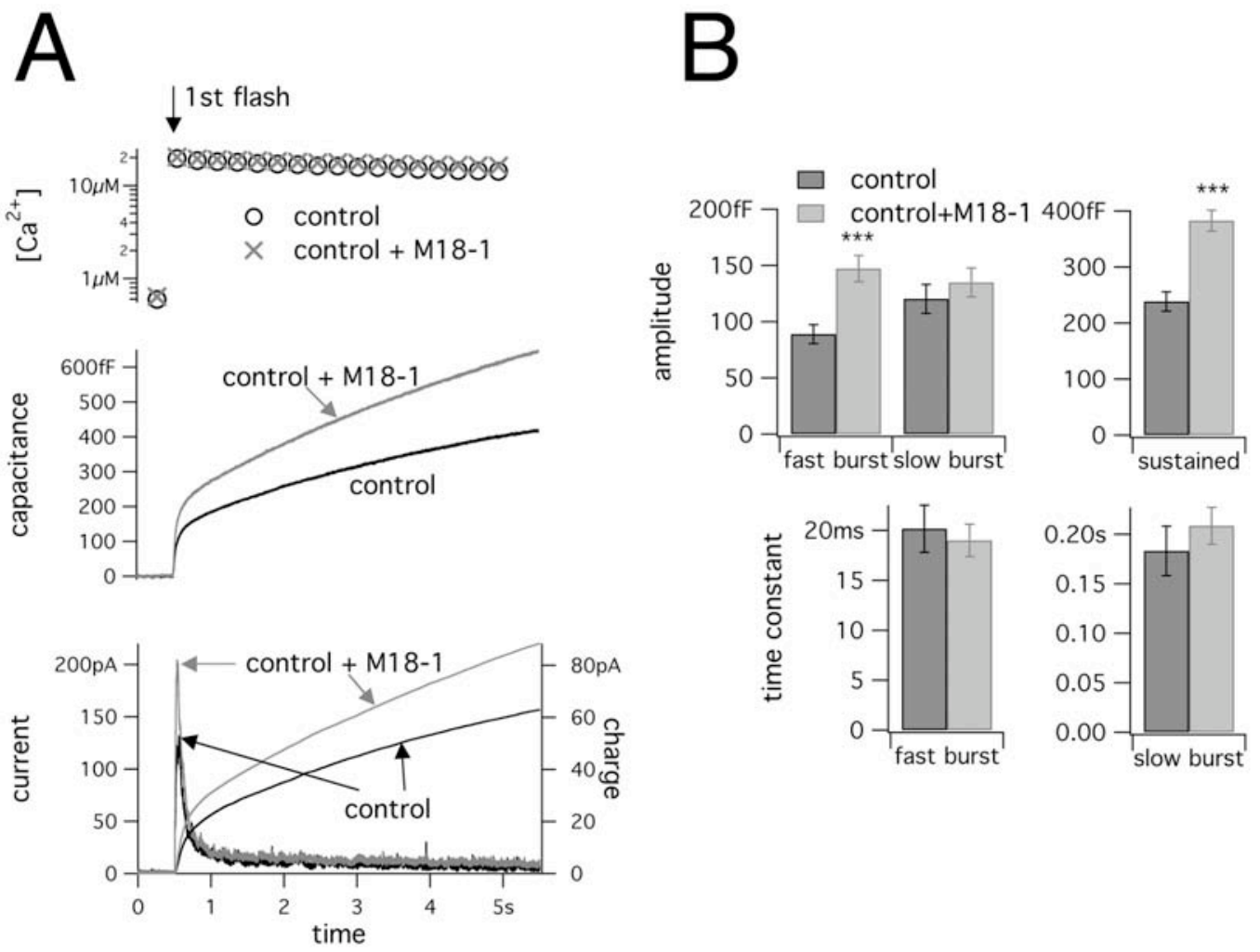

\section{Figure 12}

Munc18-1 overexpression increases secretion in wildtype mouse chromaffin cells. A) Averaged flash responses from uninfected wildtype chromaffin cells (control; $n>45$ ) and from wildtype cells overexpressing Munc18-1 (control + M18-1; $\mathrm{n}>45$ ). B) Amplitudes and time constants of different kinetic components of the capacitance responses. ${ }^{\star \star * P}<0.001$ (MannWhitney test)

\section{Confirmation of the positive role of Munc18-1 and the question of dose dependency}

The view that Munc18-1 is a positive regulator (promoter) of neurosecretion prompts the question whether Munc18-1 acts in a dose dependent manner in vivo. Previously it was shown that more than tenfold overexpression of Munc18-1 increases secretion in bovine chromaffin cells, which already express Munc18-1 (Voets et al., 2001b). However, similar experiments in Drosophila focusing on the Munc18-1 homolog ROP showed opposing results (Schulze et al., 1994; Wu et al., 1998), indicating organism specific differences in the dose dependent action of Munc18 and its homologs. This conflict motivated us to test whether overexpression of Munc18-1 can facilitate secretion in wildtype newborn mouse chromaffin cells.

Overexpression of Munc18-1 increased flash responses by $\sim 50 \%$ in wildtype newborn mouse chromaffin cells (Figure $12 \mathrm{~A}$ ). Detailed kinetic analysis showed that the fast burst and the sustained component underwent an extremely significant increase 

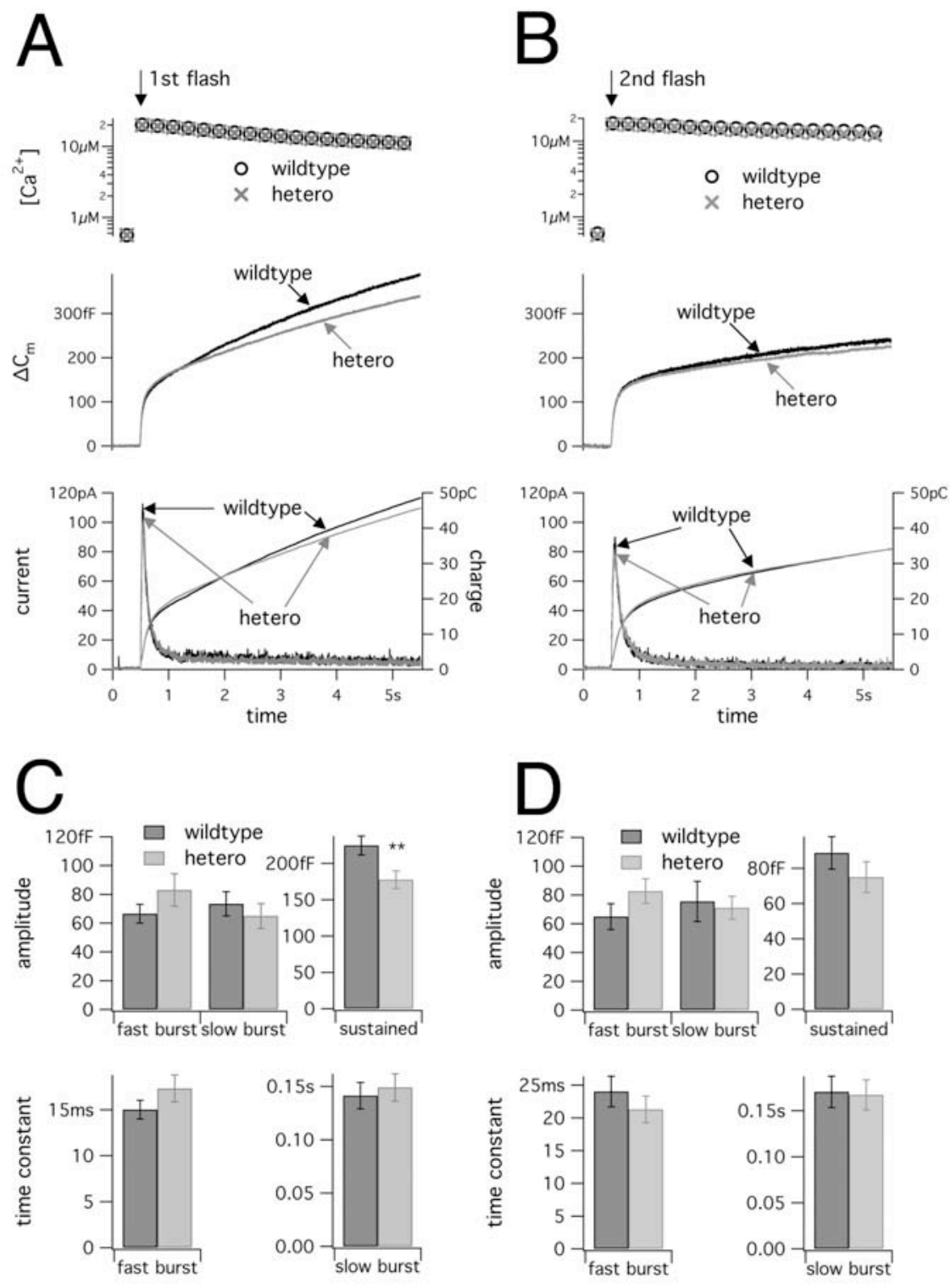

\section{Figure 13}

The sustained phase of secretion is mildly but significantly reduced in Munc18-1 heterozygotes. A-B) Averaged first and second flash responses from wildtype ( $\mathrm{n}>50$ ) and Munc18-1 heterozygote (hetero; $n>50$ ) mouse chromaffin cells. C-D) Kinetic components of first and second flash responses, respecitvely. ${ }^{\star \star P}<0.01 ;$ Mann-Whitney test.

whereas the fusion time constants were unchanged (Table 2). Second flash responses had a similar increase upon Munc18-1 overexpression (data not shown). Consistently with the electrophysiological results, our collaborators found that Munc18-1 overexpressing control cells had $\sim 50 \%$ more docked vesicles than control cells without overexpression (Figure 11B, de Wit, unpublished). We conclude that Munc18-1 overexpression increases the size of at least some of the vesicle pools without detectable effect on the fusion rates in wildtype newborn mouse chromaffin cells. 


\begin{tabular}{|c|c|c|c|c|c|c|c|}
\hline & & \multicolumn{3}{|c|}{$\begin{array}{l}\text { Munc18-1 overexpression in } \\
\text { wildtype newborn mouse cells }\end{array}$} & \multicolumn{3}{|c|}{$\begin{array}{c}\text { Munc18-1 heterozygote compared } \\
\text { to wildtype (embryonic) }\end{array}$} \\
\hline & & control & $\begin{array}{l}\text { control + } \\
\text { Munc18-1 }\end{array}$ & & wildtype & hetero & \\
\hline \multicolumn{2}{|c|}{ number of cells } & $\geq 32$ & $\geq 41$ & & $\geq 45$ & $\geq 48$ & \\
\hline \multirow[t]{3}{*}{ amplitude (fF) } & fast burst & $89 \pm 8$ & $147 \pm 11$ & $P<0.001$ & $67 \pm 7$ & $83 \pm 11$ & \\
\hline & slow burst & $120 \pm 13$ & $135 \pm 13$ & & $73 \pm 8$ & $65 \pm 9$ & \\
\hline & sustained & $239 \pm 17$ & $383 \pm 19$ & $P<0.001$ & $225 \pm 13$ & $178 \pm 12$ & $\mathrm{P}<0.01$ \\
\hline \multirow{2}{*}{$\begin{array}{c}\text { time } \\
\text { constant }(\mathrm{ms})\end{array}$} & fast & $20.2 \pm 2.4$ & $19.0 \pm 1.6$ & & $15.0 \pm 1.0$ & $17.3 \pm 1.5$ & \\
\hline & slow & $183 \pm 25$ & $209 \pm 19$ & & $141 \pm 12$ & $149 \pm 13$ & \\
\hline
\end{tabular}

\section{Table 2}

Kinetic parameters of flash responses upon Munc18-1 overexpression or in Munc18-1 heterozygote cells. Only significance levels $\mathrm{P}<0.05$ are shown (Mann-Whitney test).

It was reported that Munc18-1 expression is reduced by $\sim 50 \%$ in the adrenal glands of mice that are heterozygous to the Munc18-1 null mutation (Voets et al., 2001b). We were interested if the reduced Munc18-1 protein level couples with a decrease in secretion. Flash responses were recorded from Munc18-1 heterozygous embryonic cells (hetero) or cells from wildtype littermates (Figure 13). A small decrease was apparent in the membrane capacitance responses after the first flash stimulation (Figure 13A). This decrease originated from a small but very significant, selective reduction of the sustained component (Table 2, Figure 10C). Fast and slow burst amplitudes and time constants were indistinguishable from wildtype. Significant reduction of the sustained component was not detected after the second flash stimulation (Figure 10D).

Interestingly, more than a 50\% reduction was detected in the number of docked LDCVs in heterozygotes compared to control (wildtype) embryonic chromaffin cells (Figure 11, de Wit, unpublished observation). It can be concluded that strongly decreased large dense-core vesicle docking and slightly decreased secretion accompanies the reduced Munc18-1 protein level in heterozygous embryonic mouse chromaffin cells.

These two types of experiments show positive correlation of Munc18-1 function with increased or decreased Munc18-1 protein levels in mouse chromaffin cells, further supporting the view that Munc18-1 is a positive regulator of upstream steps of neurosecretion in mammalians. 


\section{Is the F-actin cytoskeleton a physiologically important downstream target of Munc18-1?}

What is the molecular mechanism by which Munc18-1 promotes large dense-core vesicle docking and secretion in adrenal chromaffin cells? Chromaffin cells possess an Factin network adjacent to the plasma membrane, the so-called cortical actin ring. It was shown, that agents that disrupt the integrity of the cortical actin ring can redistribute LDCVs to the plasma membrane and increase secretion in bovine chromaffin cells (Vitale et al., 1995; Gil et al., 2000). Second, the cortical actin ring was found to be thicker in Munc18-1 null cells (Matthijs Verhage, personal communication). This prompts the scenario that Munc18-1 drives LDCV docking and secretion by negatively regulating the cortical F-actin network. If this holds true, F-actin severing agents such as latrunculin A are expected to subsitute Munc18-1 at least partially. To test this hypothesis, we asked the question if latrunculin A can restore secretion in Munc18-1 deficient mouse chromaffin cells.

First we preincubated bovine chromaffin cells with 1-2 $\mu \mathrm{M}$ latrunculin A for 1224 hours in the culture medium and after fixation we stained the F-actin filaments with rhodamine labeled phalloidin. Confocal fluorescent microscopy revealed that in these cells latrunculin A disrupted the cortical actin ring that was always present in DMSO treated control cells (Figure 14A). Usually intensive rhodamine-phalloidin accumulation was observed in the center of the cells (Figure 14A right). In separate experiments we found that 10 minute latrunculin A preincubation $(10 \mu \mathrm{M})$ already caused dramatic but not complete disruption in the cortical actin ring (data not shown).

Next we checked if flash responses can report the previously described positive effect of latrunculin A in bovine chromaffin cell secretion (Gil et al., 2000). We treated the cells with the same preincubation protocol as we did before fixation for the phalloidin staining experiments ( $2 \mu \mathrm{M}$ latrunculin A for 12-24 hours, $0.1 \%$ DMSO as control). Both the burst and the sustained component of the flash responses was approximately doubled in latrunculin A treated cells (Figure 14B). The burst amplitude was $193 \pm 29 \mathrm{fF}$ in control cells and $365 \pm 42 \mathrm{fF}$ after latrunculin $A$ treatment $(\mathrm{n}=31$ in both cases; $\mathrm{P}<0.001)$. The amplitude of the sustained component increased from $124 \pm 16 \mathrm{fF}$ (control; $\mathrm{n}=29$ ) to $221 \pm 36 \mathrm{fF}$ (latrunculin $\mathrm{A} ; \mathrm{n}=31 ; \mathrm{P}<0.05$ ). The relative size of the fast and slow burst as well as the fast and slow fusion time constant was normal (not shown). Thus, latrunculin A successfully potentiates secretory flash responses in bovine chromaffin cells. 
A
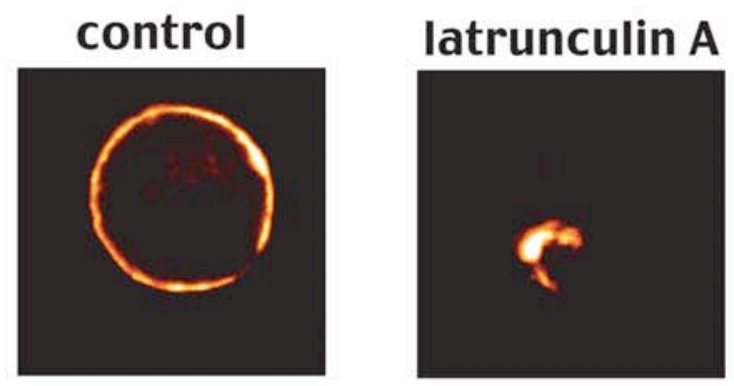

$10 \mu \mathrm{m}$

B
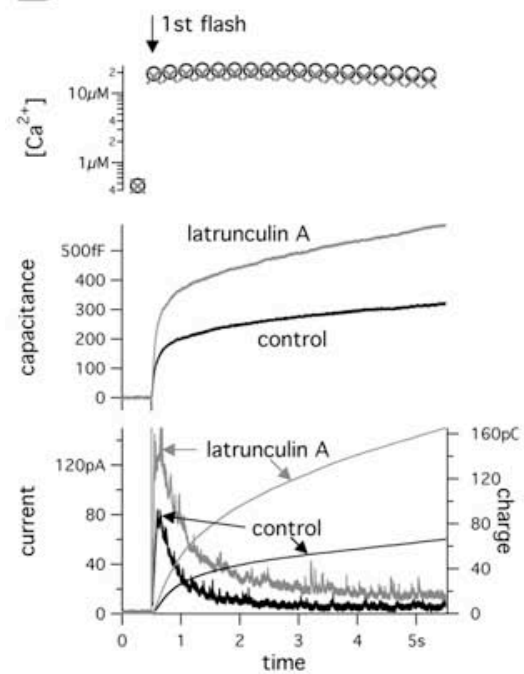

$\square$ control

$\square$ latrunculin A

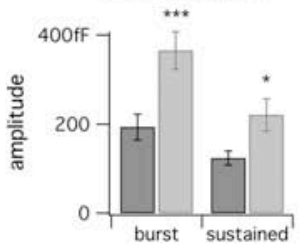

0
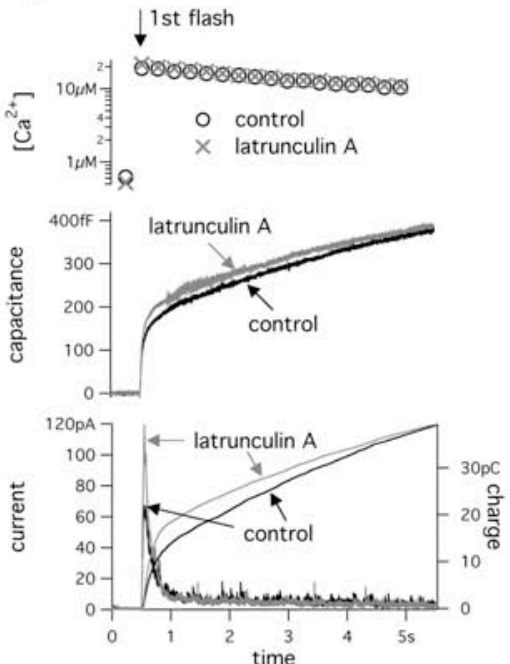

$\square$ control

$\square$ latrunculin A

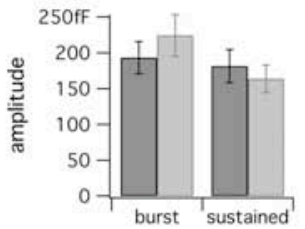

\section{Figure 14}

Latrunculin A dissotiates the cortical F-actin ring and causes a dramatic increase in bovine but not in mouse chromaffin cells. A) Confocal fluorescent image of a DMSO (control) and a latrunculin A treated bovine chromaffin cell after fixation and rhodamine-phalloidin staining. B) Averaged flash responses from bovine chromaffin cells upon latrunculin $A$ preincubation (control: $n>30$; latrunculin $A: n>30$ ). ${ }^{\star} P<0.05$; ${ }^{\star \star *} P<0.001$. C) Averaged flash responses from wildtype embyonic mouse chromaffin cells upon preincubation or acute local application of latrunculin $A$ (control: $n>17$; latrunculin $A: n>19$ )

In the following experiment we investigated the latrunculin A responsiveness of 
wildtype embryonic mouse chromaffin cells. Latrunculin A was included in the culture medium (1-2 $\mu \mathrm{M}$, overnight) or applied locally in the recording bath (50 $\mu \mathrm{M}, 5-8$

minutes). In contrast with bovine cells, embryonic mouse chromaffin cells showed no substantial increase in secretory flash responses upon latrunculin A treatment (Figure 14C). The burst and sustained component was statistically indistinguishable from DMSO treated control cells (Figure 14C). The lack of facilitation in secretion was not due to the lack of latrunculin A effect on the F-actin cytoskeleton because the cortical actin ring disappeared upon latrunculin A treatment (Matthijs Verhage, personal communication). Thus, disruption of the cortical F-actin ring does not coincide with increased secretion in wildtype embryonic mouse chromaffin cells.

\section{A}
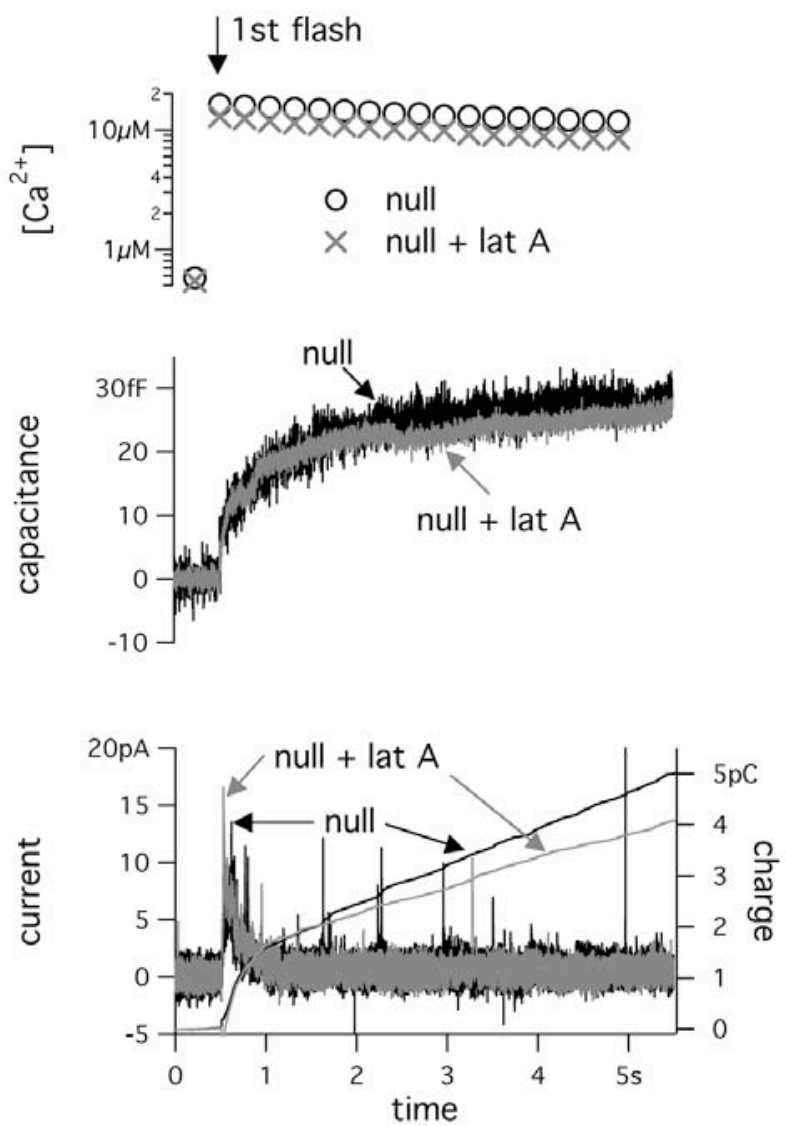
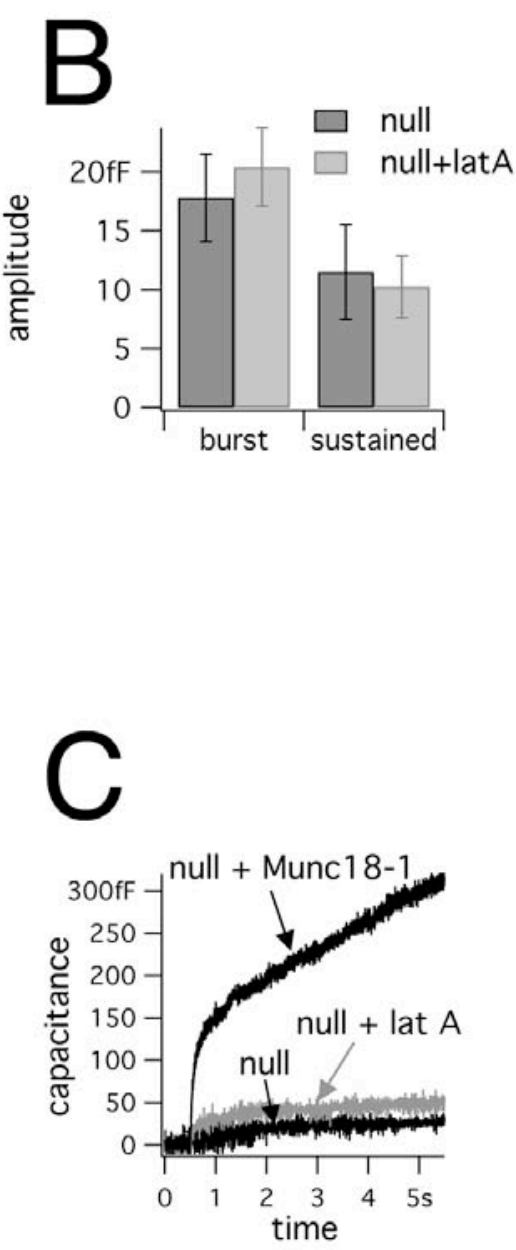

\section{Figure 15}

Latrunculin A fails to restore secretion in Munc18-1 deficient chromaffin cells. A) Averaged flash responses from DMSO (null; $n=30$ ) and latrunculin A (null + lat $A ; n=32$ ) treated Munc18-1 null mutant chromaffin cells. B) Amplitudes of the two main secretory components. C) Averaged flash responses in cells derived from the same Munc18-1 null mutant embryo, either treated with DMSO (null), latrunculin A (null + lat A) or overexpressing Munc18-1 (null + Munc18-1). The intracellular $\left[\mathrm{Ca}^{2+}\right]$ concentrations were indistinguishable in the three groups. 

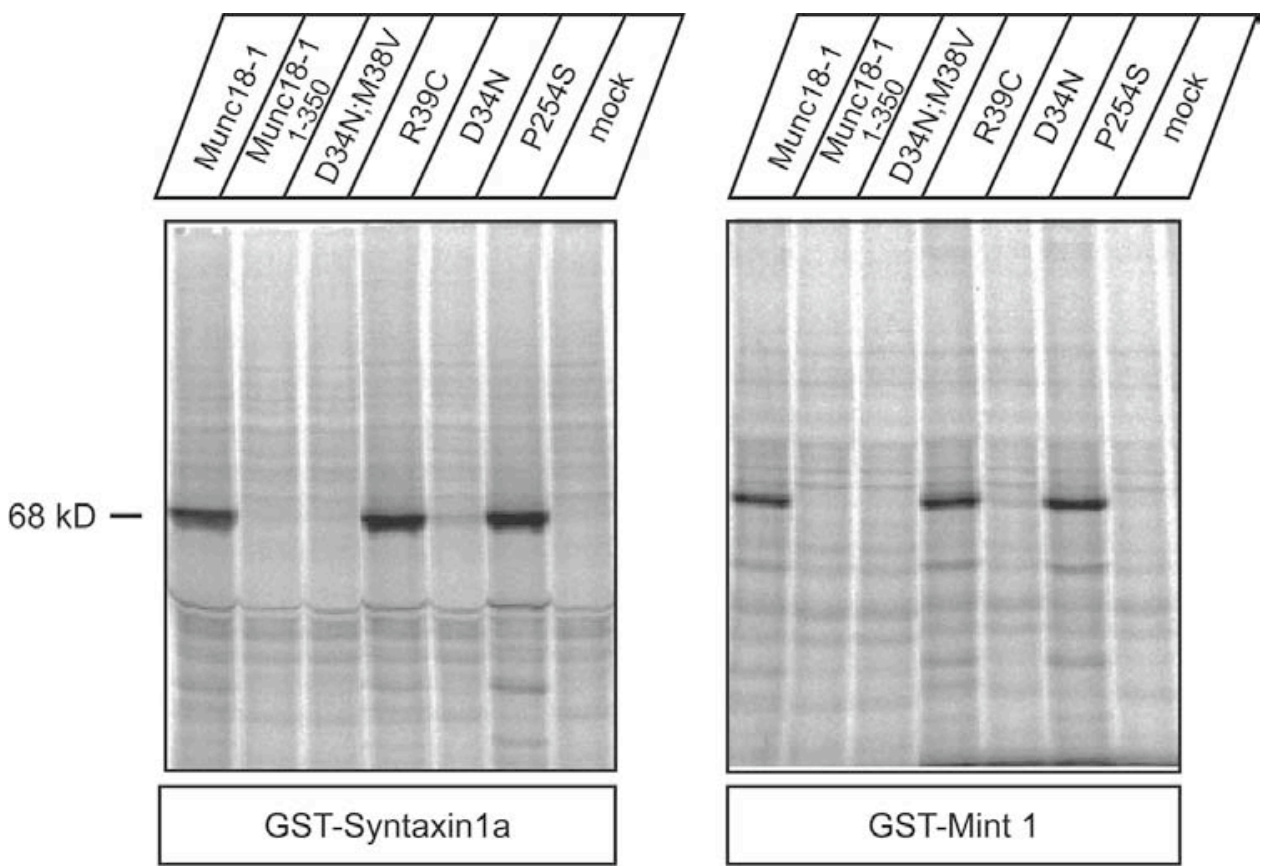

Toonen (unpublished)

\section{Figure 16}

GST pulldown experiment implies that the D34N/M38V but not the R39C mutation in Munc18-1 abolishes Syntaxin1a and Mint1 binding in vitro. Point mutations were introduced to Munc18-1 using PCR. Munc18-1 was expressed and metabolicaly labeled with $35 \mathrm{~S}$ Methionine in HEK293 cells. The cell lysates were then applied to GST-Syntaxin1a or GST-Mint1 fusion proteins bound to Glutathion-agarose beads. After washing, components were separated with SDS-PAGE. As negative control GST alone (mock) or a truncated form of the protein (Munc18-1 1-350) was used. Unlike other mutants, Munc18-1 D34N/M38V was not pulled down at all by either GST fusion proteins. Data kindly provided by Ruud F. Toonen.

Finally we turned to our original question namely, if latrunculin A can rescue secretion in Munc18-1 null cells. Latrunculin A disrupted the cortical F-actin ring and shifted the distribution of large dense-core vesicle towards the plasma membrane (Matthijs Verhage, personal communication). The question remained whether the extra amount of docked LDCVs can undergo exocytosis without Munc18-1. Figure 15A shows flash responses in Munc18-1 null cells treated with DMSO (null) or latrunculin A (null + lat A). Neither preincubation (1-2 $\mu \mathrm{M}$, overnight, $\mathrm{n}>20$ in each group) nor local drug application ( $50 \mu \mathrm{M}, 5-8$ minutes; $\mathrm{n} \geq 5$ in each group) caused apparent change in the responses, therefore all data obtained were pooled and analyzed together. The amplitude of the burst and the sustained component was unaffected by latrunculin A (burst: $18 \pm 4 \mathrm{fF}$ in null and $20 \pm 3 \mathrm{fF}$ in null + lat $\mathrm{A}, \mathrm{P}=0.92$; sustained: $12 \pm 4 \mathrm{fF}$ in null and $10 \pm 3 \mathrm{fF}$ in null + lat A, $\mathrm{P}=0.98$; Figure 14B). 
A
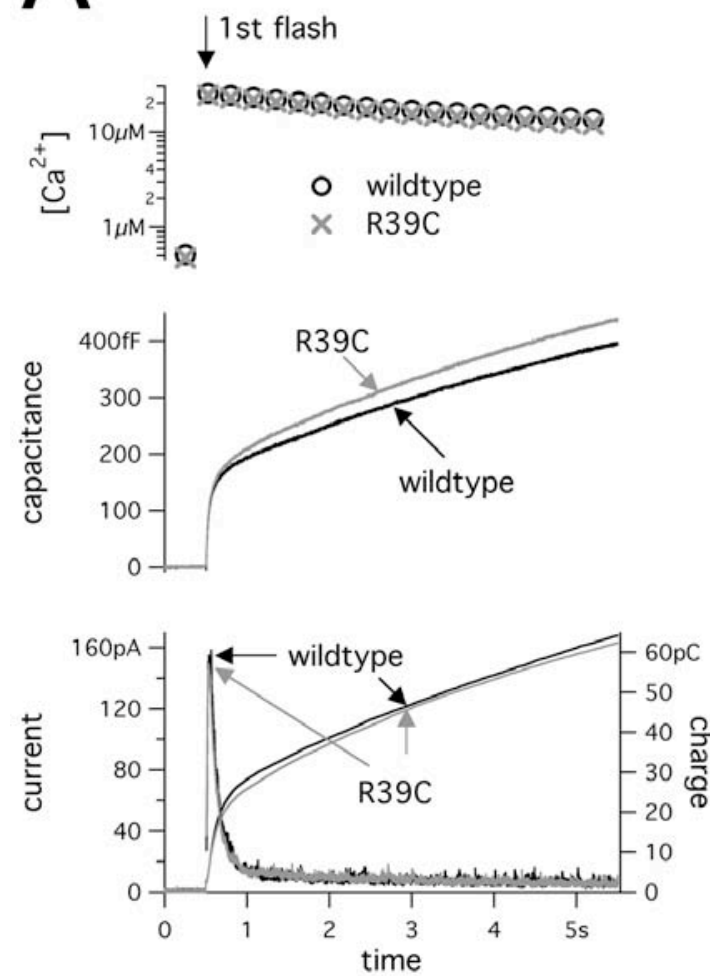

B
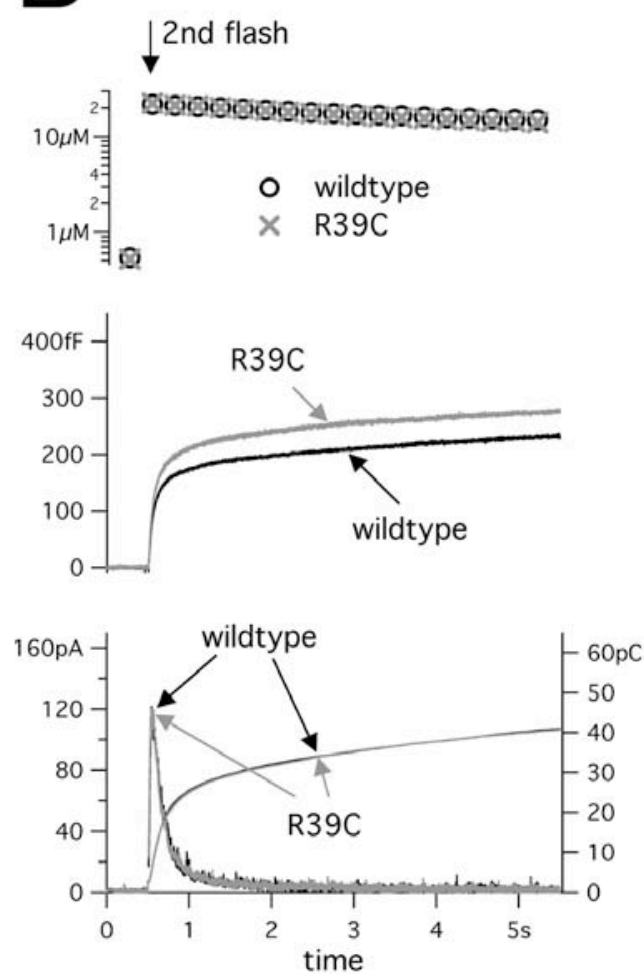

\section{Figure 17}

The R39C mutation in Munc18-1 does not induce a subsantial change in secretory flash responses. A-B) Averaged first and second flash responses from Munc18-1 null mutant chromaffin cells overexpressing either wildtype Munc18-1 (wildtype; $\mathrm{n}>50$ ) or Munc18-1 carrying the R39C mutation (R39C; $n>50$ ). The Mann-Whitney test failed to show difference in the amplitudes or fusion time constants of distinct kinetic components at $\mathrm{P}<0.05$ significance level (see text).

In one experiment, $\sim 5-5$ cells from the same Munc18-1 null embryo either were treated with latrunculin A or overexpressed Munc18-1 (Figure 15C). In this experiment reintroducion of Munc18-1 caused a $\sim 15$-fold increase (see also Figure 10), while latrunculin A could not even double the amplitude of flash responses (Figure 15C).

We conclude that disruption of the cortical F-actin ring in embryonic mouse chromaffin cells cannot substitute Munc18-1 in driving secretion.

\section{The syntaxin-Munc18-1 interaction regulates docking and secretion}

Secretory vesicle fusion is mediated by the SNARE complex. Syntaxin is a SNARE protein, which was found to form a complex also with Munc18 (Hata et al., 1993). By this interaction in vitro, Munc18 is believed to control a conformational switch of syntaxin, which is necessary for the ternary SNARE complex formation (Dulubova et al., 1999). The physiological importance of the syntaxin conformational switch was 


\begin{tabular}{|c|c|c|c|c|c|c|}
\hline \multirow{2}{*}{\multicolumn{2}{|c|}{$\begin{array}{r}\text { mutation } \\
\text { expressed form }\end{array}$}} & \multicolumn{2}{|r|}{ R39C } & \multicolumn{3}{|c|}{ D34N/M38V } \\
\hline & & wildtype & mutant & wildtype & mutant & \\
\hline \multicolumn{2}{|c|}{ number of cells } & $\mathrm{n} \geq 47$ & $\mathrm{n} \geq 51$ & $\mathrm{n} \geq 30$ & $\mathrm{n} \geq 28$ & \\
\hline \multirow[t]{3}{*}{ amplitude (fF) } & fast burst & $86 \pm 10$ & $90 \pm 8$ & $90 \pm 9$ & $41 \pm 6$ & $P<0.001$ \\
\hline & slow burst & $83 \pm 10$ & $81 \pm 10$ & $73 \pm 6$ & $44 \pm 7$ & $P<0.01$ \\
\hline & sustained & $203 \pm 15$ & $228 \pm 16$ & $182 \pm 18$ & $121 \pm 17$ & $P<0.01$ \\
\hline \multirow{2}{*}{$\begin{array}{c}\text { time } \\
\text { constant }(\mathrm{ms})\end{array}$} & fast & $15.9 \pm 1.3$ & $16.3 \pm 1.4$ & $14.0 \pm 1.3$ & $14.4 \pm 1.8$ & \\
\hline & slow & $127 \pm 12$ & $137 \pm 11$ & $169 \pm 23$ & $190 \pm 25$ & \\
\hline
\end{tabular}

\section{Table 3}

Kinetic parameters of flash responses in Munc18-1 null mutant cells overexpressing wildtype or mutant forms of Munc18-1. Only significance levels $\mathrm{P}<\mathbf{0 . 0 5}$ are indicated (Mann-Whitney test).

strikingly demonstrated in C. elegans (Richmond et al., 2001). In Drosophila the relative amount of syntaxin and the Munc18 homolog ROP was shown to regulate neurotransmitter release (Wu et al., 1998). These findings suggest that syntaxin could be a major downstream target of Munc18 in the molecular machinery of exocytosis. To test this hypothesis, we decided to interfere with the binding between syntaxin 1 and Munc181 and look for changes in large dense-core vesicle (LDCV) docking and catecholamine secretion in embryonic mouse chromaffin cells.

Our strategy was to introduce point mutations into Munc18-1 and assay binding to syntaxin 1 in vitro. Former studies provided clues about the residues of Munc18-1 that are potentially important in syntaxin 1 binding (Naren et al., 1997; Wu et al., 1998; Fisher et al., 2001). The D34N/M38V and the R39C mutation was of an outstanding interest because they were suggested to fully abolish syntaxin binding in vitro (Naren et al., 1997; Fisher et al., 2001).

Several Munc18-1 mutants were generated with PCR (Ruud F. Toonen, unpublished). 35S methionine labeled mutant Munc18-1 proteins were 'pulled down' through glutathion-agarose beads. To the beads glutation-serin-transferase (GST) conjugated syntaxin 1a was bound previously. After wash and SDS-PAGE the presence or absence of Munc18-1 (at $68 \mathrm{kD}$ ) was determined (Figure 16 Ruud F. Toonen, unpublished). Munc18-1 carrying the D34N/M38V but not the R39C mutation was undetected in the gel, which implies that Munc18-1 syntaxin 1a binding may be fully abolished by the former mutation (D34N/M38V). It should be noted that binding of Munc18-1 mutants to GST-Mint 1 showed the similar pattern as to GST-syntaxin 1a (Figure 16 right).

Next we investigated the physiological role of the R39C and the D34N/M38V mutation in LDCV fusion and catecholamine secretion. In these experiments we expressed either the wildtype or the mutant form of Munc18-1 on the 'clean genetical background' of Munc18-1 null mouse chromaffin cells.

The R39C mutation caused a small but insignificant increase in flash triggered secretion (Figure 17A-B; Table 3). It was reported that the R39C mutation specifically modified the kinetics of exocytosis release events in permeabilized chromaffin cells 

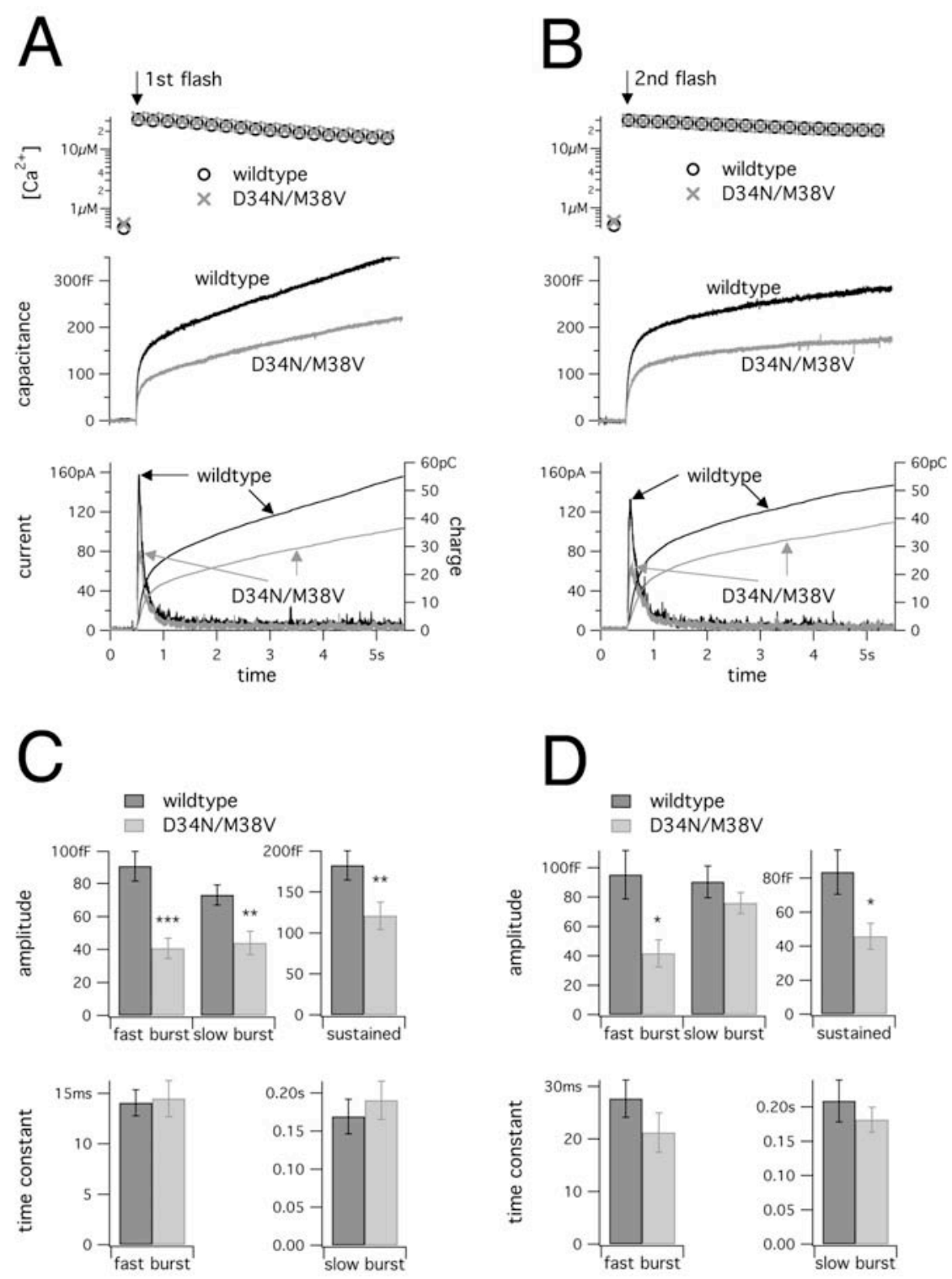

\section{Figure 18}

The D34N/M38V mutation reduces but does not fully abolish the potential of Munc18-1 to promote secretion. A-B) Averaged first and second flash responses from Munc18-1 null mutant chromaffin cells overexpressing either wildtype Munc18-1 (wildtype; $n>25$ ) or Munc18-1 carrying the D34N/M38V mutation (D34N/M38V; $n>25$ ). C-D) Kinetic components of the first and second flash responses, respectively. ${ }^{\star} \mathrm{P}<0.05$; ${ }^{\star \star} \mathrm{P}<0.01$; ${ }^{\star \star \star} \mathrm{P}<0.001$; Mann-Whitney test. Note that the amplitudes of distinct components are similarly reduced but fusion time constants are statistically indistinguishable.

(Fisher et al., 2001). However, the fusion time constants were unchanged in our essay (Table 3). Taken together, we conclude that the R39C mutation neither affects pool sizes nor fusion rates substantially in embryonic mouse chromaffin cells.

Munc18-1 carrying the D34N/M38V mutation was overexpressed in null mutant chromaffin cells (Figure 18). The secretory responses to the first and second flash stimulation showed an obvious decrease (Figure 18A-B). Quantitative analysis revealed similar $(\sim 50 \%)$ reduction in the fast- and slow burst as well as in the sustained component 

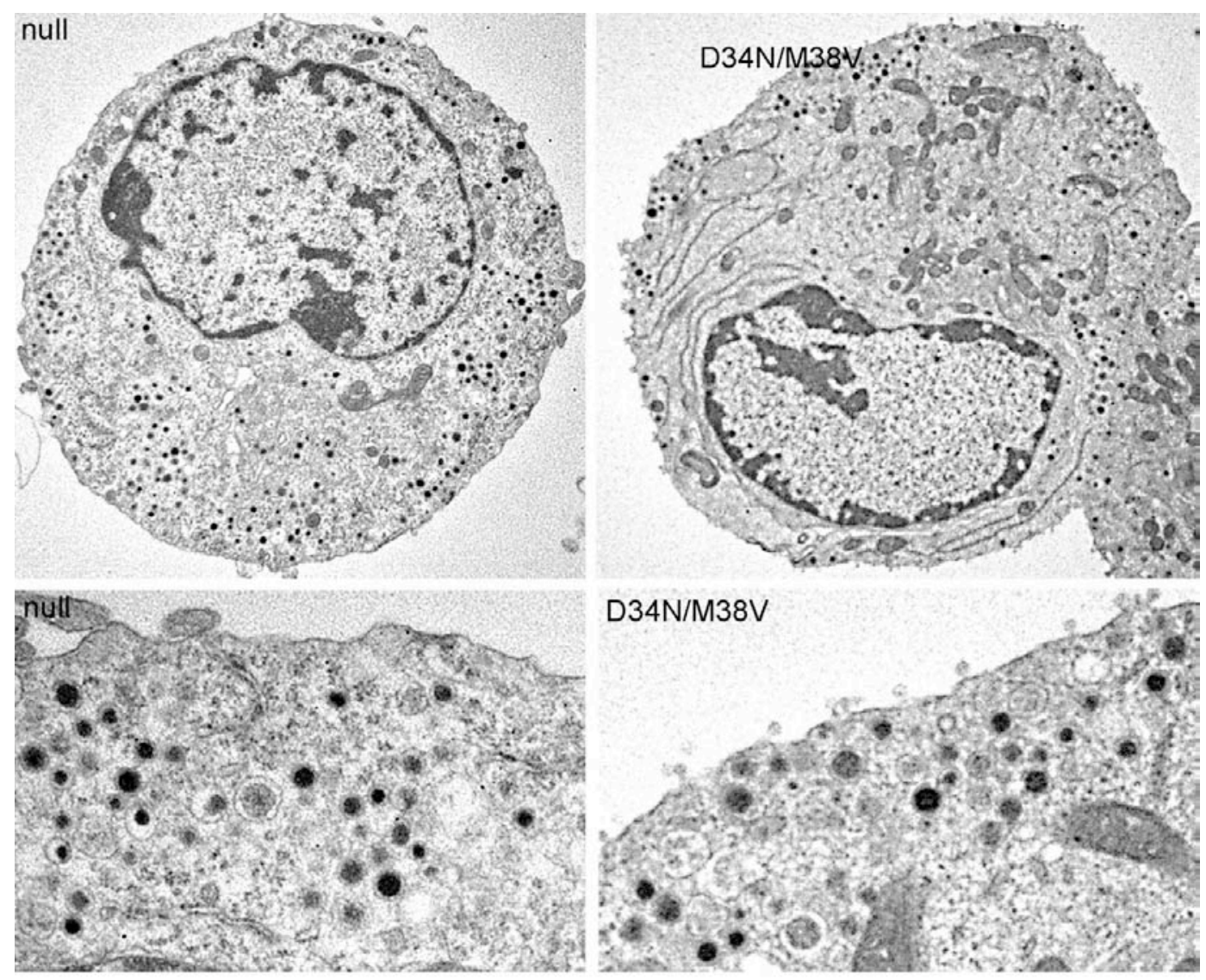

de Wit (unpublished)

\section{Figure 19}

Munc18-1 carrying the D34N/M38V mutation is able to promote large dense-core vesicle docking, although with decreased efficacy. Electromicrograph showing two Munc18-1 null mutant chromaffin cells (top). One of them overexpresses the D34N/M38V Munc18-1 mutant (D34N/M38V), the other one does not (null). Zooming in the perifery of the same two cells (bottom) reveals that the majority of large dense-core vesicles are closer to the plasma membrane in the presence of the D34N/M38V mutant than in the absence of it. The number of docked vesicles however is less with the D34N/M38V mutant than with wildtype Munc18-1 (see text and figure 11B for morphometric data).

(Table 3) suggesting smaller vesicle pools with the mutant. The fast and slow time constants were unchanged (Table 3), indicating that the D34N/M38V mutation does not interfere with the final fusion event.

Does the D34N/M38V mutation affect LDCV docking? Munc18-1 null cells expressing Munc18-1 with the D34N/M38V mutation had more docked LDCVs than nonexpressing null mutant cells (Figure 19; Heidi de Wit, unpublished). However, morphometrical analysis showed that the number of docked LDCVs is still $\sim 4$ times less in the presence of the D34N/M38V mutation than without it (null+Munc18-1).

With the above described experiments we studied the R39C and the D34N/M38V mutation in Munc18-1. We did not detect any effect of the R39C mutation on syntaxin 1a and Mint 1 binding in vitro or on flash triggered secretion in embryonic mouse 


\begin{tabular}{|c|r|c|c|c|c|c|}
\hline \multicolumn{2}{|c|}{} & control & $\begin{array}{c}\text { control + } \\
\text { Munc18-1 } \\
\text { wildtype }\end{array}$ & $\begin{array}{c}\text { P value } \\
\text { (compared } \\
\text { to control) }\end{array}$ & $\begin{array}{c}\text { control + } \\
\text { Munc18-1 } \\
\text { D34N/M38V }\end{array}$ & $\begin{array}{c}\text { P value } \\
\text { (compared } \\
\text { to control) }\end{array}$ \\
\hline & number of cells & $24 \geq$ & $24 \geq$ & & $22 \geq$ & \\
\hline \multirow{2}{*}{$\begin{array}{c}\text { amplitude } \\
\text { (fF) }\end{array}$} & fast burst & $93 \pm 13$ & $111 \pm 17$ & 0.41 & $109 \pm 20$ & 0.62 \\
\cline { 2 - 7 } & slow burst & $89 \pm 14$ & $92 \pm 13$ & 0.78 & $69 \pm 12$ & 0.32 \\
\cline { 2 - 7 } & sustained & $177 \pm 28$ & $231 \pm 24$ & 0.048 & $154 \pm 21$ & 0.80 \\
\hline \multirow{2}{*}{$\begin{array}{c}\text { time } \\
\text { const.(ms) }\end{array}$} & fast & $17.2 \pm 1.8$ & $15.9 \pm 1.6$ & 0.81 & $15.8 \pm 1.6$ & 0.90 \\
\cline { 2 - 7 } & slow & $178 \pm 30$ & $152 \pm 27$ & 0.35 & $149 \pm 20$ & 0.26 \\
\hline
\end{tabular}

\section{Table 4}

Overexpression of wildtype Munc18-1 or D34N/M38V mutant Munc18-1 in bovine chromaffin cells compared to noninfected bovine cells (control). $P$ values larger than 0.05 are displayed with grey color.

chromaffin cells in vivo. In contrarst, the D34N/M38V mutation appeared to fully abolish binding of Munc18-1 to syntaxin 1a and Mint 1 in a nonequilibrium essay in vitro. Furthermore this latter mutation also caused a partial decrease in large dense-core vesicle secretion and docking.

Next we asked the question if the D34N/M38V mutation has a dominant-negative effect on the secretory function. If yes, the expected results is that overexpression of Munc18-1 carrying the D34N/M38V mutation decreases flash responses in control cells. We used bovine cells for these experiments. Table 4 summarizes the results.

Overexpression of the D34N/M38V mutant Munc18-1 did not decrease the flash responses nor did it increase them. Overexpression of wildtype Munc18-1 lead to a small but significant membrane capacitance increase in the sustained phase. Fast and slow fusion time constants were indistinguishable in both cases. We repeated this experiment using wildtype mouse chromaffin cells and still found that overexpression D34N/M38V mutant Munc18-1 failed to decrease flash responses (data not shown).

We conclude that the D34N/M38V mutation in Munc18-1 has no effect on exocytosis in chromaffin cells when the endogenous wildtype Munc18-1 is present.

\section{Regulation of Munc18-1 dependent and independent secretion: protein kinase $\mathrm{C}$ ?}

Up till now we were concerned with the exocytic machinery downstream to Munc18-1. We confirmed that Munc18-1 is an essential promoter of large dense-core vesicle docking and catecholamine secretion in chromaffin cells. We investigated hypothetical Munc18-1 targets such as the F-actin cytoskeleton or syntaxin 1 of the SNARE complex. In this section we focus on the putative regulation of exocytosis in chromaffin cells through Munc18-1 modification. 
A
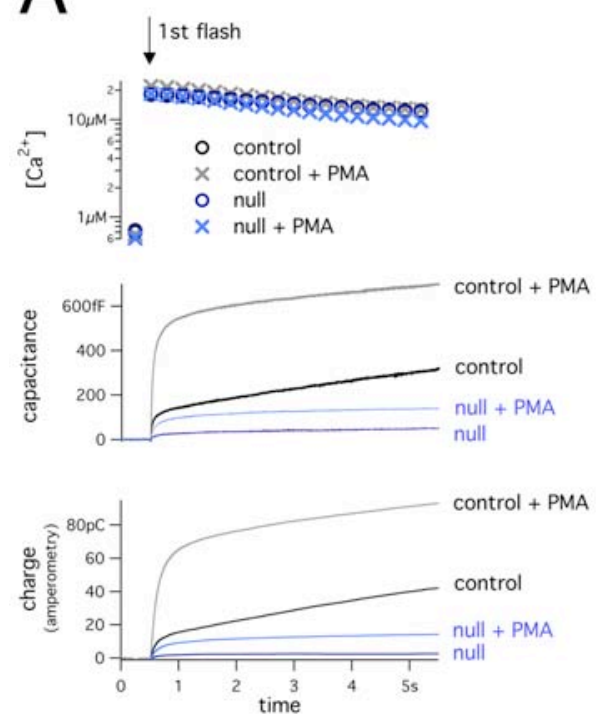

C
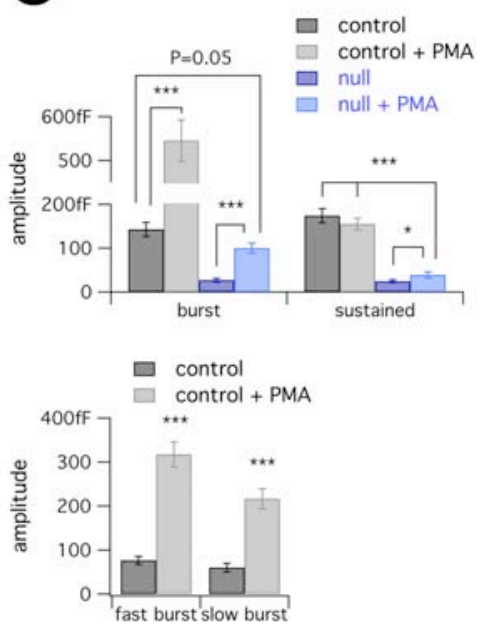
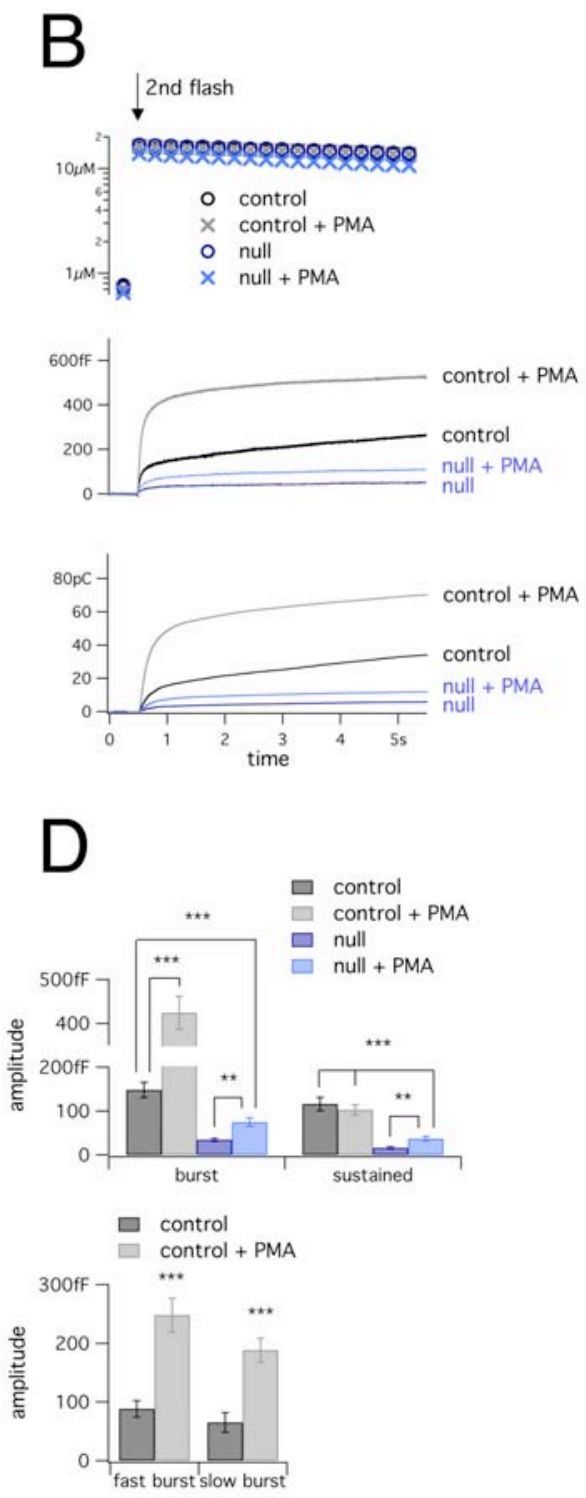

\section{Figure 20}

The 2-3-fold potentiation of secretion by phorbol esther is preserved in Munc18-1 null mutant chromaffin cells. A-B) Averaged first and second flash responses in Munc18-1 heterozygote and null mutant cells treated either with PMA or with the nonpotent analogue 4- $\alpha$-PMA. Control: Munc18-1 heterozygote with 4- $\alpha-P M A$ (n>25); control + PMA: Munc18-1 heterozygote with PMA ( $\mathrm{n}>25)$; null: Munc18-1 null mutant with 4- $\alpha-P M A$ ( $\mathrm{n}>25)$; null + PMA: Munc18-1 null mutant with PMA ( $>25$ ). Amperometric current traces are not shown for the sake of clarity. C-D) Kinetic components of the first and second flash responses, respectively. ${ }^{\star} P<0.05$; ${ }^{\star \star} P<0.01$; ${ }^{\star \star \star} P<0.001$; Mann-Whitney test.

Phorbol esters are well known potentiators of neurosecretion in the diacylglycerol (DAG) pathway in which $\mathrm{C} 1$ proteins like protein kinase $\mathrm{C}$ and Munc13 are involved (Silinsky and Searl, 2003; Brose et al., 2004). Moreover, Munc18-1 is a PKC target (Fujita et al., 1996) and PKC phosphorylation site of Munc18 was suggested to regulate the kinetics of vesicle fusion in permeabilized bovine chromaffin cells (Barclay et al., 2003). Is Munc18-1 an important downstream effector of the DAG pathway? If yes, 
A

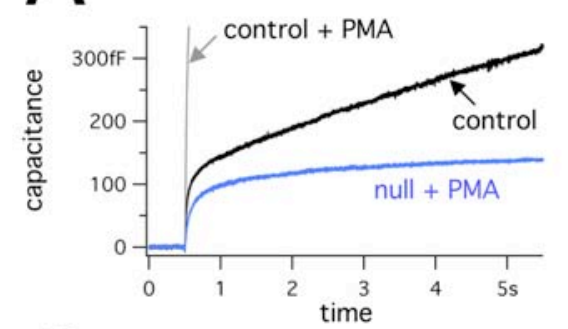

C
B

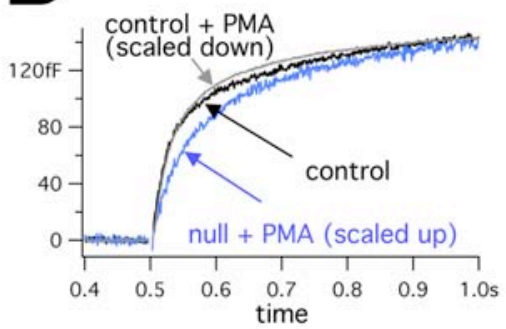

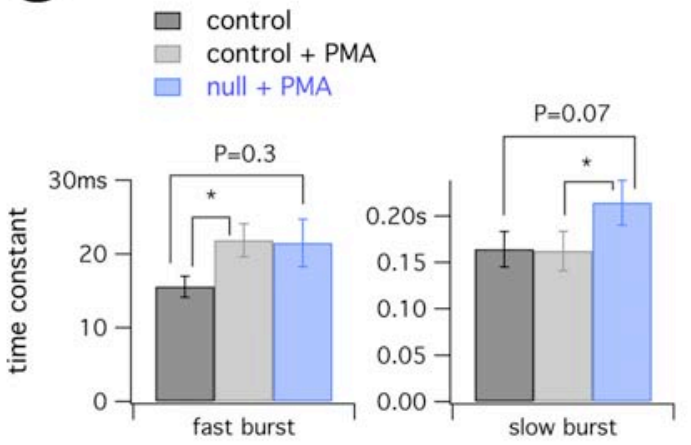

\section{Figure 21}

The time course of fast $\mathrm{Ca}^{2+}$-triggered secretion is essentially normal without Munc18-1. A) Averaged flash responses from PMA treated Munc18-1 null mutant cells (null + PMA) compared to Munc18-1 heterozygous cells with 4- $\alpha$-PMA (control) or PMA (control + PMA). Traces were taken from figure seventeen but here they are vertically expanded. B) Rescaled traces reveal slightly slower capacitance increase in Munc18-1 null mutant cells compared to control cells. Note that only the first $500 \mathrm{~ms}$ of the responses is displayed. C) Fusion time constants are depicted. * $\mathrm{P}<0.05$; Mann-Whitney test.

phorbol ester induced potentiation of secretion could be impaired when Munc18-1 is absent in vivo.

To answer this question we treated Munc18-1 null mouse chromaffin cells with the active synthetic phorbol ester PMA in $100 \mathrm{nM}$ for 5-8 minutes (null + PMA) and compared their secretory flash responses to null mutant cells treated with the inactive form, 4- $\alpha$-PMA (null; Figure 20). To assess the potency of PMA in normal situation (with Munc18-1) we also used from Munc18-1 heterozygotes from the same litter and exposed their chromaffin cells to 4- $\alpha$-PMA (control) or PMA (control + PMA; Figure 20). PMA in control cells caused a dramatic, 2-3-fold increase in the overall amplitude of the first flash responses in control cells and a relatively smaller increase in case of the second flashes (Figure 20A-B). Detailed analysis revealed that a 3.8 fold increase in the burst phase is responsible for the whole potentiation after first flashes whereas the sustained component was unaffected (Table 5; Figure 20C). The fast and slow burst component was similarly potentiated and the time course of the responses was affected 


\begin{tabular}{|r|r|c|c|c|c|c|c|}
\hline & \multicolumn{3}{|c|}{ PMA effect on control } & \multicolumn{3}{c|}{ PMA effect on null } \\
\hline & & control & $\begin{array}{c}\text { control }+ \\
\text { PMA }\end{array}$ & & null & $\begin{array}{c}\text { null + } \\
\text { PMA }\end{array}$ & \\
\hline & number of cells & $\mathrm{n} \geq 47$ & $\mathrm{n} \geq 51$ & & $\mathrm{n} \geq 30$ & $\mathrm{n} \geq 28$ & \\
\hline \multirow{4}{*}{ amplitude (fF) } & burst & $143 \pm 16$ & $545 \pm 47$ & $\mathrm{P}<0.001$ & $27 \pm 4$ & $100 \pm 11$ & $\mathrm{P}<0.001$ \\
\cline { 2 - 9 } & sustained & $174 \pm 16$ & $155 \pm 14$ & & $24 \pm 4$ & $39 \pm 7$ & $\mathrm{P}<0.05$ \\
\cline { 2 - 9 } & fast burst & $76 \pm 9$ & $317 \pm 29$ & $\mathrm{P}<0.001$ & & & \\
\cline { 2 - 9 } & slow burst & $60 \pm 10$ & $217 \pm 23$ & $\mathrm{P}<0.001$ & & & \\
\hline \multirow{2}{*}{$\begin{array}{c}\text { time } \\
\text { constant(ms) }\end{array}$} & fast & $15.6 \pm .14$ & $21.8 \pm 2.2$ & $\mathrm{P}<0.05$ & & $21.5 \pm 3.2$ & \\
\cline { 2 - 9 } & slow & $154 \pm 19$ & $162 \pm 21$ & & & $214 \pm 24$ & \\
\hline
\end{tabular}

\section{Table 5}

Effect of PMA on the sizes and kinetics of flash responses from control and Munc18-1 deficient embryonic chromaffin cells. Only significance levels $\mathrm{P}<0.05$ are indicated (Mann-Whitney test).

only a little (Table 5, Figure 21) suggesting that the rate of the final fusion event is essentially normal upon PMA treatment.

Flash responses from Munc18-1 null cells underwent a similar degree of potentiation as control cells (Figure 20A-B). The burst amplitude was 3.7 times larger with PMA than with 4- $\alpha$-PMA (Table 5; Figure 20C) and the amplitude of the sustained component was nearly doubled. Second flash responses showed relatively smaller but still extremely significant potentiation upon PMA application, consistently with the control situation (Figure 20B and D). We conclude that PMA induced potentiation is preserved in Munc18-1 null chromaffin cells. Moreover, a similar multiplication factor of potentiation was measured with or without Munc18-1. These findings suggest imply that Munc18-1 is not a major molecular link between the diacylglycerol pathway and the potentiation of secretion in chromaffin cells.

PMA induced potentiation of the flash responses in Munc18-1 null cells allowed a proper kinetical analysis of the burst phase because the signal to noise ratio in this case is in the optimal range for reliable exponential curve fitting (Figure 4A). The time course of the burst in PMA treated null mutant cells was similar to the control situation (Figure 21B). The fusion time constants of the fast and slow burst component were slightly but not significantly increased (null + PMA vs. control) supporting the hypothesis that Munc18-1 is not an executor or indispensable regulator of the final fusion step in large dense-core vesicle exocytosis.

\section{Another Munc18 isoform differently promotes docking and secretion}

In Munc18-1 deficient chromaffin cells large dense-core docking and secretion is severely impaired but not totally absent. The observation that fast $\mathrm{Ca}^{2+}$-triggered secretion can approximate normal levels under special conditions (Figure 21A) implies an efficient alternative mechanism for large dense-core vesicle (LDCV) exocytosis beside Munc18-1. 


\section{A}
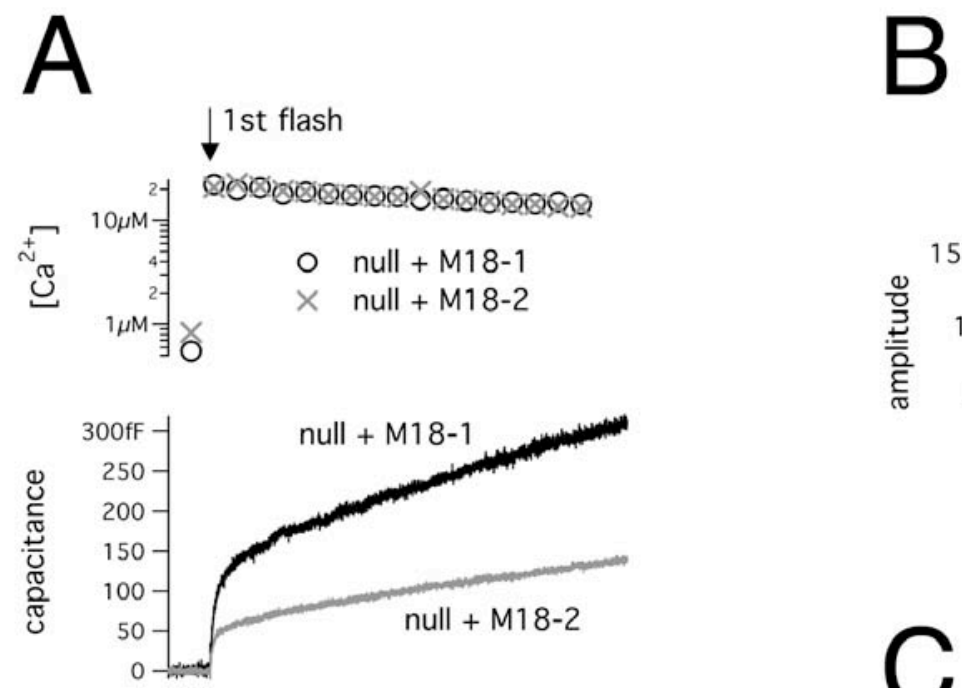

null + M18-1

null + M18-2
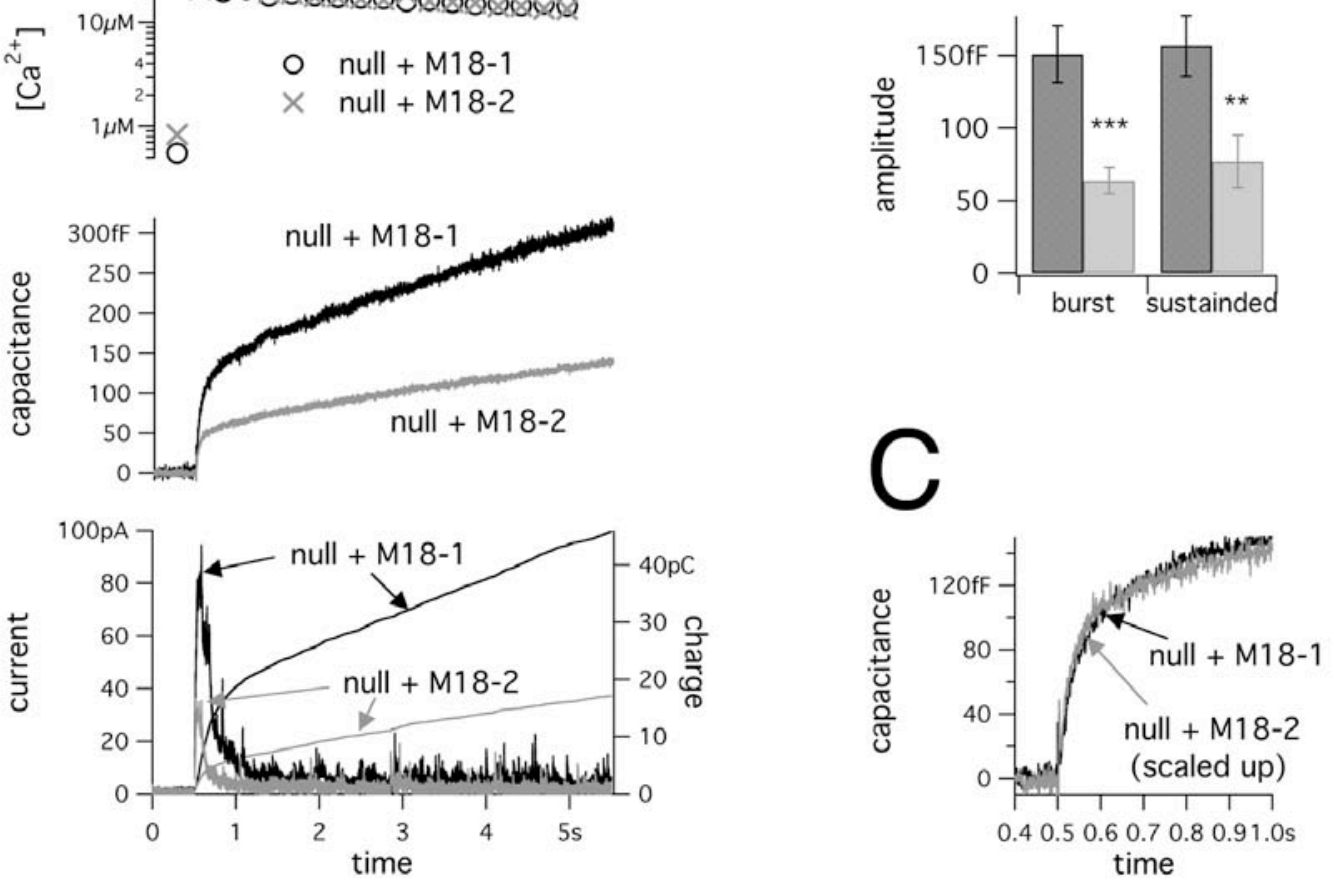

\section{Figure 22}

Munc18-2 is less efficient in promoting secretion than Munc18-1. A) Averaged secretory responses from Munc18-1 null mutant chromaffin cells overexpressing Munc18-1 (null + M18-1; $n=14$ ) or Munc18-2 (null + M18-2; $n=12$ ). B) Amplitudes of the burst and sustained component. ${ }^{* \star *} \mathrm{P}<0.001$; Mann-Whitney test. C) Time expansion of the burst phase shows qualitatively normal time course of the capacitance trace from Munc18-2 overexpressing cells. Note scaling.

This mechanism is in the diacylglycerol pathway because PMA dramatically potentiated flash responses in Munc18-1 null cells (Figure 20). The question is the molecular basis of this alternative mechanism.

Munc18-2 is the closest mammalian isoform of Munc18-1 (Toonen and Verhage, 2003). It is weakly expressed in chromaffin cells (Matthijs Verhage, personal communication). Overexpression of Munc18-2 in Munc18-1 null cells resulted in normal (wildtype like) LDCV distribution (M. Verhage, pers. com.).

We were interested if Munc18-2 is an effective promoter of LDCV secretion; therefore we recorded flash responses in Munc18-2 or Munc18-1 overexpressing Munc18-1 null cells (Figure 22). Munc18-2 overexpressing null mutant cells (null + M18-2) responded to flash stimulation with a substantial membrane capacitance increase and amperometric current that was never observed in the responses from null mutant cells without overexpression (compare 'null + M18-2' traces in Figure 22A to 'null' responses in Figure 10A). However the amplitude of the burst component was only $64 \pm 9 \mathrm{fF}(\mathrm{n}=12)$ 
with Munc18-1 overexpression it reached $151 \pm 19 \mathrm{fF}(\mathrm{n}=14 ; \mathrm{P}<0.001$; Figure 22B). The amplitude of sustained component showed a similar trend (null $+\mathrm{M} 18-2: 77 \pm 18 \mathrm{fF}$; null + M18-1: 157 $\pm 21 ; \mathrm{P}<0.001)$. When we compared the time course of the burst phase we found no apparent difference between Munc18-2 and Munc18-1 overexpressing cells (Figure 22C) suggesting that large dense-core vesicles fuse with similar rate in the two conditions.

We conclude that Munc18-2 overexpression promotes early and not final steps of LDCV exocytosis in Munc18-1 deficient mouse chromaffin cells. Munc18-1 is however significantly more potent than Munc18-2. 
Discussion 


\section{Major novel findings}

Our study is based on Voets' and colleagues publication where it was shown that in Munc18-1 null cells large dense-core vesicle docking and catecholamine secretion is largely abolished (Voets et al., 2001b). Now we confirmed these previous results and added some new findings to them. The major novel findings are:

1. large dense-core exocytosis was rescued in the null mutant cells after reintroducion of Munc18-1 (Figure 10-11)

2. introduction of the D34N/M38V mutation into Munc18-1 interferes with syntaxin1-M18-1 binding in vitro and also interferes with exocytic function at the docking step in vivo (Figure 16, 11, 18)

3. Munc18-2 can fully substitute for Munc18-1 in docking and partially in secretion (Figure 22)

The study resulted in a number of other findings: we confirmed the effect of Munc18-1 gene knockout in mouse cells (Figure 10-11) and the effect of Munc18-1 overexpression in (wildtype) bovine cells (Table 5) as it was earlier published (Voets et al., 2001b). We extended the latter finding (Munc18-1 overexpression) to newborn wildtype mouse chromaffin cells (Figure 12, Table 2). We observed fewer docked vesicles and less catecholamine secretion in Munc18-1 heterozygotes than wildtype mice (Figure 13, Table 2). Latrunculin A promoted vesicle docking but failed to promote catecholamine secretion in Munc18-1 null cells (Figure 15). Interestingly latrunculin A did not potentiate flash responses in embryonic wildtype mouse cells as it did in bovine chromaffin cells (Figure 14). We found that the R39C mutation in Munc18-1 had no detectable effect on syntaxin1 binding in vitro neither had it an effect on the flash responses in vivo (Figure 16-17, Table 3). Furthermore, the D34N/M38V mutation had no effect when the wildtype form of Munc18-1 was also present in the cells (Table 4). Finally we found that the degree of phorbol ester potentiation is similar in Munc18-1 deficient cells compared to control cells and the time course of fast $\mathrm{Ca}^{2+}$ triggered vesicle fusion is essentially normal in Munc18-1 null cells (Figure 20-21).

\section{The strength of the rescue approach}

One of our original questions was if the severe functional defect in Munc18-1 null cells as published earlier (Voets et al., 2001b) is due to the specific absence of Munc18-1 or to secondary effects? This question could be answered only with the rescue experiment, where the RNA of Munc18-1 is introduced into Munc18-1 null cells. Now we report that reintroduction of Munc18-1 restored large dense-core vesicle docking (Figure 11) and catecholamine secretion (Figure 10) to normal (wildtype) level. This result strongly suggests that the defect in large dense-core vesicle exocytosis in the Munc18-1 null cells is specifically due to the absence of Munc18-1. 
Furthermore, this result formed a basis for further experiments where the effect of any mutation in Munc18-1 can be tested on a clean genetical background. In this kind of experiment the mutant Munc18-1 can be expressed in Munc18-1 null cells and the exocytic function can be compared to null mutant cells expressing wildtype Munc18-1. In our experiments we tested two mutations in Munc18-1 using this strategy. In the case of one mutant (D34N/M38V) the flash responses were strongly reduced (Figure 18, Table 3). Thus, the D34N/M38V mutation in Munc18-1 has a marked effect on catecholamine secretion.

However, when we overexpressed the same mutant in control cells that contain the endogenous wildtype form of Munc18-1, we did not detect any reduction in the flash responses (compared to control cells without overexpression) as summarized in Table 4. We observed this result both in bovine and in embryonic wildtype mouse cells. Thus, without the rescue approach we would have failed to detect the effect of the D34N/M38V mutation. A likely explanation is that the endogenous wildtype Munc18-1 in control cells 'outcompetes' the mutant from physiologically important binding sites or in other words: the mutation is recessive. This explanation is supported by the finding that the D34N/M38V mutation in Munc18-1 abolished binding to syntaxin1a below detectable level in vitro (Figure 16).

\section{Munc18-1 is a positive regulator of large dense-core vesicle exocytosis}

Sec1/Munc18 proteins were suggested to be negative regulators of neurotransmitter release because overexpression or infusion of Sec1/Munc18 homologs inhibited transmitter release or other vesicular secretory processes in various model systems (Schulze et al., 1994; Dresbach et al., 1998; Wu et al., 1998; Riento et al., 2000). Opposing this concept, genomic null mutations in Sec1/Munc18 caused severe defects in membrane trafficking and/or transmitter release in yeast, worm, fruitfly or mouse (Brenner, 1974; Novick and Schekman, 1979; Harrison et al., 1994; Verhage et al., 2000) indicating that this protein family could play a positive role in vesiclular membrane trafficking and exocytosis.

In our study we rescued large dense-core vesicle docking (Figure 11) and catecholamine secretion (Figure 10) in Munc18-1 null mouse chromaffin cells by viral overexpression of Munc18-1. This supports the view that Munc18-1 is a positive regulator of large dense-core vesicle exocytosis in this system (Voets et al., 2001b). Second, we supported previous findings (Voets et al., 2001b) that additional overexpression of Munc18-1 increases flash responses in wildtype mouse (Figure 12, Table 2) or bovine (Table 4) chromaffin cells. Thus, unlike in the neuromuscular junction of Drosophila or the giant synapse of the squid (Schulze et al., 1994; Dresbach et al., 1998; Wu et al., 1998), in adrenal chromaffin cells supraphysiological levels of Munc18 increase release. 


\section{Discussion}

One explanation that could solve this apparent contradiction could be that Sec1/Munc18 proteins function differently in transmitter release in invertebrates as they function in vertebrates, e.g. they interact with syntaxin differently. Indeed, different binding modes of Sec1/Munc18 proteins to syntaxin are known but these modes seem to correlate more with the exact vesicular membrane trafficking pathway than with the species (Verhage et al., 2000). Another explanation may be that the relative amount of syntaxin and Munc18 is different in Drosophila compared to mouse, or it differentially affects exocytic function. In Drosophila, the inhibitory effect of Munc18 overexpression could be suppressed when syntaxin was also overexpressed (Wu et al., 1998). A third explanation is that Munc18 has a differential role in neurons and in neurosecretory cells (e.g. chromaffin cells).

In control (wildtype) cells Munc18-1 overexpression clearly potentiated large dense-core vesicle docking and catecholamine release compared to noninfected control cells (Figure 11,12, Table 2). However, in our rescue experiments, Munc18-1 null cells overexpressing Munc18-1 had similar number of docked vesicles and similar flash response amplitudes as control cells (Figure 10-11). Why did not we observe increased docking and secretion in null mutant cells upon Munc18-1 overexpression as we observed in the case of control cells? It was shown that in the adrenal glands of Munc18-1 null mice the protein level of syntaxin 1 is reduced by $70 \%$ (Voets et al., 2001b). Apart from the absence of Munc18-1 this is so far the only described difference between null mutant and wildtype chromaffin cells, therefore the most obvious explanation is that the reduced syntaxin1 level counterbalances the potentiating action of Munc18-1 overexpression in Munc18-1 null cells so that eventually there is neither loss nor gain in the exocytic function. In this case, the proportion of syntaxin/Munc18 would regulate release differently as it was described in Drosophila (Wu et al., 1998).

Increased amount of Munc18-1 (by overexpression) results in increased large dense-core vesicle docking and catecholamine secretion (Voets et al., 2001b), (Figure 12). The complete absence of Munc18-1 coincides with strongly decreased docking and secretion (Voets et al., 2001b), (Figure 10-11). Chromaffin cells that are heterozygous to the Munc18-1 null mutation were shown to express only half the amount of Munc18-1 than wildtype cells (Voets et al., 2001b). One of our new findings is that heterozygous cells have $\sim 3$ times less docked vesicles than wildtype cells (Figure 11). This result fits well into the Munc18-1 dose dependency of large dense-core vesicle exocytosis. Interestingly, the flash experiment revealed only a minor decrease of catecholamine secretion in Munc18-1 heterozygotes compared to wildtype mice (Figure 13). This is in agreement with the finding that the quantal content in the neuromuscular junction is slightly but significantly decreased in Munc18-1 heterozygous mice (Sons et al., 2003).

The decrease in the flash responses was fully assigned to a mild but very significant reduction of the sustained component, which reports the size of the docked but unprimed vesicle pool and the priming rate (Figure 4B, Table 1). Thus, the flash experiment detected probably the reduction in vesicle docking. The decrease in the sustained component was not accompanied by a decrease in releasable pool sizes, as the 


\section{Discussion}

burst amplitude was normal in heterozygotes. This implies that some mechanism e.g. upregulation of priming factors, keeps the vesicles in the releasable pools by decreasing $\mathrm{k}_{-1}$, the rate of depriming, according to the ' 4 vesicle pool model' (Figure 4B). An alternative explanation is that Munc18-1 itself acts not only at the docking step but also at the priming step and the latter action depends less on the amount of Munc18-1.

Taken together, we found a clearly positive correlation between Munc18-1 expression level, vesicle docking and catecholamine release in chromaffin cells, therefore we conclude that Munc18-1 is a positive regulator of large dense-core vesicle exocytosis.

\section{The t-SNARE syntaxin in vesicle docking?}

When we designed our experiments for the present study, one of our main questions was by which molecular mechanisms does Munc18-1 promote large dense-core vesicle docking and what are the physiologically important downstream targets? Putatively, one of the most important downstream targets is the neuronal t-SNARE syntaxin1 as I discussed in previous chapters (The t-SNARE syntaxin is an interaction partner of Munc18, Physiology of Munc18-syntaxin interaction). Munc18 and syntaxin forms a stable complex in vitro, so an obvious strategy is to introduce a mutation into Munc18-1 that affects the binding affinity to syntaxin1 and then test the functional consequences of that mutation.

We generated several mutant Munc18-1 cDNAs based on previous publications (Naren et al., 1997; Wu et al., 1998; Fisher et al., 2001). Then we expressed these mutants and found that the D34N/M38V mutant Munc18-1 protein does not bind detectably to syntaxin 1 or Mint1 in the GST pulldown assay in vitro. When we overexpressed the D34N/M38V mutant Munc18-1 in Munc18-1 null cells, we found that docking (Figure 11 ) and secretion (Figure 18, Table 3) was rescued to significantly lower extent than in the wildtype situation. These findings together imply that Munc18-1 and syntaxin1 interacting with each other promote large dense-core vesicle docking in chromaffin cells.

From one side this scenario could be expected combining the facts that (1) Munc18-1 is a major promoter of vesicle docking in chromaffin cells (Voets et al., 2001b) and (2) the interaction between Munc18-1 and syntaxin was shown both in vitro and in vivo in a great number of different systems (Jahn, 2000; Rizo and Sudhof, 2002; Toonen and Verhage, 2003).

From another side the idea is surprising because SNARE proteins are currently thought to act at vesicle priming or fusion step but not at the docking process as it was speculated in the original SNARE hypothesis (Sollner et al., 1993). In fact, up till now, alteration in vesicle docking upon manipulation with Munc18 or syntaxin (or any other SNAREs) was only detected in the chromaffin cell system (Voets et al., 2001b). Morphological docking of synaptic vesicles is completely normal in the Munc18-1 null neurons (Verhage et al., 2000) and no apparent loss in the large dense-core vesicle docking function was found in SNAP-25 deficient mouse chromaffin cells (Sorensen et 


\section{Discussion}

al., 2003b). Furthermore cleavage of SNAREs with neurotoxins did not affect synaptic vesicle docking (Schiavo et al., 2000). These points raise important questions:

1. is there a principle systematic difference between synaptic- and large dense-core vesicle docking?

2. if yes, is it due to a difference in Munc18 and/or syntaxin isoforms expressed or difference in their subcellular distribution in the two systems?

3. can cleavage or deletion of syntaxin (or the other SNAREs) also cause a defect in large dense-core vesicle docking in chromaffin cells?

The results with the D34N/M38V mutation are very suggestive but they should be interpreted with care:

First, a nonequilibrium binding assay was used to study the syntaxin1-Munc18-1 interaction in vitro. This kind of assay may fail to detect weak but physiologically relevant interactions. Thus, we cannot tell from our results if the remaining docking and secretion in the D34N/M38V mutant Munc18-1 expressing cells (which is still substantially more than in Munc18-1 deficient cells) is due to a weak binding to syntaxin1 in vivo, or to syntaxin independent mechanisms.

Concerning the first possibility, that the D34N/M38V mutation in Munc18-1 completely abolishes its binding to syntaxin1, it should be mentioned that previously this mutant was found to have zero affinity to syntaxin 1 in a similar assay and at the same time it completely failed to produce the same physiological effect on the CFTR chloride channel as the wildtype Munc18-1 (Naren et al., 1997). When the same mutation (D34N/M38V) was introduced to Munc18-2, the GST pulldown experiment detected a very small amount of Munc18-2 bound to syntaxin3 (Riento et al., 2000). These results are in agreement with ours but they do not provide evidence for complete disruption of the syntaxin-Munc18 interaction by the D34N/M38V mutation.

We cannot exclude the possibility that the lack of binding to Mint1 (Figure 16) contributed significantly to the physiological effect of the D34N/M38V mutation in Munc18-1. However, this is unlikely because Mint1 deficient mice show only very mild alterations in neurotransmitter release (Ho et al., 2003).

The other mutation (in Munc18-1) of our particular interest was R39C. It was published that the Munc18-1 carrying this mutation binds to syntaxin1 with a reduced affinity in vitro and speeds up the kinetics of final fusion events in permeabilized chromaffin cells in vivo (Fisher et al., 2001). Furthermore, the corresponding mutation in the Munc18 homolog ROP increased neurotransmission in Drosophila in vivo (Wu et al., 1998). Oddly, with the same technique (GST pulldown) as Fisher and colleagues used (Fisher et al., 2001) we observed normal Munc18-1 R39C binding to syntaxin1 (Figure 16). In agreement with our binding data we could not detect any significant effect of the R39C mutation on flash responses (Figure 17, Table 3). It is not clear what underlies these discrepancies but it indicates that (1) the GST pulldown technique is not 


\section{Discussion}

satisfyingly reliable and (2) there might be fundamental differences in large dense-core vesicle exocytosis between permeabilized and intact chromaffin cells.

Nevertheless, our data concerning the D34N/M38V mutation strongly suggests that interference with the interaction between Munc18-1 and syntaxin results in impaired large dense-core vesicle docking and catecholamine release in chromaffin cells. More supporting experimental results are needed, however, to draw further conclusions. First, an equilibrium binding assay could accurately quantify the extent by which the D34N/M38V or other mutations abolish the interaction between Munc18-1 and syntaxin1. Second, other mutations should be tested functionally that are expected to lower the binding affinity of Munc18 to syntaxin, e.g. the D34N (Figure 16) or the protein kinase C phosphorylation mutant S313D (Fujita et al., 1996; Craig et al., 2003).

\section{Munc18 in priming?}

One of the main questions that we challenged in this study was the identity of the molecular factors that can functionally substitute Munc18-1 in chromaffin cells. One obvious group of molecular candidates is different isoforms and homologs of Munc18-1. The Sec1/Munc18 family has seven genes in the human genomic database (Toonen and Verhage, 2003), including the three Munc18 isoforms: Munc18-1, -2 and -3. In mouse, Munc18-2 (Hata and Sudhof, 1995; Katagiri et al., 1995; Tellam et al., 1995) shares the closest homology (63\%) with Munc18-1. Therefore we tested Munc18-2 as a putative promoter of large dense-core vesicle docking and catecholamine secretion.

We found that overexpression of Munc18-2 in Munc18-1 deficient chromaffin cells restores vesicle docking to control level (M. Verhage, personal communication) and rescues catecholamine secretion to reduced levels (Figure 22). Combining these two results suggests that Munc18 is directly involved in large dense-core vesicle priming and Munc18-2 is a less efficient priming factor than Munc18-1 (Figure 4B). Direct involvement of Munc18 in priming could explain why neurotransmission is completely abolished in Munc18-1 null synapses despite normal synaptic vesicle docking (Verhage et al., 2000).

Munc13-1 is a vesicle priming factor in neurons and in chromaffin cells (Augustin et al., 1999; Ashery et al., 2000) and binds also to the Habc/Nsyx domain of syntaxin1 (Betz et al., 1997). These findings led to a molecular scheme (Voets et al., 2001b) where Munc18-1 and Munc13-1 could sequentially interact with syntaxin1 and prepare it for entering the SNARE complex as seen in Figure 23. Thereby Munc18-1 and Munc13-1 could act at an earlier and a later phase of priming, respectively.

We do not know however if all the morphologically docked vesicles in Munc18-2 overexpressing Munc18-1 null cells are potentially able to prime and fuse. It might be that a set of the morphologically docked vesicles is trapped in a pool from which they cannot prime. In this case we should distinguish between functional and nonfunctional 


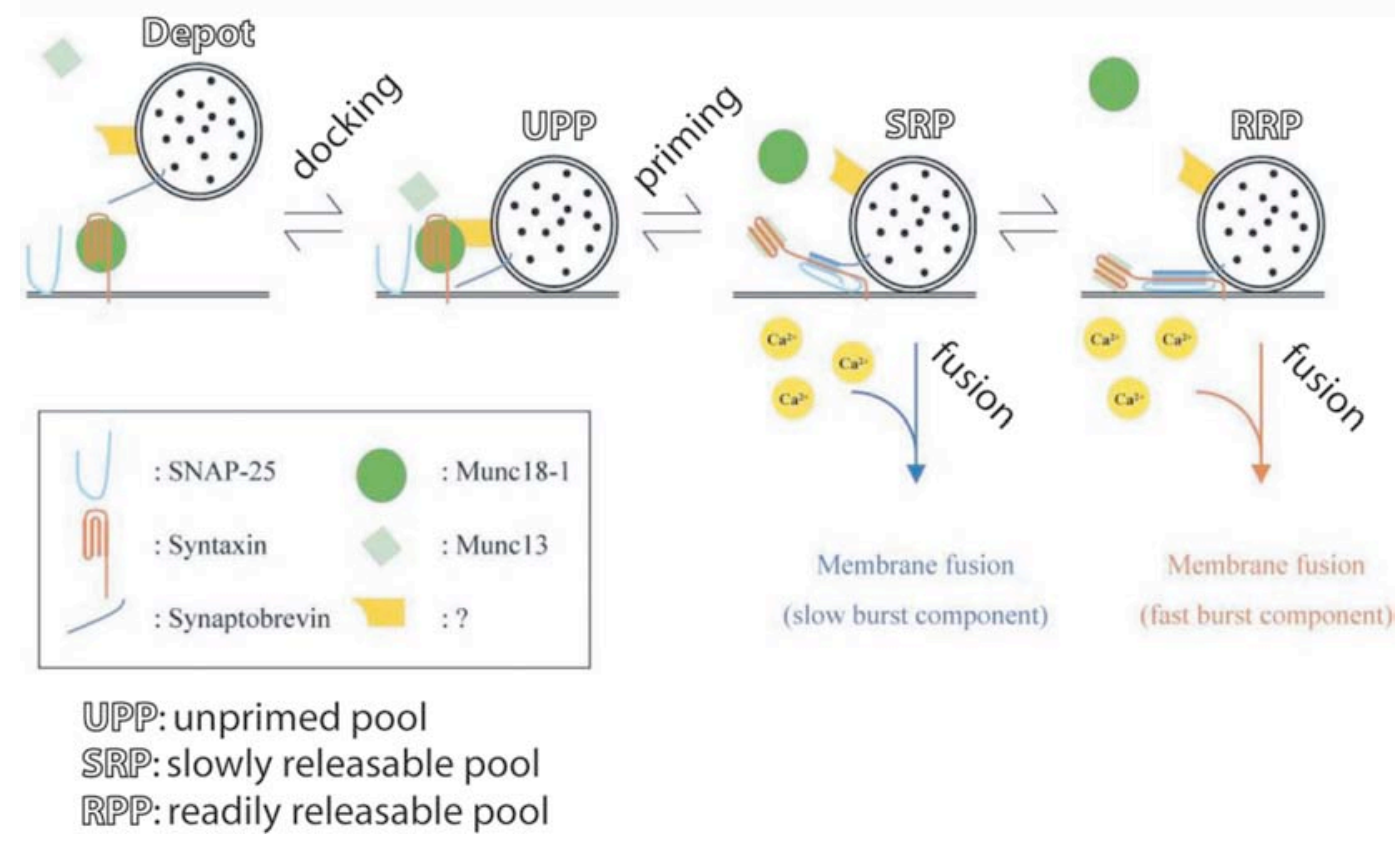

\section{Figure 23}

The role of Munc18-1 in large dense-core vesicle exocytosis. Modified from (Voets et al., 2001). One vesicle represents each vesicle pools: the depot pool, the unprimed pool (UPP), the slowly- and the rapidly releasable pool (SRP and RRP). Some elements of the exocytic protein machinery is shown: Munc18-1 and the three SNARE proteins (SNAP-25, syntaxin and synaptobrevin/VAMP) plus Munc13 and a putative vesiclular recognition factor (yellow). The syntaxin-Munc18-1 complex is drawn in the first two stages (depot and UPP) syntaxin being in the closed confromation. In the last two stages (SRP and RRP) syntaxin is in the open conformation and does not bind to Munc18.1 anymore (Dulubova et al., 1999). Instead, syntaxin assembles into the SNARE complex.

(dead-end) docking. It might be that Munc18-1 favors functional docking more than Munc18-2.

Munc18-2 as well as Munc18-1 binds strongly to syntaxin1, -2 and -3 but not to syntaxin4 (Hata and Sudhof, 1995). Munc18-2 might have lower affinity to syntaxin1 than Munc18-1 and this could account for the decreased catecholamine secretion (Figure 22). Our results with the D34N/M38V mutant Munc18-1 do not support this hypothesis because in those experiments we found that partial or full disruption of the syntaxin1Munc18-1 interaction (Figure 16) resulted in not only decreased catecholamine release (Figure18, Table 3) but also decreased large dense-core vesicle docking (Figure 11).

It is not quite clear how strongly mouse chromaffin cells express Munc18-2 but it appears that Munc18-2 is present at a low level of expression (M. Verhage, pers. comm.). This low Munc18-2 expression level might explain the remaining $\sim 10 \%$ catecholamine secretion in Munc18-1 null cells (compared to wildtype) (Voets et al., 2001b).

The F-actin cytoskeleton was proposed as a regulator of docking and secretion in bovine chromaffin cells (Vitale et al., 1995; Gil et al., 2000) therefore we tested the 
hypothesis that Munc18-1 promotes large dense-core vesicle docking through the F-actin cytoskeleton. Munc18-1 null cells were treated with latrunculin A before flash experiments to disrupt the cortical F-actin ring, but latrunculin A failed to restore secretion (Figure 15). This suggests that the F-actin cytoskeleton is not a major downstream target of Munc18-1. Contrasting this view, latrunculin A significantly increased the number of morphologically docked vesicles in Munc18-1 null chromaffin cells (M. Verhage, pers. comm.). This latter ultrastructural result combined with the former electrophysiological finding implies again that (a) large dense-core vesicles can exists in a docked but nonfunctional, silent state from which they cannot prime further or (b) Munc18 is an indispensable priming factor.

An unexpected finding is that latrunculin A increases flash responses in bovine but not in wildtype newborn mouse chromaffin cells (Figure 14). Latrunculin A increased the late component of secretory response in bovine chromaffin cells (Gil et al., 2000) but it has not been directly shown to increase the number of docked vesicles so far. To our knowledge, this is the first time that an F-acting severing agent was tested on mouse chromaffin cells and we detected no effect on the secretory function. Embryonic mouse chromaffin cells have fewer undocked large dense-core vesicles than adult bovine chromaffin cells (Plattner et al., 1997; Sorensen et al., 2003b) and this might underlie the observed discrepancy between the two systems. Alternatively, a species-specific immanent difference in the molecular machinery of exocytosis might serve as an explanation.

\section{Munc18 in final fusion event?}

The time constants obtained from the flash responses report the $\left[\mathrm{Ca}^{2+}\right]$ dependent rates of large dense-core vesicle fusion from the slowly and readily releasable pools (Voets, 2000) as summarized in Table 1. While a great number of molecular manipulations affected the vesicle pool sizes (therefore more upstream steps of exocytosis) as it was reviewed (Sorensen, 2004), fewer studies presented data on altered fusion rate constants. Mutations introduced into SNAP-25 (Wei et al., 2000; Sorensen et al., 2002) or synaptotagmin 1 (Sorensen et al., 2003a) or overexpression of tomosyn (Yizhar et al., 2004) slowed down the $\left[\mathrm{Ca}^{2+}\right]$ dependent fusion rates suggesting that these proteins are directly linked to the $\mathrm{Ca}^{2+}$ triggering of the final fusion event of large densecore exocytosis.

So far no data was published on Munc18-1 and other Munc18 homologs concerning fusion rates calculated from capacitance measurements except that overexpression of wildtype Munc18-1 had no effect on the kinetics of the flash responses (Voets et al., 2001b). In our study we did not detect any changes in fusion time constants when we rescued Munc18-1 null cells with wildtype Munc18-1 (Figure 10) or with two mutants of Munc18-1 (Figure 17-18, Table 3) even though one of the mutant (D34N/M38V) decreased amplitudes of multiple kinetic components. Neither found we 


\section{Discussion}

differences between the kinetics of flash responses with Munc18-2 rescue of null mutant cells compared to wildtype Munc18-1 rescue (Figure 22).

We could reliably measure fusion time constants from Munc18-1 deficient cells when PMA was used to potentiate catecholamine secretion (Figure 21). Figure 21B implies a minor slowdown of the burst phase in Munc18-1 null cells. It should be noted that the capacitance traces, from which the time constants are calculated (Figure 4A) report not only fusion of catecholamine containing large dense-core vesicles but also the fusion of another vesicle or membrane population which give rise to the so-called intermediate component (Xu et al., 1998). The time constant of the intermediate component is slower than that of the fast burst (Xu et al., 1998; Sorensen et al., 2003b) The intermediate component is preserved Munc18-1 null cells (data not shown). Therefore we suggest that in Munc18-1 null cells the larger relative contamination of the capacitance responses with the intermediate component could account for the mild slowdown of the burst kinetics (Figure 21).

Taken these together, the normal fusion time constants in all flash experiments presented in our study suggest that Munc18 is not directly involved in the $\mathrm{Ca}^{2+}$ triggering of the final fusion event.

Single spike amperometry is another technique to study the most downstream step of large dense-core exocytosis namely membrane fusion. While the capacitance measurement combined with $\mathrm{Ca}^{2+}$ uncaging reports the collective behavior of fusing vesicles, single spike amperometry measures fusion kinetics of individual vesicles (Neher, 1998). Some molecular manipulations resulted in slower fusion rates (membrane capacitance) without detectable changes in single spike parameters (amperometry) (Sorensen et al., 2003a; Yizhar et al., 2004). It is not quite understood how the single spike kinetics relate to fusion rates calculated from capacitance measurements but it is tempting to believe that the single spike amperometry follows only the most downstream step of membrane fusion which is independent of the $\mathrm{Ca}^{2+}$ triggering step.

Nevertheless, numerous exocytic proteins including Munc18 were proposed as regulators for membrane fusion dynamics based on single spike amperometry (Burgoyne et al., 2001). While single spike kinetics were normal in Munc18-1 null mouse chromaffin cells (Voets et al., 2001b) other investigators found changes in single fusion kinetics with mutations that targeted the syntaxin1-Munc18-1 interaction or Munc18-1 itself (Fisher et al., 2001; Barclay et al., 2003; Graham et al., 2004).

Importantly, one of the above mentioned mutations was R39C in Munc18-1, which speeded up the kinetics of final fusion events in permeabilized chromaffin cells suggesting an increased rate of kiss-and-run exocytosis (Fisher et al., 2001). In our flash experiments the R39C mutation had no effect on the fusion time constants neither did it affect the vesicle pool sizes (Figure 17, Table 3).

One explanation for this paradox could be that the R39C mutation changes the single spike kinetics in the Munc18-1 null mouse chromaffin cell rescue system without affecting the fusion time constants. So far we did not test this possibility experimentally 
(with amperometric single spike analysis) but it seems unlikely that Munc18-1 acts at the docking step (Voets et al., 2001b) does not participate in the $\mathrm{Ca}^{2+}$ triggering step (Figure 17) but acts again at the final fusion step (Fisher et al., 2001). Another explanation for the conflicting results on the $\mathrm{R} 39 \mathrm{C}$ mutation is that the biophysics of membrane fusion in intact mouse chromaffin cells are different from those in permeabilized bovine chromaffin cells. Moreover, the effect of the R39C mutation on spike kinetics was studied without the rescue approach, by overexpressing the mutant Munc18-1 in wildtype cells. A synchronized effort from various laboratories would be required to compare the two experimental systems under standardized conditions and to reach consensus on this issue.

It is a matter of debate whether Munc18 is involved in large dense-core vesicle fusion. Our experimental results and the fact that the syntaxin1-Munc18-1 complex is exclusive to the syntaxin1-SNARE complex (Dulubova et al., 1999) does not support this view.

\section{Phorbol ester induced potentiation}

One of our original motivations was to look for physiologically important upstream regulators of Munc18-1. It was described that Munc18-1 has two major protein kinase C (PKC) phosphorylation sites: S306 and S313 (Fujita et al., 1996), the latter depicted in Figure 5B2. The phosphorylated form of Munc18-1 was shown to have lower binding affinity to syntaxin1 in vitro (Fujita et al., 1996; Barclay et al., 2003). Moreover, stimulation of chromaffin cells that elevates intracellular $\left[\mathrm{Ca}^{2+}\right]$ resulted in phosphorylation of Munc18-1 at S313 in vivo (Craig et al., 2003). PKC is part of the diacylglycerol second messenger pathway and phorbol esters, analogues of diacylglycerol, activate PKC among other proteins of the $\mathrm{C} 1$ family (Brose et al., 2004). Phorbol esters also potentiate neurotransmitter release in a great number of preparations (Silinsky and Searl, 2003). We treated chromaffin cells with the synthetic phorbol ester PMA and asked whether phorbol ester induced potentiation of secretion could be impaired when Munc18-1 is absent in vivo.

We found no detectable impairment on the degree of PMA induced potentiation when Munc18-1 was absent in mouse chromaffin cells (Figure 20), which suggests that Munc18-1 is not a major PKC target in large dense-core vesicle exocytosis. To confirm this idea, we are currently testing the S306A/S312A/S313A Munc18-1 mutant, which cannot be phosphorylated by PKC. If PMA induced potentiation is normal when this triple mutation is present in Munc18-1, then we can exclude Munc18-1 as a physiologically important link between the diacylglycerol pathway and catecholamine secretion in chromaffin cells.

Interestingly it was reported using permeabilized chromaffin cells that overexpression of the phosphomimetic double mutant S306E/S313E Munc18-1 changes single vesicle release kinetics without potentiation of $\mathrm{Ca}^{2+}$ induced responses (Barclay et al., 2003). When the $S \rightarrow E$ mutation was introduced to only one or the other site (306 or 


\section{Discussion}

313) the single fusion events measured by amperometry were completely normal (Barclay et al., 2003).

The phorbol ester PMA potentiated not only catecholamine release (Figure 20) but also large dense-core vesicle docking at morphological level (M. Verhage, personal communications). It is tempting to believe that there is a casual relationship between the observed increased docking and increased secretion. However the action of PMA on the cortical F-actin ring and large dense-core vesicle docking was shown to be reminiscent to that of latrunculin A in bovine chromaffin cells (Vitale et al., 1995; Gil et al., 2000). In the present study we found that latrunculin A cannot potentiate catecholamine release in Munc18-1 null cells (Figure 15) despite strong potentiation in morphological docking. These findings raise another scenario, in which PMA increases the size of the morphologically docked vesicle pool and the size of the releasable pools by separate mechanisms.

This scenario is not unlikely because in chromaffin cells PKC seems to regulate multiple steps of large dense-core vesicle exocytosis: PKC was shown to control releasable pool refilling (Nagy et al., 2002) and the size of a highly $\mathrm{Ca}^{2+}$ sensitive pool (Yang et al., 2002). Moreover, Munc13-1, an important phorbol ester target in presynaptic function (Rhee et al., 2002), was demonstrated to promote vesicle priming in chromaffin cells (Ashery et al., 2000). Our observation that only the burst phase but not the sustained component of the flash responses was potentiated by PMA implies that the diacylglycerol pathway predominantly targets vesicle depriming $\left(\mathrm{k}_{-1}\right.$ on Figure $\left.4 \mathrm{~B}\right)$ and stimulation of this pathway helps retaining vesicles in the releasable pools. A very similar phenomenon was seen when different SNAP-25 isoforms were expressed and it was concluded that the functional difference between the isoforms is due to differential depriming rate $\mathrm{k}_{-1}$ shown in Figure 4B and Figure 7C (Sorensen et al., 2003b).

Whatever are the major molecular links between the diacylglycerol pathway and large dense-core vesicle exocytosis, it seems unlikely that Munc18-1 is one of them. What else, if not PKC, could regulate the physiological function of Munc18-1? Another kinase candidate is the cyclin dependent kinase $5(\mathrm{Cdk} 5)$, which phosphorylates Munc181 and thereby disassembles the syntaxin1-Munc18-1 complex in vitro (Fletcher et al., 1999). Recently it was shown that Cdk5 overexpression strongly increases exocytosis in pancreatic $\beta$-cells and this increase was completely due to the Cdk5 mediated phosphorylation of Munc18-1 (Lilja et al., 2004).

A further possible regulation form could be at the level of gene expression. Heterozygous mice carrying the Munc18-1 null mutation express 50\% less Munc18-1 in the adrenal gland (Voets et al., 2001b) and now we showed that this reduction in the protein level downregulates vesicle docking by $\sim 60 \%$ (Figure 11). Conversely, increased Munc18-1 protein expression upregulated vesicle docking and catecholamine release (Figure 11-12). 
Summary of the thesis 
Neurotransmitter and hormon release is based on $\mathrm{Ca}^{2+}$ dependent exocytosis. The sequential steps of exocytosis are executed by proteins and protein complexes. Formation of the SNARE complex is essential in later steps of exocytosis. The Sec1/Munc18 proteins are also essential in exocytosis and other membrane trafficking processes but their molecular and cellular function is less clear than that of the SNARE proteins.

In our work we studied the role of Munc18 in large dense-core vesicle exocytosis in adrenal chromaffin cells. We combined complementary techniques (electrophysiology, electronmicroscopy) to assay docking, priming and $\mathrm{Ca}^{2+}$ triggered fusion of the vesicles.

First, we further confirmed the view that Munc18-1 is a positive regulator of large dense-core vesicle exocytosis (Voets et al., 2001b). Second, we were interested the downstream molecular targets of Munc18-1 therefore we studied the physiological role of Munc18-1/syntaxin1 interaction. We showed that this interaction is highly important in functional vesicle docking but further experiments are needed to decide whether it is the only major factor or there are other essential downstream targets for Munc18-1. Third, we studied different Munc18 isoforms and our results imply that Munc18 may act not only at the docking but also at the priming step of large dense-core exocytosis. Although some publications argue for the regulatory role of Munc18 in single vesicle fusion kinetics, we found no sign for the direct involvement of Munc18 in $\mathrm{Ca}^{2+}$ triggered fusion. Fourth, we also focused on the upstream regulation of Munc18-1. We obtained opposing data to the hypothesis that Munc18-1 is an important element of the phorbol ester induced potentiation of catecholamine release in the diacylglycerol (DAG) route. The DAG pathway remains an important but poorly understood regulator of transmitter/hormon release, which probably has multiple branches targeting multiple molecules and exocytic steps.

Taken together, our findings provided inspiring hints about many aspects of Munc18 function in $\mathrm{Ca}^{2+}$ dependent exocytosis. Perhaps the most important aspect is to match the consecutive steps of exocytosis with the molecular happenings along the Munc18/syntaxin complex - SNARE complex axis (Figure 23). Our complementary assays combined with the gene knockout and rescue technique could promote adrenal chromaffin cells to become the first system where this match between cellular function and molecular structure is clarified. 
Appendix: applied methods 


\section{Chromaffin cell culture}

Bovine chromaffin cell preparation was made as described previously (Nagy et al., 2002). Briefly, bovine adrenal glands were collected injected with Locke's solution containing collagenase and opened. The medulla was gently minced on a neylon mesh with $50 \mu \mathrm{m}$ pore diameter to physically dissociate cells. The cell suspension was then centrifuged and the supernatant, containing erytrocytes was removed. The cells were resuspended in enriched DMEM medium (Linaris, Wertheim-Bettingen, Germany) and plated on sterile coverslips in 6 well plates. The cultures were kept at $37^{\circ} \mathrm{C}$ and at $8 \%$ $\mathrm{CO}_{2}$ for 4-5 days. The enriched DMEM solution contained $2.2 \mathrm{~g} / 1 \mathrm{NaHCO}_{3}, 4.5 \mathrm{~g} / \mathrm{l} \mathrm{D}-$ glucose, $1.028 \mathrm{~g} / 1 \mathrm{~L}$-glutamine, $10 \mathrm{ml} / 1$ insulin transferrin selenium-X (Invitrogen) and 1:250 penicillin + streptomycin $(10,000 \mathrm{U} / \mathrm{ml}$, Invitrogen $)$.

Embryonic and newborn mouse chromaffin cell culture was prepared as previously described (Sorensen et al., 2003b). Briefly, embryos - recovered with Caesarian section from the mother - or newborn mice were killed and both adrenal glands were removed. The glands were incubated with $0.2 \mathrm{ml}$ papain solution at $37^{\circ} \mathrm{C}$ for 40 minutes in a shaking waterbath. The papain solution contained $250 \mathrm{ml}$ DMEM, and 20-25 unit/ml papain (Worthington, Lakewood, NJ) equilibrated with $5 \% \mathrm{CO}_{2}$. Next $0.15 \mathrm{ml}$ inactivating solution was added to the papain solution. Inactivating solution: $225 \mathrm{ml}$ DMEM supplemented with $25 \mathrm{ml}$ heat activated fetal calf serum, $625 \mathrm{mg}$ albumin, 625 $\mathrm{mg}$ trypsin inhibitor (Sigma). The solution was then replaced with enriched DMEM solution (see above) and the glands were triturated gently with a $200 \mu$ l pipette tip until the cells were suspended. The mouse cell suspension was plated similarly to the bovine cell suspension.

\section{Electrophysiological recordings}

Membrane capacitance measurements, carbon fiber amperometry, ratiometric intracellular $\left[\mathrm{Ca}^{2+}\right]$ measurements were performed at room temperature as described previously (Nagy et al., 2002). Whole cell recordings were done with Sylgard coated patch pipettes (Kimax-51; Kimble/Kontes, Vineland, NJ) with 4-8 M $\Omega$ resistance in the bath solution. A single EPC-9 amplifier was used with the Pulse software (v 8.53), both from HEKA Electronics, Lambrecht, Germany. Capacitance was measured with the Lindau-Neher technique using the virtual lockin amplifier of Pulse: a $1 \mathrm{kHz}, 70 \mathrm{mV}$ peakto-peak amplitude sinusoid voltage stimulus was superimposed onto a DC holding potential $(-70 \mathrm{mV})$. Currents were filtered at $3 \mathrm{kHz}$ and sampled at $12 \mathrm{kHz}$.

Carbon fiber amperometry was done as described (Sorensen et al., 2003b). Briefly, $10 \mu \mathrm{m}$ thick carbon microfibers were fastened to a copper wire then electrically insulated. A sensitive surface was obtained by cutting the fiber with a razorblade. A constant voltage ( $+0.7 \mathrm{~V}$ in reference to the bath electrode) was applied. The amperometric current was recorded with an EPC-7 amplifier (HEKA) with $12 \mathrm{kHz}$ sampling frequency and $3 \mathrm{kHz}$ lowpass filtering. 
Photolysis of caged $\mathrm{Ca}^{2+}$ and intracellular $\left[\mathrm{Ca}^{2+}\right]$ measurements were done as described previously (Sorensen et al., 2002). Flashes of UV light were given by a flash lamp (Rapp Optoelektronik, Hamburg, Germany) and fluorescent excitation light was generated by a Polychrome IV monochromator (TILL Photonics, Planegg, Germany). These light sources were coupled with a light cable to the epifluorescence port of an inverted Axovert 10 microscope with a 40x Fluor objective (Zeiss, Oberkochen, Germany). The fluorescent dyes (see recording solutions) were excited at 350/380 nm. The intracellular $\left[\mathrm{Ca}^{2+}\right]$ was calculated from the ratio of the emitted fluorescent ratio according to an 'in vivo $\mathrm{Ca}^{2+}$ calibration list' (Voets, 2000).

\section{Data analysis, parameters, statistics}

The recorded and digitized signals were analyzed with Igor Pro (Wavemetrics, USA). The fast and slow burst amplitudes and time constants $\left(\tau_{\text {fast }}\right.$ and $\left.\tau_{\text {slow }}\right)$ were derived from the membrane capacitance traces after fitting the following formula:

$$
\begin{gathered}
\mathrm{f}(\mathrm{t})=\mathrm{A}_{0}+\mathrm{A}_{1}\left(1-\exp \left(-\left(\mathrm{t}-\mathrm{t}_{0}\right) / \tau_{1}\right)+\mathrm{A}_{2}\left(1-\exp \left(-\left(\mathrm{t}-\mathrm{t}_{0}\right) / \tau_{2}\right)+\mathrm{A}_{3}\left(1-\exp \left(-\left(\mathrm{t}-\mathrm{t}_{0}\right) / \tau_{3}\right)\right.\right.\right. \\
\text { where } \\
\mathrm{A} 1:=\text { fast burst amplitude } \\
\mathrm{A} 2:=\text { slow burst amplitude } \\
\tau_{1}:=\tau_{\text {fast }} \\
\tau_{2}:=\tau_{\text {slow }}
\end{gathered}
$$

The overall 'burst' amplitude was defined as the capacitance change between $\mathrm{t}=0 \mathrm{~s}$ and $\mathrm{t}=0.5 \mathrm{~s}$ relative to $\mathrm{t}_{0}$ and served as a 'fit independent parameter' to study releasable pool sizes. Similarly, the sustained amplitude was defined as capacitance change between $\mathrm{t}=0.5 \mathrm{~s}$ and $\mathrm{t}=5.0 \mathrm{~s}$.

Data are always presented as mean \pm S.E.M. The nonparametric Mann-Whitney test was used to compare experimental groups and test statistical significance.

\section{Solutions for electrophysiology}

The recording bath solution contained (in $\mathrm{mM}$ ): $145 \mathrm{NaCl}, 2.8 \mathrm{KCl}, 2 \mathrm{CaCl}_{2}, 1$ $\mathrm{MgCl}_{2}, 10$ HEPES plus $1 \mathrm{mg} / \mathrm{ml}$ D-glucose, $\mathrm{pH}$ 7.2, 300 mOsm. Latrunculin A (Calbiochem) was dissolved in DMSO and stocked in $10 \mathrm{mM}$ at $-20^{\circ} \mathrm{C}$. In the 'preincubation experiments', latrunculin A stock solution was diluted in the enriched DMEM medium in a final concentration of 1-2 $\mu \mathrm{M}$. In the 'local application experiments' the latrunculin A stock solution was diluted to $50 \mu \mathrm{M}$ in the recording bath solution. This solution was applied from a glass pipette using constant pressure. PMA and 4- $\alpha-P M A$ (both from Sigma) was kept in $100 \mu \mathrm{M}$ stock solutions dissolved in DMSO at $-20^{\circ} \mathrm{C}$. Before the recordings the stock solutions were diluted in the recording bath solution and applied locally from a glass pipette similarly to latrunculin A. 
The patch pipette solution contained (in $\mathrm{mM}$ ): 100 Cs-glutamate, $8 \mathrm{NaCl}, 4$ $\mathrm{CaCl}_{2}$, 32 HEPES, 2 MgATP, 0.3 GTP, 5 nitrophenyl-EGTA (supplied by G. EllisDavies, MCP Hahnemann University, Philadelphia, PA), 0.3 Fura-4F (Molecular Probes), 0.3 Magfura-2 (Molecular Probes), pH 7.2.

\section{Viral constructs and overexpression}

The viral vector pSFV1 (Invitrogen, San Diego, CA) was modified as described previously (Nagy et al., 2002). Green fluorescent protein (GFP)-Munc18-1 or Munc18-2 was cloned into the modified pSFV1 vector. Munc18-1 mutants were generated by sitedirected mutagenesis using PCR. Virus production was done as described (Ashery et al., 1999). $450 \mu 1$ of virus solution was activated by $100 \mu$ chymotripsin $(2 \mathrm{mg} / \mathrm{ml}$;

Boehringer Mannheim, Germany). After activation $110 \mu \mathrm{l}$ aprotinin $(6 \mathrm{mg} / \mathrm{ml}$;

Boehringer Mannheim, Germany) was added to inactivate chymotripsin. Cells were

infected 1-3 day after preparation of the cell culture. Electrophysiological recordings and fixation for electron microscopy was normally performed 4-6 hours after infection. GFP expression was checked using an excitation light at $475 \mathrm{~nm}$ wavelength. 


\section{References}


Antonin W, Fasshauer D, Becker S, Jahn R, Schneider TR (2002) Crystal structure of the endosomal SNARE complex reveals common structural principles of all SNAREs. Nat Struct Biol 9:107-111.

Ashery U, Betz A, Xu T, Brose N, Rettig J (1999) An efficient method for infection of adrenal chromaffin cells using the Semliki Forest virus gene expression system. Eur J Cell Biol 78:525-532.

Ashery U, Varoqueaux F, Voets T, Betz A, Thakur P, Koch H, Neher E, Brose N, Rettig J (2000) Munc13-1 acts as a priming factor for large dense-core vesicles in bovine chromaffin cells. Embo J 19:3586-3596.

Augustin I, Rosenmund C, Sudhof TC, Brose N (1999) Munc13-1 is essential for fusion competence of glutamatergic synaptic vesicles. Nature 400:457-461.

Barclay JW, Craig TJ, Fisher RJ, Ciufo LF, Evans GJ, Morgan A, Burgoyne RD (2003) Phosphorylation of Munc 18 by protein kinase $\mathrm{C}$ regulates the kinetics of exocytosis. J Biol Chem 278:10538-10545.

Baumert M, Maycox PR, Navone F, De Camilli P, Jahn R (1989) Synaptobrevin: an integral membrane protein of 18,000 daltons present in small synaptic vesicles of rat brain. Embo J 8:379-384.

Bennett MK, Calakos N, Scheller RH (1992) Syntaxin: a synaptic protein implicated in docking of synaptic vesicles at presynaptic active zones. Science 257:255-259.

Betz A, Okamoto M, Benseler F, Brose N (1997) Direct interaction of the rat unc-13 homologue Munc13-1 with the N terminus of syntaxin. J Biol Chem 272:25202526.

Betz WJ, Bewick GS (1993) Optical monitoring of transmitter release and synaptic vesicle recycling at the frog neuromuscular junction. J Physiol 460:287-309.

Blasi J, Binz T, Yamasaki S, Link E, Niemann H, Jahn R (1994) Inhibition of neurotransmitter release by clostridial neurotoxins correlates with specific proteolysis of synaptosomal proteins. J Physiol Paris 88:235-241.

Brenner S (1974) The genetics of Caenorhabditis elegans. Genetics 77:71-94.

Brose N, Betz A, Wegmeyer H (2004) Divergent and convergent signaling by the diacylglycerol second messenger pathway in mammals. Curr Opin Neurobiol 14:328-340.

Brose N, Petrenko AG, Sudhof TC, Jahn R (1992) Synaptotagmin: a calcium sensor on the synaptic vesicle surface. Science 256:1021-1025.

Bruns D (2004) Detection of transmitter release with carbon fiber electrodes. Methods 33:312-321. 
Burgoyne RD, Fisher RJ, Graham ME, Haynes LP, Morgan A (2001) Control of membrane fusion dynamics during regulated exocytosis. Biochem Soc Trans 29:467-472.

Catterall WA (1999) Interactions of presynaptic Ca2+ channels and snare proteins in neurotransmitter release. Ann N Y Acad Sci 868:144-159.

Ceccarelli B, Hurlbut WP, Mauro A (1973) Turnover of transmitter and synaptic vesicles at the frog neuromuscular junction. J Cell Biol 57:499-524.

Chow RH, Klingauf J, Heinemann C, Zucker RS, Neher E (1996) Mechanisms determining the time course of secretion in neuroendocrine cells. Neuron 16:369376.

Craig TJ, Evans GJ, Morgan A (2003) Physiological regulation of Munc18/nSec1 phosphorylation on serine-313. J Neurochem 86:1450-1457.

Del Castillo J, Katz B (1954) Quantal components of the end-plate potential. J Physiol 124:560-573.

Dodge FA, Jr., Rahamimoff R (1967) Co-operative action a calcium ions in transmitter release at the neuromuscular junction. J Physiol 193:419-432.

Dresbach T, Burns ME, O'Connor V, DeBello WM, Betz H, Augustine GJ (1998) A neuronal Sec1 homolog regulates neurotransmitter release at the squid giant synapse. J Neurosci 18:2923-2932.

Dulubova I, Sugita S, Hill S, Hosaka M, Fernandez I, Sudhof TC, Rizo J (1999) A conformational switch in syntaxin during exocytosis: role of munc18. Embo J 18:4372-4382.

Duncan RR, Betz A, Shipston MJ, Brose N, Chow RH (1999) Transient, phorbol esterinduced DOC2-Munc13 interactions in vivo. J Biol Chem 274:27347-27350.

Elmqvist D, Quastel DM (1965) A quantitative study of end-plate potentials in isolated human muscle. J Physiol 178:505-529.

Fasshauer D (2003) Structural insights into the SNARE mechanism. Biochim Biophys Acta 1641:87-97.

Fasshauer D, Otto H, Eliason WK, Jahn R, Brunger AT (1997) Structural changes are associated with soluble N-ethylmaleimide-sensitive fusion protein attachment protein receptor complex formation. J Biol Chem 272:28036-28041.

Fatt P, Katz B (1952) Spontaneous subthreshold activity at motor nerve endings. J Physiol 117:109-128.

Fernandez I, Ubach J, Dulubova I, Zhang X, Sudhof TC, Rizo J (1998) Threedimensional structure of an evolutionarily conserved N-terminal domain of syntaxin 1A. Cell 94:841-849. 
Fernandez JM, Neher E, Gomperts BD (1984) Capacitance measurements reveal stepwise fusion events in degranulating mast cells. Nature 312:453-455.

Fernandez-Chacon R, Konigstorfer A, Gerber SH, Garcia J, Matos MF, Stevens CF, Brose N, Rizo J, Rosenmund C, Sudhof TC (2001) Synaptotagmin I functions as a calcium regulator of release probability. Nature 410:41-49.

Fisher RJ, Pevsner J, Burgoyne RD (2001) Control of fusion pore dynamics during exocytosis by Munc18. Science 291:875-878.

Fletcher AI, Shuang R, Giovannucci DR, Zhang L, Bittner MA, Stuenkel EL (1999) Regulation of exocytosis by cyclin-dependent kinase 5 via phosphorylation of Munc18. J Biol Chem 274:4027-4035.

Fujita Y, Sasaki T, Fukui K, Kotani H, Kimura T, Hata Y, Sudhof TC, Scheller RH, Takai Y (1996) Phosphorylation of Munc-18/n-Sec1/rbSec1 by protein kinase C: its implication in regulating the interaction of Munc-18/n-Sec1/rbSec1 with syntaxin. J Biol Chem 271:7265-7268.

Garcia EP, Gatti E, Butler M, Burton J, De Camilli P (1994) A rat brain Sec1 homologue related to Rop and UNC18 interacts with syntaxin. Proc Natl Acad Sci U S A 91:2003-2007.

Geppert M, Goda Y, Hammer RE, Li C, Rosahl TW, Stevens CF, Sudhof TC (1994) Synaptotagmin I: a major $\mathrm{Ca} 2+$ sensor for transmitter release at a central synapse. Cell 79:717-727.

Gil A, Rueda J, Viniegra S, Gutierrez LM (2000) The F-actin cytoskeleton modulates slow secretory components rather than readily releasable vesicle pools in bovine chromaffin cells. Neuroscience 98:605-614.

Gladycheva SE, Ho CS, Lee YY, Stuenkel EL (2004) Regulation of syntaxin1A-munc18 complex for SNARE pairing in HEK293 cells. J Physiol 558:857-871.

Graham ME, Barclay JW, Burgoyne RD (2004) Syntaxin/Munc18 interactions in the late events during vesicle fusion and release in exocytosis. J Biol Chem 279:3275132760 .

Hamill OP, Marty A, Neher E, Sakmann B, Sigworth FJ (1981) Improved patch-clamp techniques for high-resolution current recording from cells and cell-free membrane patches. Pflugers Arch 391:85-100.

Harrison SD, Broadie K, van de Goor J, Rubin GM (1994) Mutations in the Drosophila Rop gene suggest a function in general secretion and synaptic transmission. Neuron 13:555-566.

Hata Y, Sudhof TC (1995) A novel ubiquitous form of Munc-18 interacts with multiple syntaxins. Use of the yeast two-hybrid system to study interactions between proteins involved in membrane traffic. J Biol Chem 270:13022-13028. 
Hata Y, Slaughter CA, Sudhof TC (1993) Synaptic vesicle fusion complex contains unc18 homologue bound to syntaxin. Nature 366:347-351.

Heeroma JH, Roelandse M, Wierda K, van Aerde KI, Toonen RF, Hensbroek RA, Brussaard A, Matus A, Verhage M (2004) Trophic support delays but does not prevent cell-intrinsic degeneration of neurons deficient for munc18-1. Eur J Neurosci 20:623-634.

Heuser JE, Reese TS (1973) Evidence for recycling of synaptic vesicle membrane during transmitter release at the frog neuromuscular junction. J Cell Biol 57:315-344.

Heuser JE, Reese TS, Dennis MJ, Jan Y, Jan L, Evans L (1979) Synaptic vesicle exocytosis captured by quick freezing and correlated with quantal transmitter release. J Cell Biol 81:275-300.

Ho A, Morishita W, Hammer RE, Malenka RC, Sudhof TC (2003) A role for Mints in transmitter release: Mint 1 knockout mice exhibit impaired GABAergic synaptic transmission. Proc Natl Acad Sci U S A 100:1409-1414.

Hosono R, Hekimi S, Kamiya Y, Sassa T, Murakami S, Nishiwaki K, Miwa J, Taketo A, Kodaira KI (1992) The unc-18 gene encodes a novel protein affecting the kinetics of acetylcholine metabolism in the nematode Caenorhabditis elegans. $\mathrm{J}$ Neurochem 58:1517-1525.

Hu C, Ahmed M, Melia TJ, Sollner TH, Mayer T, Rothman JE (2003) Fusion of cells by flipped SNAREs. Science 300:1745-1749.

Jaffe LA, Hagiwara S, Kado RT (1978) The time course of cortical vesicle fusion in sea urchin eggs observed as membrane capacitance changes. Dev Biol 67:243-248.

Jahn R (2000) Sec1/Munc18 proteins: mediators of membrane fusion moving to center stage. Neuron 27:201-204.

Jahn R, Sudhof TC (1999) Membrane fusion and exocytosis. Annu Rev Biochem 68:863911.

Jessell TM, Kandel ER (1993) Synaptic transmission: a bidirectional and self-modifiable form of cell-cell communication. Cell 72 Suppl:1-30.

Katagiri H, Terasaki J, Murata T, Ishihara H, Ogihara T, Inukai K, Fukushima Y, Anai M, Kikuchi M, Miyazaki J (1995) A novel isoform of syntaxin-binding protein homologous to yeast Sec1 expressed ubiquitously in mammalian cells. J Biol Chem 270:4963-4966.

Katz B, Miledi R (1967a) Tetrodotoxin and neuromuscular transmission. Proc R Soc Lond B Biol Sci 167:8-22.

Katz B, Miledi R (1967b) Ionic requirements of synaptic transmitter release. Nature 215:651. 
Khan AH, Thurmond DC, Yang C, Ceresa BP, Sigmund CD, Pessin JE (2001) Munc18c regulates insulin-stimulated glut4 translocation to the transverse tubules in skeletal muscle. J Biol Chem 276:4063-4069.

Koh TW, Bellen HJ (2003) Synaptotagmin I, a Ca2+ sensor for neurotransmitter release. Trends Neurosci 26:413-422.

Leszczyszyn DJ, Jankowski JA, Viveros OH, Diliberto EJ, Jr., Near JA, Wightman RM (1991) Secretion of catecholamines from individual adrenal medullary chromaffin cells. J Neurochem 56:1855-1863.

Lilja L, Johansson JU, Gromada J, Mandic SA, Fried G, Berggren PO, Bark C (2004) Cyclin-dependent kinase 5 associated with $\mathrm{p} 39$ promotes Munc18-1 phosphorylation and $\mathrm{Ca}(2+)$-dependent exocytosis. J Biol Chem 279:2953429541.

Locke FS (1894) Notiz über den Einfluß physiologischer Kohlsalzlösung auf die elektronische Erregbarkeit von Muskel und Nerv. Zentralb Physiol 8:166-167.

Misura KM, Scheller RH, Weis WI (2000) Three-dimensional structure of the neuronalSec1-syntaxin 1a complex. Nature 404:355-362.

Nagy G, Matti U, Nehring RB, Binz T, Rettig J, Neher E, Sorensen JB (2002) Protein kinase C-dependent phosphorylation of synaptosome-associated protein of 25 $\mathrm{kDa}$ at Ser187 potentiates vesicle recruitment. J Neurosci 22:9278-9286.

Nagy G, Reim K, Matti U, Brose N, Binz T, Rettig J, Neher E, Sorensen JB (2004) Regulation of releasable vesicle pool sizes by protein kinase A-dependent phosphorylation of SNAP-25. Neuron 41:417-429.

Naren AP, Nelson DJ, Xie W, Jovov B, Pevsner J, Bennett MK, Benos DJ, Quick MW, Kirk KL (1997) Regulation of CFTR chloride channels by syntaxin and Munc18 isoforms. Nature 390:302-305.

Neher E (1998) Vesicle pools and Ca2+ microdomains: new tools for understanding their roles in neurotransmitter release. Neuron 20:389-399.

Novick P, Schekman R (1979) Secretion and cell-surface growth are blocked in a temperature-sensitive mutant of Saccharomyces cerevisiae. Proc Natl Acad Sci U S A 76:1858-1862.

Ossig R, Dascher C, Trepte HH, Schmitt HD, Gallwitz D (1991) The yeast SLY gene products, suppressors of defects in the essential GTP-binding Ypt1 protein, may act in endoplasmic reticulum-to-Golgi transport. Mol Cell Biol 11:2980-2993.

Oyler GA, Higgins GA, Hart RA, Battenberg E, Billingsley M, Bloom FE, Wilson MC (1989) The identification of a novel synaptosomal-associated protein, SNAP-25, differentially expressed by neuronal subpopulations. J Cell Biol 109:3039-3052. 
Peters C, Bayer MJ, Buhler S, Andersen JS, Mann M, Mayer A (2001) Trans-complex formation by proteolipid channels in the terminal phase of membrane fusion. Nature 409:581-588.

Pevsner J, Hsu SC, Scheller RH (1994a) n-Sec1: a neural-specific syntaxin-binding protein. Proc Natl Acad Sci U S A 91:1445-1449.

Pevsner J, Hsu SC, Braun JE, Calakos N, Ting AE, Bennett MK, Scheller RH (1994b) Specificity and regulation of a synaptic vesicle docking complex. Neuron 13:353361.

Plattner H, Artalejo AR, Neher E (1997) Ultrastructural organization of bovine chromaffin cell cortex-analysis by cryofixation and morphometry of aspects pertinent to exocytosis. J Cell Biol 139:1709-1717.

Rettig J, Neher E (2002) Emerging roles of presynaptic proteins in Ca++-triggered exocytosis. Science 298:781-785.

Rhee JS, Betz A, Pyott S, Reim K, Varoqueaux F, Augustin I, Hesse D, Sudhof TC, Takahashi M, Rosenmund C, Brose N (2002) Beta phorbol ester- and diacylglycerol-induced augmentation of transmitter release is mediated by Munc13s and not by PKCs. Cell 108:121-133.

Richmond JE, Weimer RM, Jorgensen EM (2001) An open form of syntaxin bypasses the requirement for UNC-13 in vesicle priming. Nature 412:338-341.

Riento K, Kauppi M, Keranen S, Olkkonen VM (2000) Munc18-2, a functional partner of syntaxin 3, controls apical membrane trafficking in epithelial cells. J Biol Chem 275:13476-13483.

Rizo J, Sudhof TC (2002) Snares and Munc18 in synaptic vesicle fusion. Nat Rev Neurosci 3:641-653.

Rowe J, Corradi N, Malosio ML, Taverna E, Halban P, Meldolesi J, Rosa P (1999) Blockade of membrane transport and disassembly of the Golgi complex by expression of syntaxin 1A in neurosecretion-incompetent cells: prevention by rbSEC1. J Cell Sci 112 ( Pt 12):1865-1877.

Schiavo G, Matteoli M, Montecucco C (2000) Neurotoxins affecting neuroexocytosis. Physiol Rev 80:717-766.

Schneggenburger R, Meyer AC, Neher E (1999) Released fraction and total size of a pool of immediately available transmitter quanta at a calyx synapse. Neuron 23:399409.

Schoch S, Deak F, Konigstorfer A, Mozhayeva M, Sara Y, Sudhof TC, Kavalali ET (2001) SNARE function analyzed in synaptobrevin/VAMP knockout mice. Science 294:1117-1122.

Schulze KL, Littleton JT, Salzberg A, Halachmi N, Stern M, Lev Z, Bellen HJ (1994) rop, a Drosophila homolog of yeast Sec1 and vertebrate n-Sec1/Munc-18 
proteins, is a negative regulator of neurotransmitter release in vivo. Neuron 13:1099-1108.

Shao X, Li C, Fernandez I, Zhang X, Sudhof TC, Rizo J (1997) Synaptotagmin-syntaxin interaction: the $\mathrm{C} 2$ domain as a $\mathrm{Ca} 2+$-dependent electrostatic switch. Neuron 18:133-142.

Silinsky EM, Searl TJ (2003) Phorbol esters and neurotransmitter release: more than just protein kinase C? Br J Pharmacol 138:1191-1201.

Smith C, Neher E (1997) Multiple forms of endocytosis in bovine adrenal chromaffin cells. J Cell Biol 139:885-894.

Sollner T, Whiteheart SW, Brunner M, Erdjument-Bromage H, Geromanos S, Tempst P, Rothman JE (1993) SNAP receptors implicated in vesicle targeting and fusion. Nature 362:318-324.

Sons MS, Verhage M, Plomp JJ (2003) Role of Munc18-1 in synaptic plasticity at the myasthenic neuromuscular junction. Ann N Y Acad Sci 998:404-406.

Sorensen JB (2004) Formation, stabilisation and fusion of the readily releasable pool of secretory vesicles. Pflugers Arch 448:347-362.

Sorensen JB, Fernandez-Chacon R, Sudhof TC, Neher E (2003a) Examining synaptotagmin 1 function in dense core vesicle exocytosis under direct control of Ca2+. J Gen Physiol 122:265-276.

Sorensen JB, Nagy G, Varoqueaux F, Nehring RB, Brose N, Wilson MC, Neher E (2003b) Differential control of the releasable vesicle pools by SNAP-25 splice variants and SNAP-23. Cell 114:75-86.

Sorensen JB, Matti U, Wei SH, Nehring RB, Voets T, Ashery U, Binz T, Neher E, Rettig $\mathrm{J}$ (2002) The SNARE protein SNAP-25 is linked to fast calcium triggering of exocytosis. Proc Natl Acad Sci U S A 99:1627-1632.

Stevens CF (2003) Neurotransmitter release at central synapses. Neuron 40:381-388.

Sudhof TC (2004) The synaptic vesicle cycle. Annu Rev Neurosci 27:509-547.

Sutton RB, Fasshauer D, Jahn R, Brunger AT (1998) Crystal structure of a SNARE complex involved in synaptic exocytosis at 2.4 A resolution. Nature 395:347-353.

Tamori Y, Kawanishi M, Niki T, Shinoda H, Araki S, Okazawa H, Kasuga M (1998) Inhibition of insulin-induced GLUT4 translocation by Munc18c through interaction with syntaxin4 in 3T3-L1 adipocytes. J Biol Chem 273:19740-19746.

Tellam JT, McIntosh S, James DE (1995) Molecular identification of two novel Munc-18 isoforms expressed in non-neuronal tissues. J Biol Chem 270:5857-5863.

Toonen RF, Verhage M (2003) Vesicle trafficking: pleasure and pain from SM genes. Trends Cell Biol 13:177-186. 
Trimble WS, Cowan DM, Scheller RH (1988) VAMP-1: a synaptic vesicle-associated integral membrane protein. Proc Natl Acad Sci U S A 85:4538-4542.

Verhage M, Maia AS, Plomp JJ, Brussaard AB, Heeroma JH, Vermeer H, Toonen RF, Hammer RE, van den Berg TK, Missler M, Geuze HJ, Sudhof TC (2000) Synaptic assembly of the brain in the absence of neurotransmitter secretion. Science 287:864-869.

Vitale ML, Seward EP, Trifaro JM (1995) Chromaffin cell cortical actin network dynamics control the size of the release-ready vesicle pool and the initial rate of exocytosis. Neuron 14:353-363.

Voets T (2000) Dissection of three Ca2+-dependent steps leading to secretion in chromaffin cells from mouse adrenal slices. Neuron 28:537-545.

Voets T, Neher E, Moser T (1999) Mechanisms underlying phasic and sustained secretion in chromaffin cells from mouse adrenal slices. Neuron 23:607-615.

Voets T, Moser T, Lund PE, Chow RH, Geppert M, Sudhof TC, Neher E (2001a) Intracellular calcium dependence of large dense-core vesicle exocytosis in the absence of synaptotagmin I. Proc Natl Acad Sci U S A 98:11680-11685.

Voets T, Toonen RF, Brian EC, de Wit H, Moser T, Rettig J, Sudhof TC, Neher E, Verhage M (2001b) Munc18-1 promotes large dense-core vesicle docking. Neuron 31:581-591.

von Ruden L, Neher E (1993) A Ca-dependent early step in the release of catecholamines from adrenal chromaffin cells. Science 262:1061-1065.

Wang C, Tammi M, Tammi R (1992) Distribution of hyaluronan and its CD44 receptor in the epithelia of human skin appendages. Histochemistry 98:105-112.

Washbourne P, Thompson PM, Carta M, Costa ET, Mathews JR, Lopez-Bendito G, Molnar Z, Becher MW, Valenzuela CF, Partridge LD, Wilson MC (2002) Genetic ablation of the t-SNARE SNAP-25 distinguishes mechanisms of neuroexocytosis. Nat Neurosci 5:19-26.

Weber T, Zemelman BV, McNew JA, Westermann B, Gmachl M, Parlati F, Sollner TH, Rothman JE (1998) SNAREpins: minimal machinery for membrane fusion. Cell 92:759-772.

Wei S, Xu T, Ashery U, Kollewe A, Matti U, Antonin W, Rettig J, Neher E (2000) Exocytotic mechanism studied by truncated and zero layer mutants of the Cterminus of SNAP-25. Embo J 19:1279-1289.

Wightman RM, Jankowski JA, Kennedy RT, Kawagoe KT, Schroeder TJ, Leszczyszyn DJ, Near JA, Diliberto EJ, Jr., Viveros OH (1991) Temporally resolved catecholamine spikes correspond to single vesicle release from individual chromaffin cells. Proc Natl Acad Sci U S A 88:10754-10758. 
Wu MN, Littleton JT, Bhat MA, Prokop A, Bellen HJ (1998) ROP, the Drosophila Sec1 homolog, interacts with syntaxin and regulates neurotransmitter release in a dosage-dependent manner. Embo J 17:127-139.

Xu T, Binz T, Niemann H, Neher E (1998) Multiple kinetic components of exocytosis distinguished by neurotoxin sensitivity. Nat Neurosci 1:192-200.

Yang Y, Udayasankar S, Dunning J, Chen P, Gillis KD (2002) A highly Ca2+-sensitive pool of vesicles is regulated by protein kinase $\mathrm{C}$ in adrenal chromaffin cells. Proc Natl Acad Sci U S A 99:17060-17065.

Yizhar O, Matti U, Melamed R, Hagalili Y, Bruns D, Rettig J, Ashery U (2004) Tomosyn inhibits priming of large dense-core vesicles in a calcium-dependent manner. Proc Natl Acad Sci U S A.

Zamponi GW (2003) Regulation of presynaptic calcium channels by synaptic proteins. J Pharmacol Sci 92:79-83.

Zucker RS (1999) Calcium- and activity-dependent synaptic plasticity. Curr Opin Neurobiol 9:305-313. 
Lebenslauf

Attila Gulyás-Kovács

15.04.1976 geboren in Budapest als Sohn von István Gulyás-Kovács und Mária Molnár Ungarischer Staatsangehöriger

Juni 1994 Abitur am Táncsics Mihály Gimnázium, Budapest

September Studium der Biologie an der ELTE Universität, Budapest 1994-Juni 2000

September 1998-Juni 2000

September 1998-Juni 2000

Juni 2000

September 2001-Januar 2002

Februar 2002-Dezember 2004

Februar 2002-Dezember 2004 spezielle Fächer in Zytologie, Entwicklungs- und Neurobiologie an der ELTE Universität

Diplomarbeit in der Abteilung Physiologie und Neurobiologie der ELTE Universität, Arbeitsgruppe Dr. Ildikó Világi

Diplom in Biologie

Doktorand an der ELTE Universität

Doktorand an der Georg-August-Universität, Göttingen

\section{Publikationen}

Gulyas-Kovacs A, Doczi J, Tarnawa I, Detari L, Banczerowski-Pelyhe I, Vilagi I (2002)

Comparison of spontaneous and evoked epileptiform activity in three in vitro epilepsy models. Brain Res 945:174-180.

Vilagi I, Takacs J, Gulyas-Kovacs A, Banczerowski-Pelyhe I, Tarnawa I (2002)

Protective effect of the antiepileptic drug candidate talampanel against AMPAinduced striatal neurotoxicity in neonatal rats. Brain Res Bull 59:35-40.

Göttingen, im Dezember 2004 